\title{
Bio-bibliographisches Korrespondentenverzeichnis
}

\section{Appelius, Johann Wilhelm}

1706 - 10. September 1757 (Sulingen)

Beruf, Tätigkeit: Lehrer, Pfarrer

Biographie: 1724 Studium in Jena, um 1730 Lehrer am Merseburger Gymnasium, 1733 Hauslehrer in Hamburg, 1740 adjungierter Pfarrer in Wietzen, 1741 Pfarrer in Barrien. Ehe, Kinder: Unbekannt Mitgliedschaften: 1739 Mitglied der Deutschen Gesellschaft in Göttingen Korrespondenz: 1 Brief an Gottsched aus dem Jahr 1739

Literatur: [J. W. Appelius:] Da Herr Teller Seiner Schützin Sich als Bräutigam verband, Ward diß Blat von guten Freunden Ihm aus Merseburg gesand. Den 27. Febr. 1732; Suchier, Göttingen, Nr. 323; Philipp Meyer: Die Pastoren der Landeskirchen Hannovers und Schaumburg-Lippes seit der Reformation. Band 1. Göttingen 1941, S. 61; Jena Matrikel 3, S. 24, Nr. 176; DBI.

\section{Arnoldt, Daniel Heinrich}

7. Dezember 1706 (Königsberg) - 30. Juli 1775 (Königsberg)

Beruf, Tätigkeit: Universitätsprofessor

Biographie: Sohn des Kaufmanns Johann Friedrich Arnoldt (1673-1720) und der Luise, geb. Krehoff (1683-1768). 1721 Studium in Königsberg, 1724 Studium in Halle, 1728 Magister in Halle, 1729 Professor der praktischen Philosophie in Königsberg, 1733 Pfarrer der Altstadt und Professor der Theologie, 1735 Hofprediger, 1772 Oberhofprediger.

Ehe, Kinder: 1733 Ehe mit Marie Juliane Rogall (1717-1736), 1 Tochter: Anna Luisa Arnoldt (1735-1797/1806); 1737 Ehe mit Louise Lazarovius (1716-1738), 1 Sohn: Mathias Henrich Arnoldt (* 1738, früh verstorben); 1739 Ehe mit Marie Charlotte Vogel (1715/20-nach 1775), 1 Sohn: David Henrich Arnoldt (1740-1757), 2 Töchter: Charlotta Elisabeth Arnoldt (1741-1750), Maria Juliana Arnoldt (1744-1745)

Korrespondenz: 39 Briefe an Gottsched und 4 Briefe von Gottsched aus den Jahren 1724 bis 1766

Literatur: Zedler, Supplemente 2 (1751), Sp. 371-374; Pisanski, s. Register; Gerhard Kessler: D. Daniel Heinrich Arnoldt und der Pietistenkreis in Königsberg. In: Altpreußische Geschlechterkunde 8 (1934), S. 9-24; Gerhard Kessler: Daniel Heinrich Arnoldts Ahnentafel. In: Altpreußische Geschlechterkunde 8 (1934), S. 25-34; Perels/ Rathje/Stenzel, S. 48-50; DBI. 


\section{Behr, Georg Heinrich}

16. Oktober 1708 (Straßburg) - 9. Mai 1761 (Straßburg)

Beruf, Tätigkeit: Arzt und Jurist

Biographie: Sohn des Wundarztes Georg Adam Behr (1679-1708) und der Marie Magdalene, geb. Wehrbeck. 1723 Studium in Straßburg, 1730 Wundarzt in einem Schweizer Regiment, 1731 Studienreise durch Holland und Deutschland, Doktor der Medizin in Straßburg, Lehrtätigkeit an der Universität Straßburg, Herausgeber von Zeitungen, 1734 Hilfsmedicus am Königlichen Französischen Hospiz in Straßburg, 1738 Hofrat und Leibarzt des Fürsten von Hohenlohe-Pfedelbach, 1751 Beisitzer im Rat der Stadt Straßburg und Polizeirichter. Mitgliedschaften: 1738 Mitglied der Leopoldina, 1743 Präsident der Deutschen Gesellschaft in Straßburg

Ehe, Kinder: 1732 Ehe mit Marie Christine Walther (†1739); 1740 Ehe mit Anne Marie Schätzelin, 3 Kinder

Korrespondenz: 5 Briefe aus den Jahren 1739 bis 1755

Literatur: Zedler, Supplemente 3 (1753), Sp. 477-486; Joseph Lefftz: Die gelehrten und literarischen Gesellschaften im Elsass vor 1870. Heidelberg 1931, S. 54-64; Gustav Carl Knod (Bearb.): Die alten Matrikeln der Universität Strassburg 1621 bis 1793. Straßburg 1897. Band 1, S. 407, Band 2, S. 187.

\section{Berger, Christian Gotthelf}

1698 - April 1770

Beruf, Tätigkeit: Beamter

Biographie: 1714 Besuch der Kreuzschule in Dresden. Kanzlist in der Staatskanzlei, sachsen-weißenfelsischer Hofrat, 1746 königlich-polnischer und kurfürstlich-sächsischer Wirklicher Kriegsrat in Dresden.

Ehe, Kinder: Unbekannt

Mitgliedschaften: Senior der Weißenfelsischen Alethophilischen Gesellschaft

Korrespondenz: 1 Brief an Gottsched aus dem Jahr 1738

Literatur: Miscellanea Saxonica 4 (1770), S. 131 (Todesanzeige); Willy Richter: Die Matrikel der Kreuzschule. Gymnasium zum Heiligen Kreuz in Dresden. 2. Teil: 17131801/2. Neustadt an der Aisch 1971, S. 13.

\section{Beyer, Justus Israel}

7. März 1696 (Freiberg/Sachsen) - 26. Februar 1762 (Halle)

Beruf, Tätigkeit: Jurist, Hochschullehrer

Biographie: Sohn von Israel Beyer, Konrektors des Gymnasiums in Freiberg/Sachsen, und der Anna Susanna, geb. Rabener. Schulbesuch in Freiberg, Mittweida, Wurzen und Altenburg, 1716 Studium in Leipzig, 1720 Magister, 1722 Immatrikulation (laut Matrikel „examen pro praxi forensi”) in Wittenberg, 1722 Advokat in Dresden, 1724 Studium in Halle, 1730 Adjunkt an der Philosophischen Fakultät in Halle, 1738 außerordentlicher Professor für Philosophie in Halle.

Mitgliedschaften: Mitglied der Deutschen Gesellschaften in Leipzig und Halle, 1736 Mitglied der Prüfenden Gesellschaft in Halle 
Ehe, Kinder: Verheiratet, 1 Sohn: Justus Israel (1728-1813)

Korrespondenz: 2 Briefe an Gottsched aus dem Jahr 1738

Literatur: Nikolaus Gundling: Fortgesetzte Historie der Gelahrheit. Frankfurt; Leipzig: Wolfgang Ludwig Spring, 1746, S. 648-652; Johann Christian Förster: Übersicht der Geschichte der Universität Halle in ihrem ersten Jahrhunderte. Hrsg. und bearb. von Regina Meyer und Günter Schenk. Halle 1998, bes. S. 197; Hans-Joachim Kertscher: Die „Prüfende Gesellschaft“ in Halle. In: Detlef Döring, Kurt Nowak (Hrsgg.): Gelehrte Gesellschaften im mitteldeutschen Raum (1650-1820). Band 3. Stuttgart; Leipzig 2002, S. 71-99, bes. S. 80 f.; Döring, Deutsche Gesellschaft (s. Register); Leipzig Matrikel, S. 27; Wittenberg Matrikel, S. 22; Halle Matrikel 1, S. 24; DBI.

\section{Biedermann, Johann Gottlieb}

5. April 1705 (Naumburg) - 3. August 1772 (Freiberg/Sachsen)

Beruf, Tätigkeit: Pädagoge, Gymnasialrektor

Biographie: Sohn des Großjenaer Pfarrers Nicolaus Biedermann. Studium in Wittenberg, 1727 Magister, 1727 Hauslehrer in Coswig, 1732 Konrektor am Naumburger Gymnasium, 1742 dort Rektor, 1747 Rektor am Gymnasium in Freiberg/Sachsen, Herausgeber der Acta Scholastica (erste pädagogische Zeitschrift), bekannt unter den Zeitgenossen vor allem wegen der von ihm aufgestellten Behauptung, Musiker würden einen unmoralischen Lebenswandel führen, was um $1750 \mathrm{zu}$ einem Streitschriftenkrieg (unter besonderer Beteiligung von Johann Sebastian Bach und Johann Friedrich Doles) führte.

Ehe, Kinder: 3 Söhne: Friedrich Gottlieb (1738-1793), Johann Gottlieb (1743-1824), Johann Gottfried (1757-1808)

Korrespondenz: 15 Briefe an Gottsched aus den Jahren 1735 bis 1751

Literatur: Emil Preuß, Karl August Thümer: Quellenbuch zur Geschichte des Gymnasiums in Freiberg von der Zeit der Reformation bis 1842. Freiberg 1915, S. 197-200; Helmut Banning: Johann Friedrich Doles. Leben und Werke. Leipzig 1939, S. 24-48; Ulrich Leisinger: Biedermann und Bach - Vordergründe und Hintergründe eines gelehrten Streites im 18. Jahrhundert. In: Ulrich Leisinger, Christoph Wolff (Hrsgg.): Musik, Kunst und Wissenschaft im Zeitalter J. S. Bachs. Hildesheim; Zürich; New York 2005, S. 141-167; DBI.

\section{Bodmer, Johann Jakob}

19. Juli 1698 (Greifensee/Kanton Zürich) - 2. Januar 1783 (Zürich)

Beruf, Tätigkeit: Schriftsteller, Professor, Politiker

Biographie: Sohn von Hans Jakob Bodmer, Pfarrer in Greifensee, und der Esther, geb. Orell. Besuch des Collegium Carolinum in Zürich, geht 1718 nach Lugano, um dort Kaufmann zu werden, 1719 Aufgabe dieses Vorhabens und Eintritt in den Dienst der Zürcher Staatskanzlei, 1731 Professor für Geschichte am Collegium Carolinum in Zürich, 1747 Mitglied des Großen Rates der Stadt Zürich; ausgedehnter (zu großen Teilen erhaltener) Briefwechsel mit zahlreichen Mitgliedern der Gelehrten Welt in Europa, umfangreiche Publikation u.a. zur Dichtungstheorie und Ästhetik, Dramen, Epen, 
Übersetzungen aus verschiedenen Sprachen, Arbeiten zur altdeutschen Literaturgeschichte und historische Abhandlungen.

Mitgliedschaften: 1720 Mitbegründer der Gesellschaft der Mahler, 1725 Mitbegründer der Literarischen Gesellschaft, 1727 Mitbegründer der Helvetischen Gesellschaft (alle in Zürich), 1737 Mitglied der Deutschen Gesellschaft in Leipzig

Ehe, Kinder: 1727 Ehe mit Esther Orell (1696-1785), vier Kinder, die alle im frühen Alter starben.

Korrespondenz: 14 Briefe an Gottsched und 7 Briefe von Gottsched aus den Jahren 1732 bis 1739

Literatur: Ernst Gagliardi, Ludwig Forrer: Katalog der Handschriften der Zentralbibliothek Zürich. II. Band: Neuere Handschriften seit 1500. Lieferung 3. Zürich 1949, Sp. 1527-1535; Wolfgang Bender: Johann Jakob Bodmer und Johann Jakob Breitinger. Stuttgart 1973; Anett Lütteken: Freundlich „gegen jedermann, vertraulich gegen wenig“. Bodmers Briefwelten. In: Ulrich Johannes Schneider (Hrsg.): Kulturen des Wissens im 18. Jahrhundert. Berlin; New York 2008, S. 113-122; Barbara MahlmannBauer, Anett Lütteken (Hrsgg.): Bodmer und Breitinger im Netzwerk der europäischen Aufklärung. Göttingen 2009; DBI.

\section{Breitinger, Johann Jakob}

1. März 1701 (Zürich) - 14. Dezember 1776 (Zürich)

Beruf, Tätigkeit: Professor

Biographie: Sohn des Knopfmachers oder Zuckerbäckers und zeitweiligen Geheimsekretärs des Herzogs Georg von Württemberg Franz Caspar Breitinger (1665-1742) und der Verena, geb. Schobinger (1667-1727). Besuch des Collegium Carolinum in Zürich, 1731 Professor für Hebräisch am Collegium Carolinum, 1748 Professor für Griechisch und Chorherr am Großmünster in Zürich, ab 1720 lebenslange Zusammenarbeit und Freundschaft mit Johann Jakob Bodmer (Korrespondent).

Mitgliedschaften: 1720 Mitbegründer der Gesellschaft der Mahler, 1727 Mitbegründer der Helvetischen Gesellschaft, Mitglied der Literarischen Gesellschaft, 1768 Vorsteher der Asketischen Gesellschaft, Mitglied der Bibliotheksgesellschaft (alle in Zürich), Mitglied der Teutschen Gesellschaft in Jena

Ehe, Kinder: 1735 Ehe mit Esther Schinz († 1785), Tochter des Bäckers Hans Jakob Schinz, 2 Töchter

Korrespondenz: 1 Brief an Gottsched aus dem Jahr 1739

Literatur: Müller, Nachricht, S. 101; Hermann Bodmer: Johann Jakob Breitinger 1701-1776. Sein Leben und seine literarische Bedeutung. 1. Teil. Zürich 1897; Wolfgang Bender: Johann Jakob Bodmer und Johann Jakob Breitinger. Stuttgart 1973; Barbara Mahlmann-Bauer, Anett Lütteken (Hrsgg.): Bodmer und Breitinger im Netzwerk der europäischen Aufklärung. Göttingen 2009.

\section{Brucker, Jakob}

22. Januar 1696 (Augsburg) - 26. November 1770 (Augsburg)

Beruf, Tätigkeit: Geistlicher, Gymnasiallehrer, Philosophiehistoriker 
Biographie: Sohn des Schneiders Jakob Brucker und der Regine, geb. Weise († 1696). Lehre bei einem Augsburger Kaufmann, 1709 Besuch des St. Anna-Gymnasiums in Augsburg, 1715 Studium in Jena, 1718 Magister, Reise durch verschiedene deutsche Städte (darunter Leipzig), Aushilfsprediger und Hauslehrer in Augsburg, 1724 Rektor der Lateinschule in Kaufbeuren und Geistlicher an der Kirche zur Heiligen Dreifaltigkeit, 1734 Diakon an der Hauptpfarrkirche von Kaufbeuren und Scholarch, 1735 Mitglied des Konsistoriums der Freien Reichsstadt Kaufbeuren, 1744 Pfarrer an der HeiligKreuz-Kirche in Augsburg, 1757 Stadtpfarrer von St. Ulrich in Augsburg und Senior des Evangelischen Ministeriums.

Ehe, Kinder: 1725 Ehe mit Dorothea Regina Crophius (†1731), 1 Sohn: Philipp Jakob (* 1729); 1732 Ehe mit Anna Barbara, Tochter des Kaufbeurer Kaufmanns und Ratsherrn Johann Jakob Mayer, elf Kinder, darunter: Karl Friedrich (1733-1772), Jakob (* 1737), Christoph Heinrich (1741-1790), Christian Gottfried, Johann Ludwig, Euphrosina Barbara, Maria Regina, Rosina Elisabeth

Korrespondenz: 129 Briefe an Gottsched aus den Jahren 1736 bis 1764, 1 Brief von Gottsched aus dem Jahr 1750, 3 Briefe an Luise Adelgunde Victorie Gottsched aus den Jahren 1745 bis 1750

Mitgliedschaften: 1731 auswärtiges Mitglied der Berliner Sozietät der Wissenschaften, 1736 Mitglied der Deutschen Gesellschaft in Leipzig, 1743 Mitglied der Societas Latina in Jena, 1747 Mitglied der Accademia delle Scienze in Bologna, 1747 Mitglied der Deutschen Gesellschaft in Göttingen, 1753 Mitglied der Societas Litteraria GermanoBenedictina, 1756 Mitglied der Accademia Roveretana degli Agiati

Literatur: Zedler, Supplemente 4 (1754), Sp. 747-758; Franz Anton Veith: Bibliotheca Augustana complectens notitias varias de Vita et Scriptis Eruditorum, quos Augusta Vindelica orbi Litteratae vel dedit vel aluit. Band 8. Augsburg 1792, S. 2-55; Karl Alt: Jakob Brucker ein Schulmeister des 18. Jahrhunderts. Diss. Erlangen. Kaufbeuren 1926; Lucien Braun: Geschichte der Philosophiegeschichte. Darmstadt 1990, S. 131-150; Wilhelm Schmidt-Biggemann, Theo Stammen (Hrsgg.): Jacob Brucker (1696-1770). Philosoph und Historiker der europäischen Aufklärung. Berlin 1998; Christine Lüdke: „Ich bitte mir Euer Hochedelgebohren Gedancken aus!“ Beiträge zur Erschließung und Analyse von Jakob Bruckers Korrespondenz. Diss. Augsburg 2006 (Online-Ressource); Jena Matrikel 2, S. 92; DBI.

\section{Burgmann, Joachim Heinrich}

\section{Mai 1711 (Rostock) - 30. Dezember 1747 (Rostock)}

\section{Beruf, Tätigkeit: Pfarrer}

Biographie: Sohn des Professors der griechischen Sprache an der Universität Rostock und Pfarrers in St. Nicolai in Rostock Jakob Burgmann (1659-1724) und der Katharina Margarethe, geb. Besel. 1727 Studium in Rostock, 1732 Studium in Jena, 1734 Magister der Philosophie, 1740 zweiter Pfarrer an der Pfarrkirche in Güstrow.

Ehe, Kinder: 1742 Ehe mit Elisabeth Christiane Storch (*1722), Tochter des Güstrower Bürgermeisters Johann Gustav Storch, 1 Sohn: Johann Gustav Burgmann (1744-1795) Korrespondenz: 1 Brief an Gottsched aus dem Jahr 1738

Literatur: Zedler, Supplemente 4 (1754), Sp. 1056; Gustav Willgeroth: Die mecklenburg- 
schwerinischen Pfarren seit dem dreißigjährigen Kriege, Band 1, Wismar 1924, S. 350; Gustav W. Pieper: Züge aus dem Leben des Johann Gustav Burgmann. Bielefeld 1851; Adolph Hofmeister (Hrsg.), Ernst Schäfer (Bearb.): Die Matrikel der Universität Rostock. Band 4. Rostock 1904, S. 153, Band 6/1. Rostock 1919, S. 130; Jena Matrikel 3, S. 194.

\section{Clodius, Christian}

16. Mai 1694 Neustadt (Sachsen) - 13. Juni 1778 Zwickau

Beruf, Tätigkeit: Gymnasialdirektor

Biographie: Sohn des Christian Clodius (Klöde) (1647-1717) und der Anna Maria, geb. Krumbholz. Besuch des Görlitzer Gymnasiums, 1716 Studium in Leipzig, Hauslehrer und Gehilfe der Apothekerfamilie Linck, 1720 Magister,1732 Gymnasiallehrer und -direktor in Annaberg, 1740 Gymnasialdirektor in Zwickau.

Ehe, Kinder: Ehe mit Eleonora Sophia Scheureck (1713-1758), 7 Kinder, darunter Christian August Clodius (1737-1784)

Mitgliedschaften: 1717 Mitglied und Leiter der Teutschübenden Poetischen Gesellschaft (Deutschen Gesellschaft) in Leipzig und Begründer ihrer Bibliothek, Mitglied des Montägigen (Großen) Predigerkollegs in Leipzig, des Collegium philobiblicum, der Teutschen Rednergesellschaft, der Schweidnitzer Gesellschaft, 1735 Mitglied der Societas latina in Jena, Ehrenmitglied der Gesellschaft der freyen Künste in Leipzig

Korrespondenz: 24 Briefe an Gottsched aus den Jahren 1738 bis 1755, 2 Briefe an Luise Adelgunde Victorie Gottsched

Literatur: Familienbibel Clodius in der Ratsschulbibliothek Zwickau, Signatur: 35. 4. 25; Aufrichtiges Kennzeichen gepflogener Amité, nebst hoch-erfreuten Glückwünschen mit welchen Herrn Christian Clodium ... am 2. Octobr. im Jahr 1716 auf die Welt-berühmte Universität Leipzig reisete. Görlitz: Michael und Jacob Zipper, o. J.; Sub discessum suum ad Almam Cygneam ultimum vale dicturus Lyceo Annaemontano IV. Non. Febr. MDCCXL ... M. Christianus Clodius. Annaberg [1740]; Christian Wilhelm Franz Walch: Historia Societatis Latinae Ienensis. In: Johann Ernst Immanuel Walch (Hrsg.): Acta Societatis Latinae Ienensis 1 (1752), S. III-XXXI, XXII; Gottlieb Leberecht Richter: Allgemeines biographisches Lexikon alter und neuer geistlicher Liederdichter. Leipzig 1804, S. 40; Emil Herzog: Geschichte des Zwickauer Gymnasiums. Zwickau 1869, S. 39-42; Veröffentlichungen zur Geschichte des gelehrten Schulwesens im albertinischen Sachsen. Hrsg. im Auftrag des Sächsischen Gymnasiallehrervereins. 1. Teil. Übersicht über die geschichtliche Entwicklung der Gymnasien. Leipzig 1900, S. 230 f.; Kroker, Nr. 122; Emil Karl Blümml: Zwei Leipziger Liederhandschriften des 17. Jahrhunderts. Als Beitrag zur Kenntnis des deutschen Volks- und Studentenliedes. Leipzig 1910; Döring, Deutsche Gesellschaft, S. 165-179 u. ö.; Leipzig Matrikel, S. 54; DBI.

\section{Cocceji, Samuel von}

20. Oktober 1679 (Heidelberg) - 4. Oktober 1755 (Berlin)

Beruf, Tätigkeit: Jurist

Biographie: Sohn des Heidelberger Professor der Rechtswissenschaften Heinrich von Cocceji (1644-1719) und der Marie Salome, geb. Hugwart (Howard) († 1720). 1690 
Studium in Frankfurt an der Oder, Bildungsreise durch mehrere europäische Staaten, 1702 Professor für Rechtswissenschaften an der Universität Frankfurt an der Oder, 1716 brandenburgischer Gesandter am Wiener Hof, 1723 preußischer Kammergerichtspräsident, 1738-1739 und 1741-1746 preußischer Justizminister, 1747 Großkanzler.

Ehe, Kinder: Ehe mit Johanna Charlotte, geb. von Beschefer, 2 Töchter: Susanne Charlotte Sophie (†1794), verh. von Platen), Amalie, verh. von Vernezobre, 3 Söhne: Carl Ludwig (1724-1808), Johann Friedrich Heinrich (* 1725), Carl Friedrich Ernst (1728-1780)

Korrespondenz: 1 Brief aus dem Jahr 1738

Literatur: Rolf Straubel: Biographisches Handbuch der preußischen Verwaltungs- und Justizbeamten 1740-1806/15. Teil 1. München 2009, S. 172f.; DBI.

\section{Denso, Johann Daniel}

24. Dezember 1708 (Neustettin/Pommern) - 4. Januar 1795 (Wismar)

Beruf, Tätigkeit: Pädagoge, Übersetzer, Naturwissenschaftler

Biographie: Studium in Jena (nach Angabe der Matrikel Greifswald, in der Jenaer Matrikel nicht nachweisbar), 1730 Studium in Greifswald, 1731 Professor „des Stils und der Beredsamkeit“ am Gröningschen Kollegium in Stargard/Pommern, 1751 Professor für Beredsamkeit und Dichtkunst am Stettiner Gymnasium, 1753 Rektor der Großen Stadtschule in Wismar, trat 1793 in den Ruhestand.

Mitgliedschaften: 1733 Mitglied der Deutschen Gesellschaft in Leipzig, 1751 Mitglied der Königlich Deutschen Gesellschaft zu Greifswald

Ehe, Kinder: 1737 Ehe mit Louisa Sophia Spalding (ca. 1720-1767)

Korrespondenz: 8 Briefe an Gottsched aus den Jahren 1733 bis 1746, 2 Briefe an Luise Adelgunde Victorie Gottsched aus dem Jahr 1745

Literatur: Schultz, Greifswald, S. 123; Bio-bibliographisches Handbuch zur Sprachwissenschaft des 18. Jahrhunderts. Band 2. Tübingen 1993, S. 227-228; Rudolf Kleiminger: Die Geschichte der Großen Stadtschule zu Wismar von 1541 bis 1945. Kiel 1991, S. 110-119; Greifswald Matrikel, S. 148; DBI.

\section{Drollinger, Karl Wilhelm}

16. Dezember 1688 (Durlach) - 1. Juni 1742 (Basel)

Beruf, Tätigkeit: Jurist, Archivar, Dichter

Biographie: Sohn des markgräflichen Rechnungsrates und späteren Burgvogts von Badenweiler Johann Martin Drollinger (1656-1718) und der Catharina Sibylla, geb. Müller (1660-1699). 1703 bis 1710 Studium in Basel, 1710 Promotion zum Doktor der Rechtswissenschaften, 1711 Registrator des baden-durlachischen Geheimarchivs in Basel, 1722 Hofrat

Ehe, Kinder: Unverheiratet

Korrespondenz: 2 Briefe an Gottsched aus den Jahren 1736 und 1739

Mitgliedschaften: 1733 Mitglied der Deutschen Gesellschaft in Leipzig

Literatur: Johann Jakob Spreng: Gedächtnisrede und Ode auf den sel. Herrn Herrn Drollinger ... in hochansehnlicher Versammlung, den 4. des Brachmonats 1743. zu Ba- 
sel gehalten. In: C. F. Drollinger: Gedichte samt anderen dazu gehörigen Stücken. Basel 1743, S. I-LIV; Paul Roth: Hofrat Carl Friedrich Drollinger und die Baden-Durlachischen Sammlungen zu Basel. In: Basler Zeitschrift für Geschichte und Altertumskunde 57 (1958), S. 133-170; Hans Georg Wackernagel (Hrsg.): Die Matrikel der Universität Basel. Band 4: 1666/67-1725/26. Basel 1975, S. 345; DBI.

\section{Duncan, Johann Christoph}

$*$ in Grunau (bei Heiligenbeil), $\uparrow 1743$

Beruf, Tätigkeit: Pfarrer

Biographie: 1723 Studium in Königsberg, 1738 Pfarrer in Uexküll und Kirchholm

Ehe, Kinder: 1738 Ehe mit Christiana Elisabeth Fontin (1719-1750), 3 Söhne, von denen bis 1748 zwei verstarben.

Korrespondenz: 1 Brief an Gottsched aus dem Jahr 1738

Literatur: Brief von Olaus Benedictus Fontin (Duncans Schwager) an Gottsched (19. August 1748); Martin Ottow, Wilhelm Lenz (Hrsgg.): Die evangelischen Prediger Livlands bis 1918. Köln; Wien 1977, S. 213, Nr. 388; Königsberg Matrikel, S. 319.

\section{Eberlein, Christian Ludwig}

1678 (Leipzig) - 14. Februar 1752 (Breslau)

Beruf, Tätigkeit: Lehrer

Biographie: 1694 Studium in Leipzig, 1707 Lehrer der Mathematik und später Professor primarius am Gymnasium St. Maria Magdalena in Breslau.

Korrespondenz: 1 Brief an Gottsched aus dem Jahr 1738

Ehe, Kinder: Verheiratet, 1 Tochter und 2 Söhne, darunter Christian Gottlob Eberlein Literatur: Zu dem Grabe des ... M. Christian Ludwig Eberleins ... wollten ... Ihren treuen und alten Lehrer ... Ehrfurchtsvoll begleiten Desselben gewesene Untergebene der zweyten Ordnung. Breslau o. J.; Leipzig Matrikel 2, S. 85.

\section{Elsner, Jakob}

März 1692 (Saalfeld/Ostpreußen) - 8. Oktober 1750 (Berlin)

Beruf, Tätigkeit: Theologe, Gymnasiallehrer

Biographie: 1708 Studium in Königsberg, wegen der in Königsberg herrschenden Pest zeitweilig Informator in Kurland, 1715 Konrektor der reformierten Schule in Königsberg, 1717-1721 Aufenthalt in Holland (Studium in Leiden und Utrecht, in Utrecht Doktor der Theologie) und in den österreichischen Niederlanden, 1721 Professor der Theologie und der orientalischen Sprachen am Königlichen Gymnasium in Lingen/ Westfalen, 1722 Rektor des Joachimsthalischen Gymnasiums in Berlin, 1725 erneute Reise nach Holland, 1729 Prediger an der reformierten Parochial-Kirche in Berlin, 1741 Mitglied des Reformierten Kirchendirektoriums, zeitweilig Informator der königlichen Prinzen.

Mitgliedschaften: 1722 Mitglied der Berliner Sozietät der Wissenschaften, 1742 Direktor der Philologisch-orientalischen Klasse, 1744 Direktor der Historischen Klasse 
Ehe, Kinder: 1737 Ehe mit Elisabeth Stosch

Korrespondenz: 3 Briefe an Gottsched aus den Jahren 1737 und 1738

Literatur: Geheimes Staatsarchiv Preußischer Kulturbesitz Berlin, I. HA Rep. 92 (Nachlaß Beckmann), III, 11: Nachrichten von dem kgl. Joachimsthal. Gymnasio ..., Bl. 389-393; Johann Heinrich Samuel Formey: Èloge de M. Elsner. In: Formey: Histoire de l'Academie Royale des Sciences et belles Lettres. Berlin 1752, S. 225-231; Agnes Winter: Das Gelehrtenschulwesen der Residenzstadt Berlin in der Zeit von Konfessionalisierung, Pietismus und Frühaufklärung (1574-1740). Berlin 2008 (s. Register); Christian Ritzi: Bibliotheca Joachimica. Zur Funktion von Gymnasialbibliotheken im Wandel der Zeiten. In: Jonas Flöter, Christian Ritzi (Hrsgg.): Das Joachimsthalsche Gymnasium. Beiträge zum Aufstieg und Niedergang der Fürstenschule der Hohenzollern. Bad Heilbrunn 2009 (s. Register); Königsberg Matrikel, S. 258; DBI.

\section{Fabricius, Johann}

5. Juni 1715 (Elsfleth) - 7. April 1758 (Berne)

Beruf, Tätigkeit: Pfarrer

Biographie: Sohn des Pfarrers Anton Hermann Fabricius (1683-1722) und der Anna Catharina, geb. Froichen (um 1683-1761). Erster Unterricht durch Privatlehrer, 1729 Besuch des Gymnasiums in Hamburg, 1732 Studium in Leipzig, 1735 Informator der Kinder des Pfarrers Johann Hinrich Bojensen (1685-1757) in Ganderkesee, 1737 Lehrer des späteren dänischen Legationspredigers in Paris, Matthias Schreiber († 1784), 1742 Pfarrer in Blankenburg bei Oldenburg, 1748 Pfarrer in Berne.

Mitgliedschaften: Mitglied der Nachmittäglichen Rednergesellschaft in Leipzig, Mitglied der Societas Philomathunton in Leipzig, 1753 Ehrenmitglied der Gesellschaft der freyen Künste in Leipzig

Ehe, Kinder: 1742 Ehe mit Johanna Margarethe Peuker, Stieftochter des Pfarrers Bojensen $(\dagger 1786$, in 2 . Ehe mit Pfarrer Tobias Mentzel [1717-1772] verheiratet), 2 Töchter: Catharina Margareta (* 1745), Anna Catharina (1750-1751), 6 Söhne: Johann Heinrich (1743-1798), Gottlieb Henrich (1746-1752), Anthon Hermann (1748-1795), Gottfried (*1752), Julius Gottlieb und Johann Friedrich (Zwillinge, * 1756)

Korrespondenz: 3 Briefe an Gottsched aus den Jahren 1735 und 1738

Literatur: Johann Fabricius: Doctrinam de divinitate Christi occasione hæreseos Arianæ magis elaboratam sistit, et ... Georgio Christiano Ibbeken, ... nomine societatis $\Phi$ เ $\lambda \mathrm{o}-$ $\mu \alpha \theta$ ovv $\omega \nu v, \ldots$ sub præsidio ... Christiani Weisii, ... gratulatur. Leipzig: Bernhard Christoph Breitkopf, [1734]; Reden von Fabricius in: Schwabe, Proben, S. 212-229, 263-278, 292-311; Hille, Neue Proben, Nr. 37; Gottsched, Verzeichnis; [Johannes Ramsauer:] Die Prediger des Herzogtums Oldenburg seit der Reformation. Sonderdruck aus dem Oldenburgischen Kirchenblatt 1903-1908, S. 26f., 33, 78; Wolfgang Büsing: Das Oldenburgische Pastorengeschlecht Fabricius. In: Oldenburgische Familienkunde 5 (1963), S. 121-167, 145-152, 158-165; Leipzig Matrikel, S. 83. 
Falckenhagen, Adam

26. April 1697 (Großdalzig) - 6. Oktober 1754 (Bayreuth)

Beruf, Tätigkeit: Lautenspieler, Kammersekretär des Markgrafen von BrandenburgKulmbach

Biographie: Sohn des Lehrers Johann Christian Falckenhagen und der Eva, geb. Sachs. 1707 musikalischer Unterricht bei Johann Gottlob Erlmann (1673-1743), Onkel Falckenhagens und Pfarrer in Knauthain, 1715 Lautenunterricht bei Johann Jakob Graf (1690-1723) in Merseburg, 1715 Musiker und Kammerdiener 1719 Studium in Leipzig, 1720 Lautenlehrer in Weißenfels, Hofmusiker in Weißenfels, Lautenunterricht bei Leopold Weiß (Korrespondent) in Dresden, 1729 Anstellung in Weimar, 1732 Eintritt in die Dienste des Markgrafen von Brandenburg-Kulmbach, 1736 „Cammermusicus mit dem Rang nach dem Kapellmeister“, später auch Registrator und Kammersekretär.

Ehe und Kinder: vor 1724 Ehe mit Johanna Ämilia Kegel († 1734), Sängerin in Weißenfels, 3 Töchter: Johanna (1724-1760), die weiteren Töchter wurden 1726 und 1732 geboren und starben jeweils im selben Jahr; 1740 Ehe mit Charlotte Eberhardine, verw. Hoffmann, geb. Mayer († 1742), 1 Sohn: Adam $\left({ }^{*} 1742\right)$.

Korrespondenz: 2 Briefe an Luise Adelgunde Victorie Gottsched aus den Jahren 1738 und 1739

Literatur: Johann Gottfried Walther: Musicalisches Lexicon Oder Musicalische Bibliothec. Leipzig: Wolfgang Deer, 1732, S. 239; Heinrich Engelbert Schwartze: Historische Nachlese zu denen Geschichten der Stadt Leipzig, Sonderlich der umliegenden Gegend und Landschaft. Leipzig: Gottfried August Stopffel, 1744 (Neuausgabe Leipzig 2006), S. 234f.; Joachim Domning: Der Lautenist Adam Falckenhagen. In: Gitarre und Laute 1983, S. 322-328; Per Kjetil Farstad: German Galant Lute Music in the 18th Century. Göteborg 2000, S. 301-303; MGG 6 (2001), Sp. 668 f.; The New Grove Dictionary of Music and Musicians 8 (2001), S. 523; Leipzig Matrikel, S. 83; DBI.

\section{Flottwell, Cölestin Christian}

\section{April 1711 (Königsberg) - 2. Januar 1759 (Königsberg)}

Beruf, Tätigkeit: Universitätsprofessor

Biographie: Sohn des Diakons an der Dom- und Universitätskirche Christian Flottwell (1681-1727) und der Katharina Elisabeth, geb. Neufeld (1689-1755). Besuch der Domschule (später Kneiphöfisches Gymnasium), 1724 Studium in Königsberg, 1733 Magister in Jena, 1734 Wiederaufnahme in die Universität Königsberg, 1735 Habilitation in Königsberg, 1736 als Begleiter Johann Jakob Quandts (Korrespondent) Reise nach Karlsbad, 1741 Gründung der 1743 mit einem königlichen Privileg ausgestatteten Deutschen Gesellschaft in Königsberg, 1743 gegen Widerstände in der Universität mit Unterstützung Johann Ernst von Wallenrodts (1695-1766) ordentlicher Professor der Weltweisheit und der deutschen Beredsamkeit ohne Sitz und Stimme in der Fakultät und ohne festes Gehalt, 1750 Rektor der Domschule.

Mitgliedschaften: 1736 Mitglied der Deutschen Gesellschaft in Leipzig, Mitglied der Teutschen Gesellschaft in Jena, 1741 Mitglied der Königlichen Deutschen Gesellschaft 
in Königsberg, Mitglied der Deutschen Gesellschaft in Helmstedt, 1755 Mitglied der Deutschen Gesellschaft in Greifswald, Mitglied der Societas Latina in Jena

Ehe, Kinder: 1746 Ehe mit Marie Luise Lübeck (1716-1795), 1 Tochter: Johanna Cölestina (* 1749)

Korrespondenz: 18 Briefe von Gottsched aus den Jahren 1743 bis 1757, 123 Briefe an Gottsched aus den Jahren 1734 bis 1757, 5 Briefe an Gottsched als Mitglied der Deutschen Gesellschaft Königsberg aus den Jahren 1742 bis 1748, 7 Briefe von Flottwell an Luise Adelgunde Victorie Gottsched aus den Jahren 1736 bis 1750

Literatur: Jena, Universitätsarchiv, Bestand M, Nr. 738/1, S. 362 f.; Müller, Nachricht, S. 106, Nr. 99; Ueber die deutsche Gesellschaft in Königsberg. In: Morgenblatt für gebildete Stände 3 (1809), S. 34f.; Albert Leopold Julius Ohlert: Geschichtliche Nachrichten über die Domschule zu Königsberg in Ostpreussen von deren Stiftung im 14. Jahrhundert bis Michaelis 1831. Königsberg 1831, S. 23; C. Beckherr: Die Stammtafel der Familie Schimmelpfennig. Ein weiterer Beitrag zur Kenntniß der Königsberger Stadtgeschlechter. In: Altpreussische Monatsschrift 24 (1887), S. 263-281, 273; Krause, Flottwell; Hans Prutz: Gottsched und die „Königliche Deutsche Gesellschaft“ in Königsberg. In: National-Zeitung 46 (1893), Nr. 674 vom 3. Dezember, nicht paginiert; Ferdinand Josef Schneider: Theodor Gottlieb von Hippel in den Jahren von 1741 bis 1781 und die erste Epoche seiner literarischen Tätigkeit. Prag 1911, S. 42-45; Schultz, Greifswald, S. 125; Kessler, Altpreußische Briefe, S. 6 f., Nr. 10; Hans von Müller: Die erste Liebe des Ernst Theodor Hoffmann. Mit einigen Nachrichten über die Familien Schlunck und Flottwell, Hatt und Siebrandt nach den Quellen dargestellt. Heidelberg 1955, S. 17-22; Gallandi, S. 24; Reinhard Adam: Das Stadtgymnasium Altstadt-Kneiphof zu Königsberg (Pr.) 1304-1945. Aus der Geschichte der beiden ältesten Schulen des deutschen Ostens. Leer 1977, S. 41 f.; Heike Brachwitz: Aus dem Nachlass H. W. Quassowski III. Die Familie Flottwell, von Flottwell. In: Altpreußische Geschlechterkunde Neue Folge, Band 10, 25./26. Jahrgang (1977/78), S. 377-385; Altpreußische Geschlechterkunde Familienarchiv 18 (1996), S. 169, Nr. VII/101a; DBI.

\section{Gottschald (Gottschaldt, Gottschalck), Johann Jakob ${ }^{1}$}

21. April 1688 (Eibenstock im Erzgebirge) - 15. Februar 1759 (Schöneck im Vogtland)

Beruf, Tätigkeit: Pfarrer, Hymnologe

Biographie: Sohn des Rechtskonsulenten und Hammerherrn in Wildenthal Friedrich Gottschaldt (1642-1693) und der Maria Regina, geb. Schindler († 1721). 1702 Besuch des Gymnasiums in Altenburg, 1707 Studium der Theologie an der Universität Leipzig,

${ }^{1}$ Gottschald erklärte 1737, er habe sich zuerst Gottschalck genannt, weil dieser Name über viele Jahrhunderte in den Urkunden zu finden gewesen sei, aber seit 104 Jahren hätten sich seine Vorfahren Gottschaldt genannt, „vielleicht darum, weil damahls schon das sonst gute und in den Aemtern des Heil. Röm. Reichs selbsten noch befindliche Wort Schalck in pejorem sensum degeneriret". Diesem Gebrauch habe er sich zuletzt angepaßt. Gottschald, Lieder=Remarquen, 1. Stück, S. 36f. Die von uns gewählte Namensform entspricht der Briefunterschrift. 
1709 Magister, 1711 Studium in Wittenberg, 1713-1716 Aufenthalt im Haus des Diakons an der Dresdener Kreuzkirche, Hermann Joachim Hahn (1679-1726), 1716 Pfarrer in Somsdorf, 1721 Diakon in Eibenstock, 1739 Pfarrer in Schöneck.

Ehe, Kinder: 1716 Ehe mit Sophia Elisabeth Leuteritz, 9 Kinder, von denen 1748 noch 6 am Leben waren: Maria Sophia, Johanna Eleonora, Christiana Charlotte, Erdmuth Louise, Immanuel (1726-1793), Jakob Ludwig (1733-1790), Johann Polycarp.

Korrespondenz: 3 Briefe an Gottsched aus den Jahren 1735, 1736 und 1739, 2 Briefe an Luise Adelgunde Victorie Gottsched aus den Jahren 1736 und 1737

Literatur: Nützliche Nachrichten von denen Bemühungen derer Gelehrten und anderen Begebenheiten in Leipzig. Band. 2. Leipzig: Johann Christian Langenheim, 1745-1750, S. 514f.; Gottschald, Lieder=Remarquen, 6. Stück (1748), S. 881-887; Johann Paul Oettel: Alte und Neue Historie Der Königl. Pohln. und Churfürstl. Sächßl. freyen Berg=Stadt Eybenstock. Schneeberg: Carl Wilhelm Fulden; Eibenstock: Oettel, 1748 (Nachdruck Stuttgart 1997), S. 91-94, 288-293; Karl Gottlob Dietmann: Die gesamte der ungeänderten Augsp. Confeßion zugethane Priesterschaft in dem Churfürstenthum Sachsen und denen einverleibten Landen. 1, 3. Dresden; Leipzig: Sigismund Ehrenfried Richter [1754], S. 366-370; Dreßdnische Wöchentliche Frag= und Anzeigen 1759 (Nr. 14 vom 3. April); Johann Ernst Marbach: Beschreibung des von 1730. an privilegirten freyen Städtleins Schöneck. 1. Theil ... an das Licht gestellet von Johann Paul Oettel. Schneeberg: Carl Wilhelm Fulden, 1761, S. 42-45; Allgemeine Encyklopädie der Wissenschaften und Künste in alphabetischer Folge von genannten Schriftstellern bearbeitet und herausgegeben von J. S. Ersch und J. G. Gruber. 1. Sektion, 76. Teil. Leipzig 1863, S. 171 f.; Eduard Emil Koch: Geschichte des Kirchenlieds und Kirchengesangs der christlichen, insbesondere der deutschen evangelischen Kirche. 1. Hauptteil, Band 5. 3. Auflage. Stuttgart 1868 (Nachdruck Hildesheim; New York 1973), S. 501-503; Otto Fischer: Evangelisches Pfarrerbuch für die Mark Brandenburg. Berlin 1941, Band 1, S. 72, Band 2/1, S. 259; Grünberg 2, S. 251 f.; Kosch 6 (1978), Sp. 646; Leipzig Matrikel, S. 118; DBI.

\section{Hassen, Martin}

27. Juli 1677 (Branderode bei Naumburg) - 9. Februar 1750 (Wittenberg)

Beruf, Tätigkeit: Philosoph, Professor

Biographie: Sohn des Pfarrers Martin Hasse (Hase, Hesse) (1638-1715) und der Sabina Rumpach. Erster Unterricht bei dem Vater, 1690 Besuch der Domschule in Naumburg, 1693 Besuch der Schule in Altenburg, 1695 Besuch der Schule in Weißenfels, 1697 Studium der Theologie in Jena, 1700 Studium in Leipzig, Hofmeister in Berlin, Englischlehrer des späteren Königs Friedrich Wilhelm I., 1707 Sekretär des russischen Gesandten in Berlin Albrecht von der Lieth (1659-1718), 1710 Geheimer Kabinettssekretär in Dresden, 1711 außerordentlicher Professor der Ethik und Philosophie in Wittenberg, 1712 ordentlicher Professor der Ethik und Staatskunst in Wittenberg, 1742 kursächsischer Hofrat. Ehe, Kinder: 1714 Ehe mit Erdmuthe Sophie Trebitz, 1 Tochter: Wilhelmine Sophie (1716-1791)

Korrespondenz: 3 Briefe an Gottsched aus den Jahren 1739 bis 1742, 1 Brief an L. A. V. Gottsched aus dem Jahr 1741 
Literatur: Stadtkirchengemeinde Wittenberg, Taufbuch 1712-1739, S. 203, Nr. 215; Hamburgische Berichte 1742 (Nr. 79 vom 9. Oktober), S. 631f.; Georg August Langguth: Rector Academiae Vitembergensis ... Civibus Academicis S. P. D. Wittenberg: Ephraim Gottlob Eichsfeld, 1750 (Halle, Universitätsbibliothek Zb 5584, enthält biographische Angaben über Hassen); Erlangische Gelehrte Anmerkungen und Nachrichten 1750 (13. Stück vom 24. März), S. 101-103; Etwas von Leben Herrn Hof=Rath Martin Haßens, Moral. P. P. in Wittenberg. In: Neu=eröfnetes Historisches Curiositäten=Cabinet 1750, S. 154-157; Konrad Schröder: Biographisches und bibliographisches Lexikon der Fremdsprachenlehrer des deutschsprachigen Raumes, Spätmittelalter bis 1800. Band 2. Augsburg 1989, S. 189 f.; Michael Schippan: Zar Peter I. von Rußland und Wittenberg. In: Stefan Oehmig (Hrsg.): 700 Jahre Wittenberg. Stadt, Universität, Reformation. Weimar 1995, S. 535-544, 542-544; Brekle, Herbert E. u.a. (Hrsgg.): Bio-bibliographisches Handbuch zur Sprachwissenschaft des 18. Jahrhunderts. Die Grammatiker, Lexikographen und Sprachtheoretiker des deutschsprachigen Raums mit Beschreibungen ihrer Werke. Band 4. Tübingen 1996, S. 116 f.; Heinz Kathe: Die Wittenberger Philosophische Fakultät 1502-1817. Köln u.a. 2002, S. 320 f.; Pfarrerbuch Sachsen 3, S. 547; Klein 2, S. 318, Nr. 752; DBI.

\section{Hoffmann, Balthasar}

\section{Dezember 1697 (Bojanowo) - 12. April 1789 (Merseburg)}

\section{Beruf, Tätigkeit: Lehrer}

Biographie: Sohn des Tuchhändlers Caspar Hoffmann und der Susanna, geb. Pohl. Schulbesuch in Breslau, 1722 Studium der Philosophie und Theologie in Leipzig, 1725 Magister, 1730 Bewerbung um das Rektorat der Stiftsschule am Merseburger Dom, 1731 Konrektor in Merseburg, 1742 Rektor, 1783 Emeritierung. Mitgliedschaften: 1722 Mitglied der Deutschen Gesellschaft in Leipzig Ehe, Kinder: 1740 Ehe mit Christiana Sophia Henckel (1717-1742), 1 Tochter: Christiana Sophia (1741-1742); 1746 Ehe mit Catharina Hedwig Voigt (1724-1772), 5 Töchter: Augusta Friderica (* 1748), Johanna Elisabeth (1751-1787), Sophia Wilhelmina $(* 1753)$, Amalia Louise $(* \dagger 1759)$, Christiana Elisabeth $(1765-1800), 1$ Sohn: Theodor Balthasar

Korrespondenz: 4 Briefe an Gottsched aus den Jahren 1731 bis 1750

Literatur: Merseburg, Evangelische Schloß- und Domkirche St. Laurentii und Johannis Baptistae, Tauf-, Trau- und Sterberegister 1715-1775, 1725-1749, 1740-1775, 1776-1825; Panegyrici magisteriales (Leipzig, UB, Univ. 380c), 1725, Bl. [B4r]; Karl Gottlob Dietmann: Gesammelte Nachrichten von E. Ehrwürdigen der ungeänderten Augspurgischen Confeßion zugethanen Priesterschaft unter dem E. H. Stifts=Consistorio zu Merseburg. Dresden; Leipzig: Sigismund Ehrenfried Richter, 1759, S. 96; Balthasar Hoffmann: Sacrum seculare secundum gymnasii Martisburgensis, d. XIX Decembr. MDCCLXXV celebrandum indicit et maecenates ... ad audiendum invitat de antiquiore et recentiore scholae nostrae statu. Merseburg: Laitenberger, [1775]; Ferdinand Witte: Geschichte des Domgymnasiums zu Merseburg. 2. Teil. Merseburg 1876; 3. Teil, 1.-2. Hälfte. Merseburg 1891 f., insbesondere 3.1, S. 7-10; Kroker, Nr. 166; Hermann von Hase: Breitkopfsche Textdrucke zu Leipziger Musikaufführungen zu Bachs Zeiten. 
In: Bach-Jahrbuch 1913, S. 69-127, 93f. und 103; Alfred Gerhardt: Die wichtigeren Merseburger Chronisten und ihre Werke. In: Das Merseburger Land 14 (1929), S. 20-24, 21 f.; Balthasar Hoffmann: Von einem in der Gegend Merseburg neu entdeckten alten heidnischen Grabmaale. In: Das Merseburger Land 15 (1929), S. 15-20; Hans-Joachim Schulze: Bemerkungen zu einigen Kantatentexten Johann Sebastian Bachs. In: Bach-Jahrbuch 1959, S. 168-170, 169; Wolfgang Schmieder (Hrsg.): Thematisch-systematisches Verzeichnis der musikalischen Werke von Johann Sebastian Bach. 2., überarb. und erw. Aufl. Wiesbaden 1990, S. 811, Anh. I 16; Leipzig Matrikel, S. 166.

\section{Holtzendorff, Christian Gottlieb von}

22. April 1696 - 6. November 1755 (Dresden)

Beruf, Tätigkeit: Politiker

Biographie: Sohn des Kammerherrn Christoph Sigismund von Holtzendorff (16731715) und seiner ersten Frau Agnes Christiane, geb. von Schönberg (†24. April 1696). 1712 Studium in Wittenberg, 1715 Studium in Leipzig, im Alter von 20 Jahren in Begleitung eines Hofmeisters Kavalierstour durch Europa, 1737 Obersteuereinnehmer, 1738 Präsident des Oberkonsistoriums, 1741 Wirklicher Geheimer Rat, 1745 Erhebung in den Reichsgrafenstand.

Ehe, Kinder: 1723 Ehe mit Friederike Sophie Freiin von Bibran und Modlau (17041742), 3 Töchter: Friederike Christiane (1723-1793), Agnes Elisabeth (1726-1795), Sophia Tugendreich (1737-1742), 2 Söhne: Friedrich Gottlieb (1725-1789), Christian Traugott (1730-1807); 1745 Ehe mit Henriette Charlotte, geb. von Schieck, verw. von Miltitz (1701-1749); 1750 Ehe mit Eleonore Charlotte, geb. von Beust, verw. von Pflug (1699-1777)

Korrespondenz: 24 Briefe an Gottsched aus den Jahren 1738 bis 1755

Literatur: Dresden, Sächsisches Hauptstaatsarchiv, 12881 Genealogica Holtzendorff (1986); Neue Genealogisch=Historische Nachrichten von den Vornehmsten Begebenheiten, welche sich an den Europäischen Höfen zutragen 61-72 (1755), S. 2068-2079; Johann Wilhelm Franz Freiherr von Krohne: Allgemeines Teutsches Adels=Lexicon. Band 1/2, Hamburg: Dieterich Anton Harmsen, 1776, Sp. 143-145; Wichart von Holzendorff: Die Holtzendorff in der Mark Brandenburg und Chur=Sachsen. Berlin 1876, S. 57-59, 84f., XXII-XXV, Stammtafel I; Walter von Boetticher: Geschichte des Oberlausitzischen Adels und seiner Güter. Band 1. Görlitz 1912, S. 753-755; Leipzig Matrikel, S. 171, Wittenberg Matrikel, S. 244.

\section{Hudemann, Ludwig Friedrich}

3. September 1703 (Friedrichstadt in Schleswig) - 16. Februar 1770 (Hennstedt in Norderdithmarschen)

Beruf, Tätigkeit: Jurist, Dichter

Biographie: Sohn des Juristen und Gerichtssekretärs Hinrich Ludwig Hudemann (1668-1728) und der Anna Rosina, geb. Müller. 1721 Besuch des Gymnasiums Johanneum in Hamburg, 1725 Studium der Rechte in Halle, 1727 Studium in Leipzig, 1730 
Doktor der Rechte in Kiel, Reisen durch Holland und Frankreich, Privatgelehrter und Rechtsanwalt in Hennstedt.

Mitgliedschaften: 1736 Mitglied der Deutschen Gesellschaft in Leipzig, Mitglied der Deutschen Gesellschaft in Greifswald, 1753 Mitglied der Deutschen Gesellschaft in Göttingen

Ehe, Kinder: 1736 Ehe mit Wiebke, geb. Jochims, verw. Bump († vor 1772), 5 Töchter: Anna Katharina Louise, Margarethe Elisabeth (1741-1769), Dorothea Amalia (17431805), Christine Friederike (1747-1787), Auguste Maria, 1 Sohn: Georg Hinrich (1739-1806)

Korrespondenz: 14 Briefe an Gottsched aus den Jahren 1735 bis 1756

Literatur: Johann Heinrich Fehse: Versuch einer Nachricht von den evangelischlutherischen Predigern in dem Nordertheil Dithmarschens von dem Anfange der Religionsverbesserung an, bis auf diese Zeiten. Flensburg: Serringhausen, 1769, S. 791-798; Hans Uehlin: Geschichte der Racine-Uebersetzungen in der vorklassischen deutschen Literatur. Heidelberg, Ruprecht-Karls-Universität, Philosophische Fakultät, Dissertation, 1903, S. 61-68 und 87-96; Schultz, Greifswald, S. 113f.; Suchier, Göttingen, S. 90, Nr. 276; Roos, Breve til Gottsched, S. 64 f; Deutsches Geschlechterbuch 44 (1923), S. 163-165; Albert Malte Wagner: Klopstock und Holstein. In: Zeitschrift der Gesellschaft für Schleswig-Holsteinische Geschichte 56 (1927), S. 253-270, 258-262, 268-270; Walter Kühl: Ludwig Hudemann ein vergessener dithmarscher Dichter. In: Dithmarschen. Blätter für Heimatpflege und Heimatkultur 6 (1930), S. 85-93; Wilhelm Frels: Deutsche Dichterhandschriften. Leipzig 1934 (Nachdruck Stuttgart 1970), S. 143; Charlotte von Dach: Racine in der deutschen Literatur des 18. Jahrhunderts. Bern; Leipzig 1941 (Nachdruck Nendeln 1975), S. XI und 27f.; Robert R. Heitner: German Tragedy in the Age of Enlightenment. A Study in the Development of Original Tragedies, 1724-1768. Berkeley 1963, S. 359-363 und 401; Bach-Dokumente. Basel u. a. Band 1, 1963, S. 226f., Nr. 158; Band 2, 1969, S. 234, Nr. 325, S. 376-378, Nr. 466, S. 441-445, Nr. 564; Klaus Hurlebusch (Hrsg.): Klopstocks Arbeitstagebuch. Berlin; New York 1977, S. 271; Hans Joachim Marx: Johann Mattheson (1681-1764). Lebensbeschreibung des Hamburger Musikers, Schriftstellers und Diplomaten. Hamburg 1982, S. 20, 76, 104, 144, 156; Karl Michelson: Stadtsekretär Hudemann, sein Sohn und Johann Sebastian Bach. In: Mitteilungsblatt der Gesellschaft für Friedrichstädter Stadtgeschichte 33 (1987), S. 66-79; Dieter Martin: Das deutsche Versepos im 18. Jahrhundert. Studien und kommentierte Gattungsbibliographie. Berlin; New York 1993, S. 346-348; Hamburger literarisches Leben im 18. Jahrhundert. Ein Verzeichnis der Bestände der Staats- und Universitätsbibliothek Hamburg Carl von Ossietzky. Herzberg 1994, S. 59-61; Horst Joachim Frank: Literatur in Schleswig-Holstein. Band 2: 18. Jahrhundert. Neumünster 1998, S. 76-92; Axel Rafael Francisco Volquarts: Heinrich Christoph Leithäuser (1707-1762), Pastor in Hennstedt/Dithmarschen. Seine Vorfahren und seine Nachkommen, sowie namensgleiche Familien. Hamburg 1998, S. 143 und 173f.; Heiner Schmidt: Quellenlexikon zur deutschen Literaturgeschichte. Band 14. Duisburg 1998, S. 127; Heide Hollmer, Albert Meier (Hrsgg.): Dramenlexikon des 18. Jahrhunderts. München 2001, S. 135; Alexander Nebrig: Rhetorizität des hohen Stils. Der deutsche Racine in französischer Tradition und romantischer Modernisierung. Göttingen 2007, S. 93, 107 f., Anm. 83, 384-386; Halle Matrikel 1, S. 240; Leipzig Matrikel, S. 175; DBI. 


\section{Janus, Christian Friedrich Jakob}

16. Mai 1715 (Torgau) - 20. Dezember 1790 (Bautzen)

Beruf, Tätigkeit: Jurist, Beamter

Biographie: Sohn des Konrektors Daniel Friedrich Janus (1683-1760) und der Johanne Rosine, geb. Hüfner († 1747). Besuch des Gymnasiums in Torgau, 1731 Besuch des Gymnasiums in Bautzen, 1734 Studium in Leipzig, 1737 Notariat, 1738 Rückkehr nach Bautzen, 1739 Oberamtsadvokat in Bautzen, 1760 Domstiftssyndicus in Bautzen, 1767 Landsyndicus, 1770 Oberamtsvizekanzler, Oberamtskanzler der Markgrafschaft Oberlausitz. Mitgliedschaften: Mitglied der Nachmittäglichen Rednergesellschaft; 1753 Ehrenmitglied der Gesellschaft der freyen Künste in Leipzig

Ehe, Kinder: um 1742 Ehe mit Christiane Helene Keßler, 2 Söhne ermittelt: Karl August (1743-1784), Christian Adolph (*1761)

Korrespondenz: 5 Briefe an Gottsched aus den Jahren 1738 und 1739, ein Brief aus dem Jahr 1750

Literatur: Hille, Neue Proben, Nr. 54; Gottsched, Verzeichnis; Leipziger Adreß=Post= und Reise=Calender, Auf das Jahr Christi 1754. Leipzig: Johann Gabriel Büschel, 1754; Lausitzisches Magazin 3 (1770), S. 218-222; 17 (1784), S. 154f.; 19 (1786), 162f.; 23 (1790), S. 4; 24 (1791), S. 3 und 30; Dreßdnische Wöchentliche Frag= und Anzeigen von allerhand dem gemeinen Wesen nöthigen und nützlichen Sachen 1791 (Nr. 2 vom 11. Januar); DBI.

\section{Jariges, Philippe Joseph de}

\section{November 1706 (Berlin) - 9. November 1770 (Berlin)}

Beruf, Tätigkeit: Philosoph, Jurist, Politiker

Biographie: Sohn des brandenburgisch-preußischen Offiziers Joseph Pandin de Jariges (1655-1720) und der Marie, geb. Morel (1666-1729). Besuch des Joachimsthalschen Gymnasiums in Berlin, 1724 Studium der Philosophie und der Rechtswissenschaften in Halle, 1727 Hof- und Kriminalrat, 1729 Direktor bei der Maison de Refuge und französischer Revisionsrat, 1733-1748 Sekretar der Berliner Sozietät der Wissenschaften, 1735 Mitglied im französischen Oberkonsistorium und im französischen Obergericht, 1740 Direktor des französischen Obergerichts, 1748 Geheimer Oberappellationsrat, 1755 Großkanzler und Staatsminister.

Mitgliedschaften: 1731 anwesendes Mitglied, 1744 ordentliches Mitglied, 1755 Ehrenmitglied der Berliner Sozietät der Wissenschaften

Ehe, Kinder: 1728 Ehe mit Marie Anne de Vignolles, von 10 Kindern sind 6 früh verstorben, bekannt sind 2 Töchter: Marianne (* 1729), Elisabeth Marie (* 1730), 1 Sohn: Charles Elie $(\dagger 1786)$.

Korrespondenz: 2 Briefe an Gottsched aus den Jahren 1733 und 1738

Literatur: Beyträge zu der juristischen Literatur in den preußischen Staaten. Berlin: Christian Friedrich Voß, 1 (1775), S. 226-239, 2 (1778), S. 292-294; Gottfried von Ising: Aus dem Leben des Großkanzlers Friedrichs des Großen Philipp Joseph de Jariges und seiner Familie. In: Mitteilungen des Vereins für die Geschichte Berlins 44 (1927), S. 55-61; Friedrich Moll: Die Hugenottenfamilie von Jariges. In: Der Herold 2 (1941), S. 173-180; Halle Matrikel 1, S. 245; DBI. 


\section{Jauna, Dominique}

um $1663^{2}$ - wahrscheinlich nach 1747

Beruf, Tätigkeit: Seidenzüchter, Kaufmann, Generalintendant des Handels für die österreichischen Erbstaaten

Biographie: Um 1680 Ankunft in Zypern, Besitzer einer Maulbeerbaumplantage bzw. Seidenraupenzucht auf Zypern, 1702 Konkurs, 1702 verläßt Zypern ohne Familie, Aufenthalt in Kairo, 1739 Denkschrift zur Eroberung von Ägypten, Palästina und Zypern durch Frankreich.

Ehe, Kinder: vor 1696 Ehe mit einer Tochter der Witwe Simoni, Maronitin, 1 Sohn

Korrespondenz: 6 Briefe an Gottsched aus den Jahren 1737 und 1738

Literatur: Johann Paul Reinhard: Vollständige Geschichte des Königsreichs Cypern. Teil 1. Erlangen; Leipzig: Wolfgang Walther, 1766, S. VIII; Constantin von Wurzbach: Biographisches Lexikon des Kaiserthums Oesterreich 10 (1863), S. 112f.; François Charles-Roux: Les origines de l'expédition d'Égypte. Paris 1920, S. 25-27; Paul Masson: Histoire du commerce français dans le Levant au XVIIIe siècle. Paris 1911, S. 561 f.;

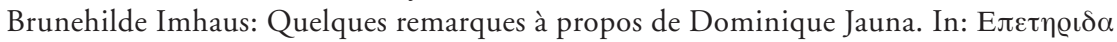
27 (2001), S. 127-132; Anna Pouradier Duteil-Loizidou: Consulat de France à Larnaca. Documents inédits pour servir à l'histoire de Chypre. Nikosia, Tome 5 (1706-1708). 2006, S. 475-477.

\section{Jerusalem, Johann Friedrich Wilhelm}

\section{November 1709 (Osnabrück) - 2. September 1789 (Braunschweig)}

\section{Beruf, Tätigkeit: Theologe}

Biographie: Sohn des Pastor primarius und Superintendenten Theodor Wilhelm Jerusalem (1668-1726) und der Katherine Marie, geb. Wehrkamp (1684-1769). 1717 Schulbesuch in Osnabrück, 1727 Studium der Theologie in Leipzig, 1731 Magister in Wittenberg, Bildungsreise nach Holland, 1734 als Hofmeister zweier westfälischer Adliger Immatrikulation in Göttingen, 1737 Reise nach England, 1740 Rückkehr nach Deutschland, Hauslehrer, 1742 Hofprediger und Erzieher des Erbprinzen Karl Wilhelm Ferdinand von Braunschweig-Wolfenbüttel (1735-1806), 1744 Probst des Aegidienklosters Braunschweig, 1745 wurde nach seinem Plan das Collegium Carolinum in Braunschweig begründet, 1745 Kurator, 1747 Direktor des Collegium Carolinum, 1749-1752 Abt des Klosters Marienthal, 1752 Abt des Klosters Riddagshausen.

Mitgliedschaften: Mitglied der Nachmittäglichen Rednergesellschaft in Leipzig, Mitglied der Teutschen Gesellschaft in Jena, Mitglied der Deutschen Gesellschaft in Göttingen, Mitglied der Gesellschaft der freyen Künste in Leipzig

\footnotetext{
2 Wurzbach gibt als Geburtsjahr „um 1668“, Imhaus „dans les années 1660“; unsere Angabe stützt sich auf den Porträtstich mit Unterschrift: Le chevalier Dominique Jauna Âgé de 79. Ans.; darunter: Josep: Schell Pinx. 1742; vgl. Dominique Jauna: Histoire générale des Roïaumes de Chypre, de Jerusalem, d’Arménie, et d'Egypte. Leiden: Jean Luzac, 1747, Frontispiz.
} 
Ehe, Kinder: 1742 Ehe mit Martha Christina, geb. Pfeiffer, verw. Albrecht (1709-1778), 4 Töchter: Philippine Charlotte (1743-1823), Magdalene Christine Marie (1745-1750), Sophie Elisabeth Regina (1748-1819), Friederike Magdalene (1750-1836), 1 Sohn: Karl Wilhelm (1747-1772)

Korrespondenz: 26 Briefe an Gottsched aus den Jahren 1736 bis 1755, 1 Brief an Luise Adelgunde Victorie Gottsched aus dem Jahr 1747, 1 Brief von Luise Adelgunde Victorie Gottsched aus dem Jahr 1747

Literatur: Hille, Neue Proben, Nr. 10; Müller, Nachricht, S. 101; Gottsched, Verzeichnis; Leipziger Adreß=Post $=$ und Reise=Calender, Auf das Jahr Christi 1754. Leipzig: Johann Gabriel Büschel, 1754; Johann Joachim Eschenburg: Ueber Johann Friedrich Wilhelm Jerusalem. Berlin: Vieweg, 1791 (auch in Deutsche Monatsschrift 1791, S. 97-135); Johann Friedrich Wilhelm Jerusalem: Entwurf einer Lebensgeschichte des Verfassers. Von ihm selbst kurz vor seinem Tode aufgesetzt. In: Jerusalem: Nachgelassene Schriften. Zweiter Theil. Braunschweig: Schulbuchhandlung, 1793, S. 1-34; Friedrich Koldewey: J. Fr. W. Jerusalem (1709-1789). In: Zeitschrift für die historische Theologie 1869, S. 530-574; August Roloff: Abt Jerusalem und die Gründung des Collegium Carolinum zu Braunschweig. Eine Studie zur Genesis der Deutschen Aufklärung. Berlin 1910; Karl Wilhelm Jerusalem: Aufsätze und Briefe. Heidelberg 1925; Suchier, Göttingen, Nr. 161; Fritz Meyen: Johann Friedrich Wilhelm Jerusalem, Abt zu Riddagshausen (1709-1789). In: Braunschweigisches Jahrbuch 53 (1972), S. 159-182; Helmuth Albrecht: Catalogus Professorum der Technischen Universität Carolo-Wilhelmina zu Braunschweig. Teil 1: Lehrkräfte am Collegium Carolinum 1745-1877. Braunschweig 1986, S. 38 f.; Wolfgang Erich Müller: Johann Friedrich Wilhelm Jerusalem. Eine Untersuchung zur Theologie der „Betrachtung über die vornehmsten Wahrheiten der Religion“. Berlin; New York 1984; Klaus Erich Pollmann (Hrsg.): Abt Johann Friedrich Wilhelm Jerusalem (1709-1789). Beiträge zu einem Colloquium anläßlich seines 200. Todestages. Braunschweig 1991; Heiner Schmidt: Quellenlexikon zur deutschen Literaturgeschichte 15 (1998), S. 25 f.; Horst-Rüdiger Jarck (Hrsg.): Braunschweigisches Biographisches Lexikon 8. bis 18. Jahrhundert. Braunschweig 2006, S. 375 f.; DBI.

\section{John, Johann Siegmund}

2. Januar 1697 (Jauer) - 6. Oktober 1749 (Breslau)

Beruf, Tätigkeit: Lehrer

Biographie: Sohn des Bäckers Johann Christoph John (ca. 1671-nach 1749) und der Margaretha, geb. Körber († vor 1749). 1708 Schulbesuch in Jauer, 1714 Besuch des Gymnasiums St. Elisabeth in Breslau, 1717 Studium in Wittenberg, 1719 Magister, 1724 Breslau, Hofmeister in verschiedenen Familien, 1734 Lehrer der 3. und 4. Ordnung am Gymnasium zu Maria Magdalena, 1739 2. Lehrer und 1744 1. Lehrer der 2. Ordnung am Elisabethgymnasium, 1746 Dritter Professor am Magdalenengymnasium, 1748 dessen Prorektor.

Mitgliedschaften: Mitglied der Teutschen Gesellschaft in Jena

Ehe, Kinder: 1735 Ehe mit Susanna Magdalena Heine, 1 Tochter, 2 Söhne, darunter Johann Gottlob (* 1745). 
Korrespondenz: 1 Brief an Gottsched aus dem Jahr 1738

Literatur: Gelehrte Neuigkeiten Schlesiens 1737, S. 398-401, 1739, S. 573, 1740, S. 284f. und 1741-1742, S. 120, 257-263, 413-416; Wöchentliche Breßlauische und auf das Interesse der Commercien der Schlesischen Landen eingerichtete Frag= und Anzeigungs=Nachrichten 1745, S. 49; Johann Gottlieb Biedermann: Nova acta scholastica 2/1 (1749), S. 56; Neuer Büchersaal 9 (1750), S. 74-79; Müller, Nachricht, S. 113, Nr. 70; Joseph Becker: Schlesier in der Deutschen Gesellschaft zu Jena. In: Zeitschrift des Vereins für Geschichte Schlesiens 64 (1930), 138-154; DBI.

\section{Kahle, Ludwig Martin}

5. Mai 1712 (Magdeburg) - 5. April 1775 (Berlin)

Beruf, Tätigkeit: Universitätsprofessor, Jurist, Beamter

Biographie: Sohn des Pfarrers Martin Kahle (1668-1742) und der Christiane Dorothea, geb. Röber $(\dagger 1729)$. Unterricht durch Hauslehrer, Besuch der Domschule in Magdeburg, 1730 Studium in Jena, 1733 Studium in Halle, 1734 Magister, 1735 Adjunkt der Philosophischen Fakultät in Halle, 1735-1737 Reise nach Holland, England und Frankreich, 1737 Professor der Philosophie in Göttingen, 1740-1741 Verfasser der Göttingischen Zeitungen von gelehrten Sachen, 1744 Doktor der Rechte in Göttingen, 1747 außerordentlicher Professor der Rechte in Göttingen, 1750 Hofrat und Professor an der Staatsakademie in Hanau, 1751 ordentlicher Professor der Rechtswissenschaft in Marburg, 1753 Hof- und Kammergerichtsrat in Berlin, 1764 Geheimer Rat und Justitiar des General-Ober-Finanz-Kriegs- und Domänendirektoriums Berlin.

Mitgliedschaften: Mitglied der Deutschen Gesellschaft in Göttingen

Ehe, Kinder: 1739 Ehe mit Lucie Magdalena Meyer († 1775), mehrere Söhne, darunter Conrad Christian (* 1748)

Korrespondenz: 1 Brief an Gottsched aus dem Jahr 1738

Literatur: Gustav Roethe: Göttingische Zeitungen von gelehrten Sachen. In: Festschrift zur Feier des hundertfünfzigjährigen Bestehens der Königlichen Gesellschaft der Wissenschaften zu Göttingen. Berlin 1901, S. 600 f.; Suchier, Göttingen, S. 66; Wilhelm Ebel: Catalogus professorum Gottingensium 1734-1962. Göttingen 1962; Luigi Cataldi Madonna: Die „Logica probabilium“ des Ludwig Martin Kahle. In: Europa in der Frühen Neuzeit. FS Günter Mühlpfordt. Band 2. Weimar u. a. 1997, S. 149-163; Pfarrerbuch Sachsen 4, S. 447; Rolf Straubel: Biographisches Handbuch der preußischen Verwaltungs- und Justizbeamten 1740-1806/15. München 2009, S. 469; DBI.

\section{Kemna, Ludolf Bernhard}

24. August $1713^{3}$ (Lüneburg) - 11. Februar 1758 (Danzig)

Beruf, Tätigkeit: Lehrer, Pfarrer

3 Auf dem Bild der St. Barbara Kirche in Danzig, in der Kemna seit 1755 Pfarrer war, wird MDCCXII als Geburtsjahr angegeben; vgl. Kunstdenkmäler der Stadt Danzig 5, S. 144. 
Biographie: Sohn des Kaufmanns Jacob Kemna und der Elisabeth, geb. Mattfeld. Besuch des Johanneums, 1734 Studium in Jena, 1736 Studium in Leipzig, 1738 Magister, 1738 Rektor der Marienschule in Danzig, 1756 (Prätorius 1755) Prediger an St. Barbara in Danzig. Mitgliedschaften: Mitglied der Nachmittäglichen Rednergesellschaft, 1754 Mitglied der Gesellschaft der freyen Künste

Ehe, Kinder: Ehe mit Dorothea Concordia Haselau (* 1720), 3 Töchter: Anna Elisabeth (* 1745), Concordia (*1747), Luise Christine (* 1750), 2 Söhne: Samuel Bernhard (1748-1773), Johann Gottlieb (* 1753)

Korrespondenz: 12 Briefe an Gottsched aus den Jahren 1738 bis 1755

Literatur: Vetter, Magistri; Panegyrici magisteriales (Leipzig, UB, Univ. 380c), 1738, S. XX-XXII; Heinrich Clemens Dithmar: De Baccalaureis Commentatio. Leipzig: Langenheim, 1738 (Kemna, dem Stubengenossen, gewidmet, mit dem Dithmar eine „animorum coniunctio“ verbinde); Hille, Neue Proben, Nr. 60; Gemeinnützige Danziger Anzeigen, Erfahrungen und Erläuterungen allerley nützlicher Dinge und Seltenheiten. Vom Jahr 1755, S. 252; Librorum Viri Plurimum Reverendi M. Ludolphi Bernhardi Kemnae, V. D. M. ad Ædem D. Barbarae, dum viveret, meritissimi Catalogus, quorum Auctio publica Die XXIX. Maji, Anni MDCCLVIII., in Ædibus a B. Dn. Possessore inhabitatis $\&$ (ut vulgo dicitur) auf Langgarten hinter der Kirchen sitis fiet per Jo. Gotfr. Barthelsen. Danzig: Schreiber, 1758; Ephraim Prätorius: Danziger Lehrer Gedächtniß. Berlin; Stettin; Leipzig: Johann Heinrich Rüdiger, 1760, S. 16 und 94; Ludwig Rhesa: Kurzgefaßte Nachrichten von allen seit der Reformation an den evangelischen Kirchen in Westpreußen angestellten Predigern. Königsberg 1834, S. 64; Danziger familiengeschichtliche Beiträge 1 (1929), S. 61, Nr. 64; Kunstdenkmäler der Stadt Danzig 5: St. Trinitatis, St. Peter und Paul, St. Bartholomäi, St. Barbara, St. Elisabeth, Hl. Geist, Engl. Kapelle, St. Brigitten. Auf Grund der Vorarbeiten von Willi Drost bearbeitet von Franz Swoboda. Stuttgart 1972, S. 144 f.; Jena Matrikel 2, S. 227, Nr. 156; Leipzig Matrikel, S. 192; Gottsched, Verzeichnis; Leipziger Postcalender 1754; Weichbrodt 1, S. 227; 3, S. 59; DBI.

\section{Kopp, Johann Friedrich}

1716 (Dresden) - 8. März 1755 (Dresden)

Beruf, Tätigkeit: Hof- und Justizienkanzleisekretär

Biographie: Eltern unbekannt. 1727 Besuch der Landesschule St. Afra in Meißen, 1733 Studium in Leipzig, 1736 Hofmeister eines Adligen, kursächsisch-polnischer Regimentsquartiermeister in Kölleda, Sekretär des kursächsischen Generals en chef Wolf Heinrich Graf von Baudissin (1671-1748), 1743 Secretarius supernumerarius in der Landesregierung, 1750 nach Auskunft des Dresdener Adreßbuchs neben anderen Trägern des Namens Kopp wohnhaft in der Dresdner Neustadt in Kopps Hause in der Clostergasse.

Ehe, Kinder: Unverheiratet

Korrespondenz: 20 Briefe an Gottsched aus den Jahren 1737 bis 1748

Literatur: Dresden, Sächsisches Hauptstaatsarchiv, Loc. 30669: Die Secretarien betr. Vol. I: 1693-1761 (Bewerbungsbriefe und Anstellungsrevers); Dresden, Regionalkirchenamt, Bestattungsbuch der Dreikönigskirchgemeinde Dresden von 1755, Kopp an Johann Michael Francke, Kölleda 23. Juli 1739, Halle, Universitäts- und Landesbibliothek Sachsen-Anhalt, Misc. 2 13, Bl. 141-144; Neuer Büchersaal 1/2 (1745), 
S. 99-116, Neuer Büchersaal 1/2 (1745), S. 99-116, 6/3 (1748), S. 269-274; Das Jetztlebende Königliche Dreßden. Dreßden: Christian Robring, 1750, S. 54; Dreßdnische Wöchentliche Frag= und Anzeigen 1755 (Nr. 12 vom 18. März); Der mit denen neuesten Stadt $=$ Land $=$ und Weltgeschichten beschäftigte Annaliste 1755 (Nr. 21 vom 14. April), S. 323; Neu=eröffnete Historische Correspondenz von Alten und Neuen Curiosis Saxonicis 1755, S. 183; August Hermann Kreyssig: Afraner-Album. Verzeichniss sämmtlicher Schüler der Königlichen Landesschule zu Meissen von 1543 bis 1875 . Meißen 1876, S. 252; Hedwig Wagner: Tasso daheim und in Deutschland. Einwirkungen Italiens auf die deutsche Literatur. Berlin 1905, S. 89-101; Franz Ulbrich: Die Belustigungen des Verstandes und des Witzes. Ein Beitrag zur Journalistik des 18. Jahrhunderts. Leipzig 1911, S. 78 f.; Karl Gröschl: Die deutschen Übersetzungen Voltaire'scher Tragödien bis zu Goethes Mahomet und Tancred. Ein Beitrag zur Geschichte Voltaires in Deutschland. Prag 1912 (Nachdruck Hildesheim 1973), S. 3, 28-37; Ida-Marie Cattani: Studien zum deutschen Tassobild des 17. und 18. Jahrhunderts. Freiburg, Univ., Philos. Fak., Diss., 1941; Christian Fürchtegott Gellert: Briefwechsel. Hrsg. von John F. Reynolds. Band 1. Berlin; New York 1983, S. 2, 4 und 281 (Erl. zu Z. 20 und 22); Achim Aurnhammer: Torquato Tasso im deutschen Barock. Tübingen 1994, S. 4 f., 238-248; Friedrich von Hagedorn: Briefe. Berlin; New York 1997, Nr. 60, Z. 68 f., Nr. 61, Z. 19 und Nr. 117, Z. 51; Gabriele Ball: Moralische Küsse. Gottsched als Zeitschriftenherausgeber und literarischer Vermittler. Göttingen 2000, S. 312-321 u. ö.; Leipzig Matrikel, S. 210; DBI (Koppe).

\section{Krohse, Johann Andreas}

nach 1700 (vermutlich Spandau)

Beruf, Tätigkeit: Jurist, Auditeur

Biographie: Vermutlich Sohn des Spandauer Zuchthauspredigers Johann Krohß (16761732) und der Dorothea Elisabeth, geb. Rittner (um 1686-1771). 1727 Studium in Halle, 1739 Aufenthalt in Leipzig, 1744 Auditeur bei dem Regiment Nr. 13 unter Generalleutnant Friedrich Sebastian Wunibald Graf von Truchseß zu Waldburg (1677-4. Juni $1745)$ in Berlin. Über den weiteren Lebensweg konnte nichts ermittelt werden.

Ehe, Kinder: Nicht ermittelt

Briefe: 1 Brief an Gottsched aus dem Jahr 1739

Literatur: Krohse an Jean Henri Samuel Formey, 22. Juni 1745, Staatsbibliothek zu Berlin - Preußischer Kulturbesitz, Nachlaß Formey, Kasten 2; Adres-Calender, Der Königl. Preuß. Haupt $=$ und Residentz=Städte Berlin 1744, S. 10; Daniel Friedrich Schulze: Zur Beschreibung und Geschichte von Spandow. Hrsg. von Otto Recke. Spandau 1913, S. 338-340; Otto Fischer: Evangelisches Pfarrerbuch für die Mark Brandenburg. Berlin 1941. Band 2/1, S. 454; Halle Matrikel 1, S. 104.

\section{Kulmus, Johann Adam}

23. März 1689 (Breslau) - 30. Mai 1745 (Danzig)

Beruf, Tätigkeit: Arzt, Gymnasialprofessor

Biographie: Sohn des Bäckers Adam Kulmus und der Maria, geb. Flegel. Besuch des 
Gymnasiums Maria Magdalena, nach dem frühen Tod der Eltern nahm ihn der ältere Bruder Johann Georg Kulmus 1706 zu sich nach Danzig. Besuch des Gymnasiums, 1711 Studium der Medizin, Mathematik und Physik in Halle, Studienaufenthalte in Leipzig, Jena, Altdorf und Straßburg, 1715 Promotion in Basel, anschließend Aufenthalt in Holland, Kontakte u.a. zu Herman Boerhaave, nach der Rückkehr nach Danzig erteilte er Privatunterricht in Anatomie und Chirurgie, 1725 Professor für Medizin und Physik am akademischen Gymnasium.

Mitgliedschaften: 1721 Mitglied der Leopoldina, 1735 Mitglied der Berliner Sozietät der Wissenschaften

Ehe, Kinder: 1721 Ehe mit Concordia, geb. Ebeling, verw. Leuschner $(† 1773$ im Alter von 90 Jahren), über Kinder des Ehepaares ist nichts bekannt.

Korrespondenz: 9 Briefe an Gottsched aus den Jahren 1729 bis 1741

Literatur: Halle, Deutsche Akademie der Naturforscher Leopoldina, Archiv, Matrikel Nr. 356; Rector, inspector et professores civibus Athenaei Gedanensis s. p. d. eosque ad exsequias solemnes viri ... Joannis Adami Kulmi ... die XVII. kal. Julias anni hujus MDCCXXXXV ... perhumaniter convocant. Danzig: Thomas Johannes Schreiber, 1745 (Leipzig, UB, 4-Vit.2420); Memoria viri excellentissimi ... Joannis Adami Kulmi. In: Acta physico-medica Academiae Caesareae Leopoldino-Carolinae naturae curiosorum exhibentia Ephemerides 9 (1752): Appendix mit eigener Paginierung, S. 295-304; Ludovici, Wolff 3, S. 181-184; Theodor Hirsch: Geschichte des academischen Gymnasiums in Danzig. Danzig 1837, S. 53 und 63; Altpreußische Geschlechterkunde 11 (1937), S. 11; Kessler, Altpreußische Briefe, S. 11, Nr. 27; Danziger familiengeschichtliche Beiträge 6 (1941), S. 21; Anna Mosingiewicz: Jan Adam Kulmus i jego portret w bibliothece Gdańskiej Polskiej Akademii Nauk. In: Libri Gedanenses: Rocznik Biblioteki Gdańskiej Polskiej Akademii Nauk 11-12 (1993/1994), S. 47-77; Michael Sachs: Die „Anatomischen Tabellen“ (1722) des Johann Adam Kulmus (16891745). Ein Lehrbuch für die (wund-)ärztliche Ausbildung im deutschen Sprachraum und in Japan. In: Sudhoffs Archiv 86 (2002), S. 69-85. Michael Sachs (Bearb.): Historisches Ärztelexikon für Schlesien. Frankfurt am Main. Band 3 (H-K) 2002, S. 342 f; DBI.

\section{Kulmus, Johann Ernst}

25. März 1709 (Danzig) - 1769 (vermutlich Danzig)

Beruf, Tätigkeit: Arzt

Biographie: Sohn des Arztes Johann Georg Kulmus (Korrespondent) und der Regina Konkordia, geb. Tessin ( $† 1710) .1726$ Besuch des Gymnasiums in Danzig, 1730 Studium der Medizin in Leipzig, 1732 Doktor der Medizin, anschließend Arzt in Danzig, 1745 Stadtphysicus in Danzig.

Ehe, Kinder: 1739 Ehe mit Anna Eleonora, geb. Davidson, verw. Steinhart (1717-1784), 1 Tochter: Renate Florentine Concordia (1755-1788), 3 Söhne: Johann Daniel (17401744), Georg Gottlieb (1741-1743), Johann Ludwig (*1745).

Korrespondenz: 1 Brief an Gottsched aus dem Jahr 1738

Literatur: Johann David Steinmüller: Ein Arzt muß sich, ausser seiner Wissenschaft, auch noch andre bekannt machen. Als Herr Johann Ernst Kulmus, im Jahre 1732 den 
19. Sept. auf der Universität Leipzig die Doctorwürde erhielt. In: Schwabe, Proben, S. 58-72; Friedrich Börner: Nachrichten von den vornehmsten Lebensumständen und Schriften Jeztlebender berühmter Aerzte und Naturforscher in und um Deutschland. Band 3. Wolfenbüttel: Johann Christoph Meißner, 1753, S. 353; Otto Schmidt: Sektionsberichte aus Danziger Physikatsakten der Jahre 1691-1769, ein Beitrag zur Geschichte der gerichtlichen Medizin: In: International journal of legal medicine 37 (1943), S. 203-217, 216 f.; Weichbrodt 1, S. 105 und 5, S. 77; Michael Sachs (Bearb.): Historisches Ärztelexikon für Schlesien. Frankfurt am Main. Band 3 (H-K) 2002, S. 343; Leipzig Matrikel, S. 222.

\section{Lamprecht, Jacob Friedrich}

1. Oktober 1707 (Hamburg) - 8. Dezember 1744 (Berlin)

Beruf, Tätigkeit: Journalist

Biographie: Sohn des Notars Hinrich Diterich Lambrecht (†1736) und der Anna Rahel, geb. Indorff. Längerer Aufenthalt als Hofmeister in Berlin, 1732 Studium der Philosophie und Rechtswissenschaften in Leipzig, Mai 1735 Empfang des Ehepaares Gottsched in Berlin, Mai-Ende Juni 1735 Kuraufenthalt in Karlsbad, 1736 Reise nach England, 1737-1740 Redakteur des Hamburgischen Correspondenten, 1740 Redakteur der Berlinischen Nachrichten von Staats- und gelehrten Sachen, 1742 Sekretär im Auswärtigen Amt, 1744 Sekretär des Prinzen Heinrich von Preußen, 1743 deputierter Meister der Freimaurerloge zu den drei Weltkugeln in Berlin, 1743 und 1744 Meister vom Stuhl, Amtsverzicht aus Krankheitsgründen.

Mitgliedschaften: 1733 Mitglied der Deutschen Gesellschaft in Leipzig, 1744 Mitglied der Berliner Sozietät der Wissenschaften

Ehe, Kinder: Unverheiratet

Korrespondenz: 14 Briefe an Gottsched aus den Jahren 1733 bis 1740

Literatur: Hamburg, Staatsarchiv, Taufbuch der Hamburger St. Petrikirche, A VIII b $1 \mathrm{f}$, S. 212 und Traubuch der St. Petrikirche, A VIII c 1 a, S. 162; Johann Matthias Dreyer: Vorbericht Von den Lebensumständen des Herrn Geheimen Secretairs Lamprechts. In: Jakob Friedrich Lamprecht: Der Menschenfreund, Aus seinen Hinterlassenen Schriften vermehrt und verbessert. Hamburg: Georg Christian Grund; Leipzig: Adam Heinrich Holle, 1749, S. a4-[b4v], ergänzter Wiederabdruck in: Journal von und für Deutschland 7 (1790), 1.-6. Stück, S. 302-310; Jacob Friedrich Lamprecht. In: Allerley aus dem Reiche des Verstandes und Witzes 2 (1774), S. 231-240; Franz August von Etzel: Geschichte der Großen National-Mutter-Loge der Preußischen Staaten genannt zu den drei Weltkugeln. 4. Auflage. Berlin 1875, S. 16, 20; Kroker, Nr. 271; Fritz Flasdieck: Jakob Friedrich Lamprecht. Ein Beitrag zur Geschichte der literarischen Kritik im 18. Jahrhundert. Düsseldorf 1908; Erich Widdecke: Geschichte der Haude- und Spenerschen Zeitung 1734-1874. Berlin 1925, S. 36-39; [Jacob Friedrich Lamprecht:] Schreiben eines Schwaben an einen deutschen Freund in Petersburg von dem gegenwärtigen Zustande der Opera in Hamburg. Hamburg 1937; Martin Schulz: Die kulturpolitische Bedeutung des "Gelehrten Artikels“ in den Berliner Tageszeitungen des 18. Jahrhunderts. Berlin, Friedrich-Wilhelms-Universität, Philos. Fak., Diss., 1940, S. 30-39; Hans-Friedrich Meyer: Die Berlinischen Nachrichten von Staats- und gelehrten Sachen (1740-1874). 
In: Heinz-Dietrich Fischer (Hrsg.): Deutsche Zeitungen des 17.-20. Jahrhunderts. München 1972, S. 103-114, 106; Franklin Kopitzsch: Grundzüge einer Sozialgeschichte der Aufklärung in Hamburg und Altona. Hamburg 1982, S. 309-311; Perels/ Rathje/Stenzel, S. 113; Kosch 9 (1984), Sp. 840; Böning/Moepps, Sp. 179, 220; Brigitte Tolkemitt: Der Hamburgische Correspondent: Zur öffentlichen Verbreitung der Aufklärung in Deutschland. Tübingen 1995; Karlheinz Gerlach (Hrsg): Berliner Freimaurerreden 1743-1804. Frankfurt am Main u. a. 1996, S. 11-16; Leipzig Matrikel, S. 226; DBI.

\section{Lange, Karl Heinrich}

9. September 1703 (Juliusburg, Fürstentum Oels in Niederschlesien) - 17. Februar 1753 (Lübeck)

Beruf, Tätigkeit: Lehrer

Biographie: Sohn des Kellermeisters der Herzogin Anne Sophie von Bernstadt-Juliusburg und Ratsherrn in Juliusburg Martin Lange und der Maria Elisabeth, geb. Franzke. Besuch der Stadtschule Juliusburg, 1717 Eintritt in das Gymnasium St. Elisabeth in Breslau, 1720 Studium der Mathematik, Philosophie und Theologie in Jena, als Magister hielt Lange seit 1725 poetische und homiletische Collegia, 1726 Reise nach Wolfenbüttel, Bekanntschaft mit Johann Lorenz Mosheim, 1728 Adjunkt Zacharias Stampeels am Katharineum in Lübeck, 1731 dessen Nachfolger als Subrektor und Bibliothekar der Stadtbibliothek, 1739 Konrektor am Katharineum.

Mitgliedschaften: 1729 Mitglied der Deutschen Gesellschaft in Leipzig, 1739 Mitglied der Societas Latina in Jena, 1747 Mitglied der Deutschen Gesellschaft in Göttingen, 1750 Mitglied der Teutschen Gesellschaft in Jena

Ehe, Kinder: 1729 Ehe mit Maria Hedwig Stampeel (1703-1780), die Ehe blieb kinderlos.

Korrespondenz: 19 Briefe an Gottsched aus den Jahren 1727 bis 1748

Literatur: Müller, Nachricht, S. 101; Christoph Gotthilf Kohlreif: Die immerwährende Tugend der Redlichkeit (Glückwunschgedicht für Carl Heinrich Lange anläßlich seiner Ernennung zum Mitglied der Teutschen Gesellschaft in Jena am 21. März 1750). Lübeck: Fuchs, 1750; Johann Friedrich Möllrath: Wohlverdientes Ehrengedächtniß, welches dem ... M. Carl Heinrich Lange, des hiesigen Gymnasii Conrectorn ... am Tage seiner Beerdigung den 27. Februar. dieses $1753^{\text {sten }}$ Jahres ... gestiftet worden. Lübeck: Johann Daniel August Fuchs, [1753]; Johann Heinrich von Seelen: Memoria ... Caroli Henrici Langii, conrectoris Lubecensis meritissimi. Lübeck: Johann Nikolaus Green, [1753]; Johann Georg Christoph Arnold: Elogium Caroli Henrici Langii. In: Acta societatis latinae Ienensis. Band 3. Jena 1754, S. 337-342; Kroker, Nr. 241; Suchier, Göttingen, S. 64, Nr. 35; Biographisches Lexikon für Schleswig-Holstein und Lübeck 7 (1985), S. 118 f.; Marwinski, Fabricius, S. 73; DBI.

\section{Lemker, Heinrich Christian}

6. Januar 1703 (Ebstorf) - 13. Oktober 1779 (Müden/Aller)

Beruf, Tätigkeit: Lehrer, Pfarrer

Biographie: Sohn des Kaufmanns Harder Rudolf Lemker (1678-1714) und der Anna So- 
phia, geb. Jahnke (1678-1752). 1710 Unterricht durch Hauslehrer, 1717 Besuch der Michaelisschule in Lüneburg, 1721 Studium in Wittenberg, 1724 Aufenthalt in Halle, Leipzig, Magdeburg, Helmstedt, 1725 Studium in Helmstedt, Hofmeistertätigkeit, 1729 Konrektor an der Michaelisschule in Lüneburg, 1742 Pfarrer in Scharnebeck, 1751 Pfarrer in Müden an der Aller.

Mitgliedschaften: 1735 Mitglied der Deutschen Gesellschaft in Leipzig, 1745 Mitglied der Deutschen Gesellschaft in Göttingen, Mitglied der ökonomischen Gesellschaft in Celle

Ehe, Kinder: 1730 Ehe mit Anna Ilsabe Boye (1711-1759), mehrere Kinder, von denen eine Tochter den Vater überlebte: Maria Sophie (1741-1794); 1765 Ehe mit Anna Elisabeth Lucie Olshausen $(\dagger 1789)$

Korrespondenz: 9 Briefe an Gottsched aus den Jahren 1736 bis 1750

Literatur: Ebstorf, Evangelisch-lutherisches Pfarramt, verschiedene Kirchenbücher; Acta historico-ecclesiastica 7 (1744), S. 306; Konrad Arnold Schmid: An Herrn Heinr. Christ. Lemker, Pastor zu Müden an der Aller, bey der Feyer seiner fünfzigjährigen Amtsführung. Den 28. Jun. 1779. In: Der Teutsche Merkur vom Jahr 1779, Viertes Vierteljahr, S. 97-103; Acta historico-ecclesiastica nostri temporis 6/41 (1780), S. 120-132; Waniek, S. 218, 275; Kroker, Nr. 287; Suchier, Göttingen, Nr. 37; Theodor Wotschke: Die Niedersächsischen Berichterstatter der Acta historico-ecclesiastica. In: Zeitschrift der Gesellschaft für niedersächsische Kirchengeschichte 22/23 (1927/28), S. 218-276, 249-251; Hans Funke: Schloß-Kirchenbuch Hannover 1680-1812. Band 2. Hannover 1993, Nr. 2406; Ulrich Löffler: Lissabons Fall - Europas Schrecken. Die Deutung des Erdbebens von Lissabon im deutschsprachigen Protestantismus des 18. Jahrhunderts. Berlin; New York 1999, S. 196-198; Christopher Voigt: Der englische Deismus in Deutschland. Eine Studie zur Rezeption englisch-deistischer Literatur in deutschen Zeitschriften und Kompendien des 18. Jahrhunderts. Tübingen 2003; Hans Funke: Die evangelisch-lutherischen Pastoren des Kreises Uelzen. Uelzen 2004, S. 210; Wittenberg Matrikel, S. 272; DBI.

\section{Lindner, Kaspar Gottlieb}

Beruf, Tätigkeit: Arzt, Dichter, Journalist

Biographie: Sohn des Caspar Lindner und der Anna Catharina, geb. Kirstein. Privatunterricht und Besuch der Schule in Liegnitz, 1723 Eintritt in das Gymnasium St. Elisabeth in Breslau, auf Anraten des Arztes Johann Georg Brunschwitz (1684-1734) sieht sich Lindner nach einer Erkrankung genötigt, das beabsichtigte Theologiestudium zugunsten der Medizin aufzugeben, 1726 Studium in Jena, 1727 Studium in Halle, 1729 medizinische Promotion in Halle, Rückkehr nach Liegnitz, 1733 praktischer Arzt in Hirschberg, 1740 Herausgeber der Gelehrten Neuigkeiten Schlesiens, 1742-1759 Ratsherr der Stadt Hirschberg.

Mitgliedschaften: Mitglied des Hirschberger Dichterkreises Collegium poeticum, 1737 Mitglied der Deutschen Gesellschaft in Leipzig, 1737 Mitglied der Leopoldina (Leonides II.)

Ehe, Kinder: Unverheiratet

Korrespondenz: 6 Briefe an Gottsched aus den Jahren 1736 bis 1740 
Literatur: Halle, Deutsche Akademie der Naturforscher Leopoldina, Archiv, M 398; Andreas Elias Büchner: Academiae Sacri Romani Imperii Leopoldino-Carolinae Naturae Curiosorum historia. Halle: Gebauer, 1755, Nr. 468; Johann Daniel Hensel: Historisch=Topographische Beschreibung der Stadt Hirschberg in Schlesien seit ihrem Ursprunge bis auf das Jahr 1797. Hirschberg: Wolfgang Pittschiller, 1797, S. 610 f.; Schlesische Lebensbilder 2 (1926), S. 99-103; Willy Klawitter: Die Zeitungen und Zeitschriften Schlesiens von den Anfängen bis zum Jahre 1870. Breslau 1930, S. 93 Nr. 482; Willy Klawitter: Die ältesten moralischen Wochenschriften in Schlesien. In: Schlesische Geschichtsblätter 1932, S. 6-11; Arno Lubos: Geschichte der Literatur Schlesiens. 1. Band. München 1960, S. 181-183; Mechthild Hofmann: „Journal von Frauen für Frauen“. Eine Kuriosität für die ehrwürdige Leopoldina. In: Triangel. Das Radio zum Lesen. 8. Oktober 2003, S. 70-72; Michael Sachs: Historisches Ärztelexikon für Schlesien: Biographisch-bibliographisches Lexikon schlesischer Ärzte und Wundärzte (Chirurgen). Bd. 4 (L-O). Frankfurt am Main 2006, S. 117-119; Halle Matrikel 1, S. 268; Jena Matrikel 3, S. 61; DBI.

\section{Ludovici, Karl Günther}

7. August 1707 (Leipzig) - 5. Juli 1778 (Leipzig)

Beruf, Tätigkeit: Universitätsprofessor

Biographie: Sohn des Philosophieprofessors Christian Ludovici (1663-1732) und der Christine Sophie, geb. Ittig (†1731). 1709 Deposition an der Leipziger Universität, Unterricht durch Hauslehrer und Besuch der Thomasschule, 1724 Studium in Leipzig, 1728 Magister der Philosophie, 1731 Assessor der Philosophischen Fakultät, 1733 ordentlicher Professor der Philosophie, 1739 Übernahme der Redaktion des Zedlerschen Lexikons ab Band 19, 1761 Professor des Aristotelischen Organs.

Mitgliedschaften: 1730 Mitglied der Deutschen Gesellschaft in Leipzig, 1738 Mitglied der Berliner Sozietät der Wissenschaften, Mitglied und Bibliothekar der Gesellschaft der freyen Künste in Leipzig, 1765 Mitglied der Öconomischen Societät in Leipzig.

Ehe, Kinder: Unverheiratet

Korrespondenz: 1 Brief an L. A. V. Gottsched aus dem Jahr 1738, 2 Briefe an Gottsched aus den Jahren 1742 und 1750

Literatur: Neue Zeitungen 1732 (Nr. 8 vom 28. Januar), S. 70-72 (Vita des am 15. Januar verstorbenen Christian Ludovici); Zedler 18 (1738), Sp. 1005-1012; Kroker, Nr. 250, Rudolf Seyffert: Carl Günther Ludovici und sein Hauptwerk, die Akademie der Kaufleute. In: Carl Günther Ludovici: Grundriss eines vollständigen Kaufmanns-Systems. Stuttgart 1932, S. I-XXIV; Gerd Quedenbaum: Der Verleger und Buchhändler Johann Heinrich Zedler 1706-1751. Hildesheim; New York 1977, S. 238-248; DBI.

\section{Maichel, Daniel}

14. Oktober 1693 (Stuttgart) - 20. Januar 1752 (Abtei Königsbronn)

Beruf, Tätigkeit: Universitätsprofessor

Biographie: Sohn des Bürgers und Gerichtsverwandten Daniel Maichel (1663-1694) und der Anna Margarete, geb. Reichert (1671-1701). Besuch der Klosterschulen Blau- 
beuren und Bebenhausen, 1710 Studium in Tübingen, 1713 Magister, 1718 Reisen durch die Schweiz, Frankreich, England, Holland, Italien und Deutschland, zuletzt als Hofmeister der Grafen Friedrich Wilhelm und Viktor Sigismund von Gräveniz, 1724 ordentlicher Professor der Philosophie und außerordentlicher Professor der Theologie in Tübingen, 1726 Professor der Logik und Metaphysik, 1730 Doktor der Theologie, 1734 Visitationsrecht (Pädagogarchat) über die Lateinschulen des Landes ob der Steig, 1739 Professor der Moralphilosophie, 1749 Ende der akademischen Laufbahn aus gesundheitlichen Gründen, Abt des Klosters Königsbronn.

Mitgliedschaften: Mitglied der Académie des Sciences, Belles-Lettres et Arts de Lyon, 1736 Mitglied der Deutschen Gesellschaft in Leipzig, 1739 Mitglied der Society for Promoting Christian Knowledge

Ehe, Kinder: 1724 Ehe mit Maria Magdalena Aulber (1708-1762), 3 Töchter: Charlotte Dorothee (1733-1780), Eleonore Magdalene (*1734), Marie Jacobine $\left({ }^{*} 1735\right)$

Korrespondenz: 11 Briefe an Gottsched aus den Jahren 1735 bis 1744, ein Brief an Luise Adelgunde Victorie Gottsched aus dem Jahr 1740

Literatur: Zedler 19 (1739), Sp. 528f.; Andreas Christoph Zeller: Ausführliche Merckwürdigkeiten der Hochfürstl. Würtembergischen Universitaet und Stadt Tübingen. Tübingen: Berger, [1743], S. 395 f., 481 und 513; Tübingische Berichte von gelehrten Sachen auf das Jahr 1752, S. 119-122; Elias Friedrich Schmersahl: Neue Nachrichten von jüngstverstorbenen Gelehrten. 2. Stück. Leipzig: Carl Ludwig Jacobi, 1753, S. 353-359; August Friedrich Bök: Geschichte der herzoglich Würtenbergischen Eberhard Carls Universität zu Tübingen im Grundrisse. Tübingen: Johann Georg Cotta, 1774, S. 172 f.; Ferdinand Friedrich Faber: Die Württembergischen Familien=Stiftungen. 7. Heft. Stuttgart 1853 (Nachdruck Stuttgart 1940), S. 60, \$155; 8. Heft. Stuttgart 1854 (Nachdruck Stuttgart 1940), S. 132, \$ 140 und S. 135, $\$ 150-151$; Kroker, Nr. 291; Reinhold Scholl: Die Bildnissammlung der Universität Tübingen 1477 bis 1927. Stuttgart 1927, S. 39, Nr. 122; Hans-Wolf Thümmel: Die Tübinger Universitätsverfassung im Zeitalter des Absolutismus, Tübingen 1975; Tübingen Matrikel 3, Nr. 30830; DBI.

\section{Manhardt, Johann Kaspar}

12. Oktober 1685 (Sondershausen) - 7. März 1747 (Ebeleben)

Beruf, Tätigkeit: Pfarrer

Biographie: Sohn des Bürgermeisters Johann Melchior Manhardt und der Anna Maria. 1721 Substitut, 1722 Pfarrer in Ebeleben, Inspektor und Konsistorialassessor in Ebeleben.

Ehe, Kinder: 1721 Ehe mit Catharina Elisabeth Biel (1693-1729), 2 Töchter: Christina Magdalena (1722-1724), Melusine Magdalene (*† 1724), 2 Söhne: August Friedrich (1725-1727), Johann Christian (1727-1734); 1731 Ehe mit Regina Maria Wunderlich (* 1710), 2 Töchter: Augusta Victoria (* 1732), Charlotte Dorothea Ernestina (17351736), 4 Söhne: Friedrich Michael (1733-1736), Johann Christian (1738-1739), Johann Caspar $(* \dagger 1739)$, Friedrich Christian (1741-1771)

Korrespondenz: 1 Brief an Gottsched aus dem Jahr 1738

Literatur: Johann Michael Manhardt: Als ... Johann Caspar Manhardt, Des Hochfürstl. Schwartzb. Consistorii zu Ebeleben Hochverordneter Assessor, wie auch wohlmeritirter 
Pastor der Christlichen Gemeinde daselbst, und derselben Dioeces Hochverordneter Inspector, In einem gesegneten Alter von 62. Jahren das Zeitliche mit der seeligen Ewigkeit verwechselt ... Sondershausen: Bock, [1747]; Pastoren der Inspection Ebeleben: Die nach vielen Leiden wieder erfreuete Seele ... Sondershausen: Bock, [1747]; Erasmus Rudolph Heinrich Rath u. a.: Als ... Johann Caspar Manhardt, Des Hochfürstl. Schwartzb. Consistorii zu Ebeleben Hochansehnlicher Assessor, wie auch hochmeritirter Pastor der Christlichen Gemeinde daselbst, und derselben Dioeces Hochverordneter Inspector, Nach seinem 2.jährigen überstandenem harten Lager den 7. Martii 1747. In CHristo JEsu seinem Erlöser sanfft und seelig entschlief ... Sondershausen: Bock, [1747]; Johann Georg Reiff: Bey dem Grabe Des ... Johann Caspar Manhardt ... Sondershausen: Bock, [1747] (die Gelegenheitsgedichte sind im Thüringischen Staatsarchiv Rudolstadt überliefert); Bernhard Möller: Thüringer Pfarrerbuch. Band 2: Fürstentum SchwarzburgSondershausen. Neustadt an der Aisch 1997, S. 268.

\section{Manteuffel, Ernst Christoph von}

\section{Juli/2. August 1676 (Kerstin) - 30. Januar 1749 (Leipzig)}

Beruf, Tätigkeit: Diplomat, Politiker, Mäzen

Biographie: Sohn des preußischen Landrats im Fürstentum Cammin, Christoph Arnd von Manteuffel $(\dagger 1713)$ und der Elisabeth Clara, geb. von Bonin. Privatunterricht, 1693 Studium in Leipzig, 1697 Besuch des Kammergerichts Wetzlar, Reise durch Holland und Frankreich, 1699 Kammerjunker am preußischen Hof in Berlin, 1701 Eintritt in kursächsische Dienste, 1704 kursächsischer und königlich-polnischer Hof- und Legationsrat in Dresden, 1705-1707 und 1709-1710 Gesandter in Kopenhagen, 1708 Kammerherr, 1709 Reichsfreiherr, 1710 Wirklicher Geheimer Rat, Gesandtschaftsdienste in Hamburg, 1711-1716 Gesandter am preußischen Hof, 1716 Kabinettsminister, 1719 Reichsgraf, 1730 politischer motivierter Rückzug aus dem kursächsischen Dienst, Aufenthalt auf pommerschen Gütern, 1733-1740 Aufenthalt in Berlin, ab 1741 Aufenthalt in Leipzig.

Mitgliedschaften: Mitglied des Weißen Adlerordens, 1736 Stifter der Gesellschaft der Alethophilen, Mitglied der Deutschen Gesellschaft in Greifswald, 1748 Mitglied der Royal Society in London

Ehe, Kinder: 1712 Verlöbnis mit Katharina Elisabeth von Chwalowsky (1700-1712), 1713 Ehe mit Gottliebe Agnete Charlotte, verwitwete Baroness von Trach, geb. Baronin von Bludowski (1690-1756), 5 Töchter: Charlotte Sophie Albertine (1714-1768), Wilhelmine Ernestine (1715-1771), Friederike Marie Margarete $\left({ }^{*} \dagger 1716\right)$, Henriette Johanna Konstantia (1718-1785), Luise Marianne (*1719, 1743 Ehe mit Ferdinand von Münchhausen), 2 Söhne: August Jakob (*† 1719), Christoph Friedrich von Mihlendorff, Adoptivsohn (1727-1803).

Korrespondenz: 81 Briefe von Gottsched aus den Jahren 1737 bis 1746, 73 Briefe an Gottsched aus den Jahren 1737 bis 1746, 47 Briefe von Luise Adelgunde Victorie Gottsched aus den Jahren 1738 bis 1746, 57 Briefe an Luise Adelgunde Victorie Gottsched aus den Jahren 1738 bis 1746

Literatur: Ehrenmaal welches Dem weiland erlauchten und hochgebohrnen Reichsgrafen und Herrn ... Ernst Christoph, des Heil. Röm. Reichs Grafen von Manteufel, ... 
aufgerichtet worden. Leipzig: Johann Gabriel Büschel, [1750]; Neuer Büchersaal 7 (1748), S. 43-54; Georg Schmidt: Die Familie v. Manteuffel (Freiherrlich SächsischNiederlausitzer Linie). Berlin 1905; Schultz, Greifswald, S. 115; Bronisch, Manteuffel; DBI.

\section{Marschall, Heinrich Wilhelm}

16. Mai 1702 (Herrengosserstedt) - 16. März 1754 (Crossen)

Beruf, Tätigkeit: Beamter

Biographie: Sohn des Oberforstmeisters Heinrich Christoph Marschall (1672-1737) und der Rahel Sophie, geb. von Fletscher (um 1690-1763, Korrespondentin). 1718 Studium in Leipzig, 1736-1737 in dänischem Auftrag in London, dänischer Hofjunker, Legationssekretär und Oberhofgerichtsassessor in Schleswig.

Ehe, Kinder: Ehe mit einer Frau von Konen (Kayn) aus dem Hause Brödel. 1 Tochter: Sophie Charlotte Irene

Korrespondenz: 2 Briefe an Luise Adelgunde Victorie Gottsched aus den Jahren 1739 und 1750.

Literatur: Etzdorf, Kirchenbuch Crossen 1684-1779, S. 1018; Friedrich Hausmann (Hrsg.): Repertorium der diplomatischen Vertreter aller Länder seit dem Westfälischen Frieden (1648). 2. Band, S. 36; 1: 1648-1715, 1936; 2: 1716-1763; Julius Marschall von Altengottern: Erbmarschalle in Thüringen. Band 1: Genealogie und Geschichte. Rohr im Gebirge: Selbstverlag, 1995, 3. und 5. Stammtafel der Herrengosserstedter Hauptlinie; Band 2: Lebensgeschichte. 2001, S. 107 und 114.

\section{May, Johann Friedrich}

23. März 1697 (Türchau) - 5. Januar 1762 (Leipzig)

Beruf, Tätigkeit: Universitätslehrer, Professor

Biographie: Sohn des Pfarrers Johann Friedrich May (1660-1734) und der Anne Eleonore, geb. Gerber († 1736). 1712, 1714-1717 Besuch des Gymnasiums in Zittau, 1718 Studium in Leipzig, 1722 Magister, Hofmeister adliger Studenten, Erzieher in der Leipziger Kaufmannsfamilie Dufour, Mitarbeiter an der moralischen Wochenschrift Die Vernünftigen Tadlerinnen, Sekretär der Deutschen Gesellschaft, 1738 Senior der Deutschen Gesellschaft, 1741 außerordentlicher Professor der Philosophie, 1742 ordentlicher Professor der Moral und Politik.

Mitgliedschaften: 1723 Mitglied der Deutschen Gesellschaft in Leipzig, 1724 Mitglied des großen Predigerkollegs in Leipzig, Mitglied der Vertrauten Rednergesellschaft in Leipzig, Mitglied der Gesellschaft der Alethophilen in Leipzig

Ehe, Kinder: Unverheiratet

Korrespondenz: 25 Briefe an Gottsched aus den Jahren 1730 bis 1742, darunter zwei, die May als Mitglied bzw. Senior der Deutschen Gesellschaft verfaßt hat, 1 Brief von Gottsched aus dem Jahr 1738, 2 Briefe an Luise Adelgunde Victorie Gottsched aus dem Jahr 1742

Literatur: Panegyrici magisteriales (Leipzig, UB, Univ. 380c), 1722, Bl. C2v; Nomina sociorum, qui collegio concionatorio maiori, atque antiquiori, quod Lipsiae, in templo aca- 
demico hebdomadibus, convenire solet. Leipzig: Bernhard Christoph Breitkopf, 1725, Nr. CCCCLXXXIX; Friedrich Eckarth: Historisches Tage=Buch, Darinnen die vornehmsten Todes=Fälle ... Insonderheit auch in Lausitz, und Zittauischer Gegend des 1734. Jahrs enthaltend. Lauban: Nicolaus Schille, [1734], S. 144 f.; Singularia historicolitteraria Lusatica 3/28 (1744), S. 260 f.; Der mit denen neuesten Stadt= und Land= und Weltgeschichten beschäftigten Annaliste 18 (1762), Erste Hälfte, S. 211; Carl Gottlob Moráwek: Geschichte von Bertsdorf bei Zittau. Zittau 1867, S. 161 f.; Oskar Friedrich: Album des Gymnasiums zu Zittau. Zittau 1886, S. 25; Ekkehard Gühne: Gottscheds Literaturkritik in den „Vernünfftigen Tadlerinnen“ (1725/26). Stuttgart 1978, S. 16f.; Detlef Döring: Beiträge zur Geschichte der Gesellschaft der Alethophilen in Leipzig. In: Detlef Döring, Kurt Nowak (Hrsgg.): Gelehrte Gesellschaften im mitteldeutschen Raum (1650-1820). Teil 1. Stuttgart; Leipzig 2000, S. 95-150; Döring, Deutsche Gesellschaft, S. 144-156 u. ö.; Repertorium Haller, S. 330; Leipzig Matrikel, S. 257; DBI.

\section{Meiern, Johann Gottfried von}

1. Mai 1692 (Bayreuth) - 16. Oktober 1745 (Hannover)

Beruf, Tätigkeit: Archivdirektor, Jurist

Biographie: Sohn des Kammerdirektors Johann Simon von Meiern (1654-1721) und der Anna Barbara, geb. Höflich (1670-1750). Besuch des Gymnasiums in Bayreuth, 1707 Studium der Rechtswissenschaft in Halle, 1709 Studium in Leipzig, anschließend Mitarbeiter des reichsritterschaftlichen Konsulenten Johann Friedrich Schober in Nürnberg, 1715 Doktor der Rechtswissenschaft in Gießen, 1715 Professor der Sittenlehre in Gießen, 1716 außerordentlicher Professor der Rechte in Gießen, 1720 Kammerkonsulent des Markgrafen Georg Wilhelm von Brandenburg-Bayreuth (1678-1726) in Bayreuth, 1727 Hof- und Kanzleirat in Kurhannover, 1729 Direktor des königlichen und kurfürstlichen Archivs in Hannover, 1739 Herausgeber der Göttingischen Zeitungen von gelehrten Sachen, 1740 Geheimer Justizrat.

Mitgliedschaften: 1736 Mitglied der Deutschen Gesellschaft in Leipzig

Ehe, Kinder: 1715 Ehe mit Maria Sibylle Zeller (um 1689-1726), 1 Tochter: Johanna Wilhelmine Felicitas; 1727 Ehe mit Dorothea Amalia, geb. Stisser, verw. Block (1683-1768), die Ehe blieb kinderlos.

Korrespondenz: 2 Briefe an Gottsched aus den Jahren 1736 und 1738

Literatur: Kurd von Schlözer: Die Familie von Meyern in Hannover und am Markgräflichen Hof zu Baireuth. Berlin 1855; Antje Oschmann: Johann Gottfried von Meiern und die „Acta Pacis Westphalicae publica“. In: Heinz Duchhardt (Hrsg.): Der Westfälische Friede. München 1998, S. 779-803; Hans Funke: Schloss-Kirchenbuch Hannover 1680-1812. Band 2. Hannover 1993, Nr. 2748; Leipzig Matrikel, S. 265 („Meyer, Ioh. Gottfried Baruth. Franc."); DBI.

\section{Mencke, Friedrich Otto}

3. August 1708 (Leipzig) - 14. März 1754 (Leipzig)

Beruf, Tätigkeit: Jurist, Politiker, Universitätsprofessor

Biographie: Sohn des Dichters und Historikers Johann Burkhard Mencke (1674-1732) 
und der Katharina Margaretha, geb. Gleditsch (1684-1732). Unterricht durch den Vater und verschiedene Hauslehrer, Besuch der Nikolaischule, 1722 Studium in Leipzig, 1725 Magister, Studium der Rechte, 1733 juristische Doktorwürde in Wittenberg, 1735 kursächsischer Hof- und Justizrat, 1743 Ratsherr in Leipzig, Professor an der Universität Leipzig.

Mitgliedschaften: 1734 Mitglied der Berliner Sozietät der Wissenschaften, Mitglied der Akademie der Wissenschaften in Bologna, 1750 Mitglied der Arcadischen Gesellschaft in Rom, 1752 Mitglied der Societas Latina in Jena

Ehe, Kinder: 1732 Ehe mit Johanna Katharina Langguth († 1779), 5 Töchter: Johanna Friederika (* 1734), Christiane Wilhelmine (* 1735), Katharina Sophia (1737-1738), Christiane Sophia (* 1739), Johanna Dorothea (* 1747), 1 Sohn: Otto Burkhard (17411759)

Korrespondenz: 3 Briefe an Gottsched an Gottsched aus den Jahren 1739, 1751 und 1752

Literatur: Vetter; Memoriae Friderici Ottonis Menkenii. Leipzig: Breitkopf, 1755; Nova Acta Eruditorum 1755, S. 46-48; Johann Gerber: Elogium Friderici Ottonis Menkenii. In: Acta Societatis latinae 4 (1755), S. 279-290; Leben und Schrifften Herrn Friedrich Otto Menckens. In: [Gottlob August Jenichen:] Allerneueste Nachrichten Von Juristischen Büchern 10/79 (1755), S. 634-641; Commentarii Lipsienses litterarii 2 (1755), S. 87-92; Maria Lieber: Lodovico Antonio Muratori und die Gelehrtenfamilie Mencke. In: Transactions of the Ninth International Congress on the Enlightenment. Münster 23-29 July 1995. Oxford 1996, S. 238-242; DBI.

\section{Metschel, Johann Christian}

aus Leipzig

Beruf, Tätigkeit: Student

Biographie: Möglicherweise Sohn des Schneiders Elias Metzschel. 1722 Deposition in Leipzig, 1734 Studium in Wittenberg, 1735 Studium in Halle.

Ehe, Kinder: Unbekannt

Korrespondenz: 1 Brief an Gottsched aus dem Jahr 1738

Literatur: Leipzig Matrikel, S. 264; Wittenberg Matrikel, S. 307; Halle Matrikel 2, S. 152.

\section{Metzler, Daniel Gottlieb}

8. März 1691 (Erdmannsdorf) - 18. August 1744 (Grimma)

Beruf, Tätigkeit: Pfarrer, Superintendent

Biographie: Sohn des Pfarrers Damian Gottfried Metzler (1651-1730) und der Anna Regina, geb. Höpner (1661-1720). 1703 Besuch der Landesschule Schulpforta, Studium in Leipzig, ${ }_{4}^{4} 1713$ Magister, 1718 Pfarrer in Rittersgrün, 1722 Pfarrer in Geringswalde, 1730 Superintendent in Grimma.

${ }^{4} \mathrm{Als}$ Immatrikulationsjahr wird in der gedruckten Matrikel 1703 angegeben; vgl. Leipzig Matrikel 2, S. 288. 
Ehe, Kinder: um 1720 Ehe mit Rosina Elisabeth Heß († 1746), 1 Kind $(* \dagger 1721)$

Korrespondenz: 3 Briefe an Gottsched aus dem Jahr 1739, 1 Brief an Luise Adelgunde Victorie Gottsched aus dem Jahr 1739

Literatur: Leipzig, Sächsisches Staatsarchiv, 22021 Konsistorium Leipzig, Nr. 266; Leipzig, Sächsisches Staatsarchiv Nr. 5474: Testamente des Amtes Leipzig Bd. 11, 17461747, Bl. 92 f. und Bl. 153-164; Vetter; Erdmannsdorf (Sachsen), Evangelisch-Lutherische Trinitatiskirchgemeinde, Taufregister 1691, S. 164 (alt); Sterberegister 1720, S. 105 (alt), Nummer 6; Panegyrici magisteriales (Leipzig, UB, Univ. 380c), 1713, Bl. B 2r; Daniel Gottlieb Metzler: Letzte Geistliche Rede an seine Gemeinde, von dem Aus der wahren Gottseligkeit entspringenden Wohlverhalten derer Reisenden, Nach deren Anleitung Er selbst den 18 August 1744 Seine Himmelsreise, da diese Rede, den 16 August desselbigen Jahres, am XII Sonnt. nach Trinitatis über das ordentl. Evangelium Marc. VII, 31-37. in der Klosterkirche zu Grimma gehalten war, seliglich vollführet hat. Leipzig: Bernhard Christoph Breitkopf, [1744]; Zedler 20 (1739), Sp. 1410; Karl Gottlob Dietmann: Die gesamte der ungeänderten Augsp. Confeßion zugethane Priesterschaft in dem Churfürstenthum Sachsen. Dresden; Leipzig: Sigismund Ehrenfried Richter. Band 1 [1752], S. 143; Band 2 [1754], S. 1085-1087; Christian Gottlob Lorenz: Die Stadt Grimma im Königreiche Sachsen. Leipzig 1856 ff., S. 73 und 1372 f.; Max Hoffmann (Hrsg.): Pförtner Stammbuch 1543-1893 zur 350jährigen Stiftungsfeier der Königlichen Landesschule Pforta. Berlin 1893, Nr. 4825; F. R. Albert: Die Mutzschener Pietisten. In: Mitteilungen des Wurzener Geschichts- und Altertumsvereins 2/1 (1914), S. 79-117, 80-83, 92f., 97f., 101; Grünberg 2, S. 594; Günther Wartenberg: Der Pietismus in Sachsen - ein Literaturbericht. In: Pietismus und Neuzeit 13 (1987), S. 103-114, 108; Detlef Döring: Beiträge zur Geschichte der Gesellschaft der Alethophilen in Leipzig. In: Detlef Döring, Kurt Nowak (Hrsgg.): Gelehrte Gesellschaften im mitteldeutschen Raum (1650-1820). Teil 1. Stuttgart; Leipzig 2000, S. 95-150, 110 f; Jonny Hielscher: Daniel Gottlieb Metzler (1691-1744). Der erste Pfarrer von Rittersgrün. In: Amtsblatt der Gemeinde Breitenbrunn/Erzgebirge 2009, Nr. 4, S. 14; Leipzig Matrikel 2, S. 288; DBI.

\section{Minor, Melchior Gottlieb}

28. Dezember 1693 (Zülzendorf) - 24. September 1748 (Gutschdorf)

Beruf, Tätigkeit: Pfarrer, preußischer Konsistorialrat

Biographie: Sohn des Pfarrers Melchior Minor (1667-1721) und der Juliane Elisabeth, geb. von Netz († 1698). Unterricht durch den Vater und Johann Wilhelm Eckbrecht, 1705 Besuch der lateinischen Schule des Waisenhauses in Halle, 1710 Besuch des Gymnasiums in Zittau, 1712 Studium in Wittenberg, 1713 Studium in Halle, 1713 Studium in Jena, 1714 Rückkehr nach Schlesien, Hofmeister junger Adliger, 1720 Ordination in Liegnitz, 1720 Pfarrer in Tepliwoda, 1722 Diakon, 1727 Wahl zum ersten Pfarrer an der Gnadenkirche in Landeshut, vom Kaiser nicht bestätigt, Ablehnung auswärtiger Pfarrstellenangebote (Görlitz 1734, Hamburg 1739 und 1744, Hannover 1742) auf Bitten und zugunsten der Gemeinde Landeshut, 1741 Pastor primarius in Landeshut; 1742 Inspektor der Kreise Landeshut und Bolkenhain, 1746 Inspektor des Kreises Schweidnitz und des Fürstentums Münsterberg, 1746 Oberkonsistorialrat. 
Ehe, Kinder: 1721 Ehe mit Anna Amalia Behnisch, 5 Töchter und 3 Söhne, von denen 1 Tochter und 2 Söhne früh verstarben, die älteste Tochter Johanna Amalia heiratete 1742, die anderen Kinder waren beim Tod des Vaters unverheiratet, Sohn: Carl Gottlieb.

Korrespondenz: 7 Briefe an Gottsched aus den Jahren 1737 bis 1748, 1 Brief an Luise Adelgunde Victorie Gottsched aus dem Jahr 1748

Literatur: Gelehrte Neuigkeiten Schlesiens 1741 und 1742, S. 100-102; Ernst Ludwig Rathlef: Geschichte Jeztlebender Gelehrten. 1. Teil. Celle: Joachim Andreas Deetz, 1740, S. 195-209; Johann Friedrich Burg: Das offene Auge JESU, ... Bey dem Thränenvollen Leichbegängnüsse Des ... Herrn Melchior Gottlieb Minor ... Als Derselbe am 24. September im Jahr 1748. auf der Reise nach Breßlau zu Gotschdorff bey Striegau ... von dieser Welt selig abgefordert worden. Breslau: Carl Wilhelm Graß, [1748]; Beiträge zu den Acta Historico-Ecclesiastica. Band 2. Weimar: Siegmund Heinrich Hoffmann, 1750, S. 41-64; Nova Acta Historico-Ecclesiastica 2/11 (1760), S. 318 f.; Ehrhardt, Presbyterologie 1, S. 536 f.; 2, S. 357 f.; Benjamin Gottlieb Steige: Bolkenhainsche Denkwürdigkeiten aus Handschriften, Urkunden und Büchern. Hirschberg: Krahn, 1795, S. 278 f.; Oskar Friedrich (Bearb.): Album des Gymnasiums zu Zittau. Zittau 1886, S. 26; Martin Schian: Melchior Gottlieb Minor, insbesondere als Prediger. In: Correspondenzblatt des Vereins für Geschichte der evangelischen Kirche Schlesien 13 (1913), Heft 2, S. 337-354; Halle Matrikel 1, S. 296; Jena Matrikel 2, S. 526; Wittenberg Matrikel, S. 309; DBI.

\section{Möhring, Paul Heinrich Gerhard}

21. Juli 1710 (Jever) - 28. Oktober 1792 (Jever)

Beruf, Tätigkeit: Arzt

Biographie: Sohn des Rektors und späteren Pfarrers Gottfried Victor Möhring (1681-1750) und der Sophia Katharina, geb. Töpken. Schulbesuch in Jever, 1729 Besuch des Gymnasium academicum in Danzig, 1732 Studium in Wittenberg, 1733 Doktor der Medizin in Wittenberg, 1733 praktischer Arzt in Jever, 1739 Leibarzt des Statthalters von Jever, Prinz Johann Ludwig von Anhalt-Zerbst-Dornburg (1688-1746), 1742 Stadt- und Landphysikus in Jever, Militärarzt, 1743 Leibarzt Johann Ludwigs von Anhalt-Zerbst und seines Bruders Christian August, Fürstlicher Rat, Aufsicht über Bibliothek in Jever, vor 1757 Leibarzt der Grafen von Bentinck, 1763 Hofrat, Mitarbeiter an der 1731-1745 erscheinenden medizinischen Fachzeitschrift Commercium litterarium ad rei medicae et scientiae naturalis incrementum institutum.

Mitgliedschaften: 1736 Mitglied der Leopoldina, 1790 Mitglied der Akademie der Wissenschaften in St. Petersburg

Ehe, Kinder: 1743 Ehe mit Juliana Damm, 4 Kinder, darunter Heinrich Gerhard (1751-1810) und Nicolaus Laurenz († nach 1811)

Korrespondenz: 1 Brief an Gottsched aus dem Jahr 1739

Literatur: Johannes Ramsauer: Die Prediger des Herzogtums Oldenburg seit der Reformation. Oldenburg 1909, S. 136 und 267; Jan van Dieken: Ostfriesische Pflanzenforscher 1: Paul Heinrich Gerhard Moehring. In: Ostfriesland. Zeitschrift für Kultur, Wirtschaft und Verkehr 1970, Heft 3, S. 17; Bernhard Schönbohm: Bekannte und berühmte 
Jeverländer ... Jever 1981, S. 17-19; Biographisches Handbuch zur Geschichte des Landes Oldenburg. Oldenburg 1992, S. 469 f.; Friedrich-Wilhelm Schaer: Verwaltungsund Beamtengeschichte der Herrschaften Jever, Varel und Kniphausen. Mit alphabetischem Beamtenverzeichnis 16. Jahrhundert - 1807. Oldenburg 2001, S. 178; Repertorium Haller, S. 349 f.; Enno Schönbohm: P. H. G. Möhring - Ein jeverscher Arzt und Naturforscher im 18. Jahrhundert. In: Ferne Fürsten. Das Jeverland in Anhalt-Zerbster Zeit. Band 2. Oldenburg, 2004, S. 253; Tilman Tassilo Rupert Rau: Das Commercium litterarium. Die erste medizinische Wochenschrift in Deutschland und die Anfänge des medizinischen Journalismus. Bremen 2009, S. 80; DBI.

\section{Mosheim, Johann Lorenz}

\section{Oktober 1693 (Lübeck) - 9. September 1755 (Göttingen)}

Beruf, Tätigkeit: Theologe, Universitätsprofessor, Abt

Biographie: Sohn des Offiziers Ferdinand Sigismund von Mosheim und der Magdalena Catharina, geb. Prißen (†1732). 1707 Eintritt in das Katharineum in Lübeck, danach Hauslehrer, 1716 Studium der Theologie in Kiel, 1718 Magister, 1719 Assessor in der Philosophischen Fakultät, 1723 Professor der Theologie in Helmstedt, 1726 Abt des lutherischen Klosters Marienthal, 1727 des Klosters Michaelstein, 1729 Generalschulinspektor des Herzogtums Wolfenbüttel, 1732 Präsident der Leipziger Deutschen Gesellschaft, 1747 Professor der Theologie und Kanzler der Universität Göttingen.

Mitgliedschaften: Mitglied der Deutschen Gesellschaft in Leipzig, Mitglied der Teutschen Gesellschaft in Jena, Mitglied der Deutschen Gesellschaft in Göttingen

Ehe, Kinder: 1723 Ehe mit Elisabeth Margareta zum Felde (1705-1732), 2 Töchter: Sophia Ludovica (* 1725, früh verstorben), Dorothea Auguste Margarete (1727-1766), 3 Söhne: Gottlieb Christian (1728-1788), Georg Christoph (1729-1730), August Adolf (1732-1770); 1733 Ehe mit Elisabeth Dorothee von Haselhorst (1699-1740), die Ehe blieb kinderlos; 1742 Ehe mit Elisabeth Henrica Amalia von Voigts, 1 Tochter: Wilhelmina Johanna Justina $(\dagger 1823)$.

Korrespondenz: 51 Briefe an Gottsched aus den Jahren 1728 bis 1746, 1 Brief an Luise Adelgunde Victorie Gottsched aus dem Jahr 1742

Literatur: Ad parentialia nobilissimae feminae Elisabetae Margaretae natae Feldeniae viri venerabilis Ioannis Laurentii Moshemii ... coniugi desideratissimae in templo academico die XXVIII Septembris a. MDCCXXXII [...] invitant Academiae Iuliae prorector et senatus. Helmstedt: Paul Dietrich Schnorr, [1732]; Brucker, Bilder=sal 1 (1741); Müller, Nachricht, S. 100; Karl Heussi: Zur Lebensgeschichte Johann Lorenz von Mosheims. In: Gerhard Müller (Hrsg.): Zeitschrift der Gesellschaft für niedersächsische Kirchengeschichte 10 (1905), S. 96-123; Karl Heussi: Johann Lorenz Mosheim. Ein Beitrag zur Kirchengeschichte des achtzehnten Jahrhunderts. Tübingen 1906; Suchier, Göttingen, S. 67, Nr. 73; Angelika Alwast, Jendris Alwast: Mosheim, Johann Lorenz. In: Biographisches Lexikon für Schleswig-Holstein und Lübeck. Band 10. Neumünster 1994, S. 258-263; Theologische Realenzyklopädie 23 (1994), S. 365-367; Martin Mulsow (Hrsg.): Johann Lorenz Mosheim (1693-1755): Theologe im Spannungsfeld von Philosophie, Philologie und Geschichte. Wiesbaden 1997; DBI. 


\section{Neuber, Johann}

22. Januar 1697 (Reinsdorf bei Zwickau) - Februar 1759 (Dresden)

Beruf, Tätigkeit: Schauspieler, Theaterprinzipal

Biographie: Sohn des Bauern Johann Neuber. Besuch der Lateinschule in Zwickau, 1712 Studium in Leipzig, 1717 Verbindung mit der Schauspielerin Friederike Caroline Weißenborn, seiner späteren Ehefrau (Korrespondentin). Im selben Jahr schließt sich das Paar in Weißenfels der Spiegelbergschen Truppe an. Ein Wechsel zur Haackeschen Schauspieltruppe erfolgte vermutlich bereits 1718, ist indes erst für Ende Januar 1722 aus den Quellen belegbar. 1725 Übernahme der Haack(-Hoffmann)schen Truppe, 1727 Erwerb des Privilegs als königlich-polnische und kurfürstlich-sächsische deutsche Hofkomödianten und erste Kontakte zu Gottsched, 1732 hochfürstlich braunschweigischlüneburgisches, 1736 schleswig-holsteinisches Privileg. März 1740 Aufbruch nach Rußland an den Hof der Zarin Anna Iwanowna († Oktober 1740), Ostern 1741 Rückkehr nach Deutschland und Bruch mit Gottsched, 1743 Auflösung der Truppe und 1744 Gründung einer neuen Schauspielergesellschaft, bis 1750 alljährliche Auftritte in Leipzig, außerdem in Dresden, Warschau und Frankfurt am Main. Herbst 1750 erneute Auflösung der Truppe und Aufgabe der Prinzipalschaft, 1755 bis zum Beginn des Siebenjährigen Krieges Auftritte mit einer neu gegründeten Truppe in Dresden, seit 1756 freie Wohnung im Hause des königlichen Leibarztes Löber. Die Publikationen von RedenEsbeck und Rudin/Schulz bieten vorzügliche Übersichten über die zahlreichen Aufenthaltsorte und Spielzeiten der Neuberschen Truppe.

Ehe, Kinder: 1718 Ehe mit Friederike Caroline Weißenborn (1697-1760), die Ehe blieb kinderlos.

Korrespondenz: 14 Briefe an Gottsched aus den Jahren 1730 bis 1736, 1 Brief an Luise Adelgunde Victorie Gottsched aus dem Jahr 1739

Literatur: Reden-Esbeck; Schüddekopf; Bärbel Rudin: Venedig im Norden oder: Harlekin und die Buffonisten. „Die Hochfürstl. Braunschw. Lüneb. Wolffenbüttelschen Teutschen Hof-Acteurs" (1727-1732). Reichenbach im Vogtland 2000; Rudin/Schulz; Bärbel Rudin in Verbindung mit Horst Flechsig und Lars Rebehn (Hrsgg.): Lebenselixier. Theater, Budenzauber, Freilichtspektakel im Alten Reich. Band 1. Reichenbach im Vogtland 2004; Leipzig Matrikel, S. 282; DBI.

\section{Pfaff, Christoph Matthäus}

25. Dezember 1686 (Stuttgart) - 19. November 1760 (Gießen)

Beruf, Tätigkeit: Universitätsprofessor, Theologe

Biographie: Sohn des evangelischen Predigers an der St. Leonhardskirche in Stuttgart und nachmaligen Professors der Philosophie und der Theologie in Tübingen Johann Christoph Pfaff (1651-1720) und der Anna Maria, geb. Alber (1668-1733). Besuch des Eberhardsgymnasiums in Stuttgart, 1697 anatolische Schule in Tübingen, 1699 Immatrikulation in Tübingen, 1700 Aufnahme ins Tübinger Stift, 1702 Magister, 1704 theologisches Examen, Vikar in Lustnau, 1705 Stiftsrepetent in Tübingen, 1706 Antritt einer dreijährigen Studienreise mit Aufenthalten in Dänemark, Holland und England (Oxford und Cambridge), 1709 Begleiter und Reiseprediger des Erbprinzen Friedrich 
Ludwig (1698-1731) mit dreijährigem Aufenthalt in Turin am Hofe des Herzogs von Savoyen Victor Amadeus II. (1726-1796), 1713 Reise nach Holland und Frankreich, 1714 Ernennung zum Professor der Theologie in Tübingen, 1717 Antritt dieser Professur, Doktor der Theologie, 1720 Rektor, Probst an der Tübinger Stiftskirche und Kanzler der Universität, 1724 kaiserlicher Hofpfalzgraf (Comes Palatinus), 1727 Abt des Klosters Lorch und Mitglied des Württembergischen Landtags, 1756 Professor der Theologie und Kanzler der Universität Gießen, hessen-darmstädtischer Generalsuperintendent.

Mitgliedschaften: 1731 Mitglied der Berliner Sozietät der Wissenschaften

Ehe, Kinder: 1723 Ehe mit Maria Susanna von Rauner (1700-1753); die Ehe blieb kinderlos.

Korrespondenz: 13 Briefe an Gottsched aus den Jahren 1737 bis 1756

Literatur: Christian Polycarp Leporin: Verbesserte Nachricht/ Von Des Hochberühmten Tübingischen Cantzlers und Professoris Theologiæ Primarii ... D. Christoph Matthäi Pfaffens/ Leben/ Controversien und Schrifften/ Nebst einem Catalogo Derer Neuesten Unions-Schrifften/ An das Licht gestellet. Leipzig; Aschersleben: Gottlob Ernst Struntz: 1726; Brucker, Bilder=sal 1 (1741); Eugène Guillaume Théodore de Budé: Lettres inédites adressées de 1686 à 1737 à J.-A. Turrettini, théologien genevois. Band 1. Paris 1887, S. 159-162; Günther Thomann: Christoph Matthäus Pfaff (1686-1760) und die Anfänge der dogmengeschichtlichen Disziplin. In: Blätter für Württembergische Kirchengeschichte 85 (1985), S. 83-133, 92-96; Wolf Friedrich Schäufele: Christoph Matthäus Pfaff und die Unionsbestrebungen des Corpus Evangelicorum 1717-1726. Mainz 1998; Matthias J. Fritsch: Religiöse Toleranz im Zeitalter der Aufklärung. Naturrechtliche Begründung - konfessionelle Differenzen. Hamburg 2004, S. 213-215; DBI.

\section{Poley, Heinrich Engelhard}

15. November 1686 (Emseloh bei Sangerhausen) - 15. November 1762 (Weißenfels)

Beruf, Tätigkeit: Gymnasialprofessor, Bibliothekar

Biographie: Sohn des evangelischen Predigers Jakob Poley († 1725) und der Katharina Dorothea, geb. Okel († 1709) aus Quedlinburg. Schulbesuch in Naumburg und Quedlinburg, 1708 Studium (vermutlich der Philosophie und Theologie) in Jena, 1712 Fortsetzung des Studiums in Leipzig, 1713 Magister der Philosophie in Wittenberg. Die frühen Stationen seiner beruflichen Laufbahn sind nicht bekannt. 1727 Professor der Logik, Metaphysik und Mathematik am Gymnasium illustre Augusteum in Weißenfels, später auch Vorsteher der fürstlichen Bibliothek.

Mitgliedschaften: 1733 Mitglied der Deutschen Gesellschaft in Leipzig. Ernst Christoph Graf von Manteuffel (Korrespondent) führt Poley in einem Brief vom 10. Februar 1741 als „Candidat" der Gesellschaft der Alethophilen in Weißenfels (nicht bei Holderrieder). Ehe, Kinder: Vermutlich 1728 Ehe mit Rosine Werner (†1742) aus Pegau, die Ehe blieb kinderlos.

Korrespondenz: 37 Briefe an Gottsched aus den Jahren 1732 bis 1757

Literatur: Johann Lorenz Holderrieder: Historische Nachricht von der Weißenfelsischen Alethophilischen Gesellschaft. Leipzig: Johann Friedrich Lankisch Erben, 1750; Des sel. 
Hrn. Professor Poleys zu Weißenfels, Leben. In: Anmuthige Gelehrsamkeit 9 (1762), S. 693-701; Kroker, Nr. 270; Alfred Junge: J. Chr. Gottsched und seine Weißenfelser Freunde. In: Bilder aus der Weißenfelser Vergangenheit. Festgabe zur Feier des fünfzigjährigen Bestehens des Weißenfelser Vereins für Natur- und Altertumskunde (18741924). Weißenfels 1925, S. 61-98; Stefan Lorenz: Wolffianismus und Residenz. Beiträge zur Geschichte der Gesellschaft der Alethophilen in Weißenfels. In: Detlef Döring, Kurt Nowak (Hrsgg.): Gelehrte Gesellschaften im mitteldeutschen Raum (1650-1820). Teil III. Leipzig 2002, S. 113-144; Klein 1, S. 184-189; 2, S. 193-200, 471-477 (der Kupferstich auf S. 194 oben links stellt allerdings nicht Poley, sondern John Locke dar); Pfarrerbuch Sachsen 6, S. 537 f.; Jena Matrikel 2, S. 599; Leipzig Matrikel, S. 307; Wittenberg Matrikel, S. 355; DBI.

\section{Pyra, Immanuel ${ }^{5}$ Jacob $^{2}$}

\section{Juli 1715 (Cottbus) - 14. Juli 1744 (Berlin)}

Beruf, Tätigkeit: Konrektor, Lyriker, Dichtungstheoretiker, Übersetzer Biographie: Sohn des Amtsadvokaten ${ }^{6}$ und Schreibers Immanuel Pyra und der Eva Maria, geb. Röting. 1730 Gymnasium in Bautzen, 1734 Studium der Theologie in Halle, 1736 Informator im Waisenhaus der Franckeschen Anstalten, Hofmeister in Poplitz und Heiligenthal, 1737 Übersiedlung nach Laublingen in das Pfarrhaus seine Freundes Samuel Gotthold Lange (1711-1781), 1742 Konrektor am Köllnischen Gymnasium in Berlin.

Mitgliedschaften: 1734 Mitbegründer des Ersten Halleschen Dichterkreises (Gesellschaft zur Beförderung der deutschen Sprache, Poesie und Beredsamkeit)

Ehe, Kinder: Unverheiratet

Korrespondenz: 2 Briefe an Gottsched aus den Jahren 1737 und 1738

Literatur: Cottbus, Traubuch der Oberkirche St. Nikolai 1730, S. 132; Taufregister der Oberkirche St. Nikolai, 1715, S. 478; Gustav Waniek: Immanuel Pyra und sein Einfluß auf die deutsche Litteratur des achtzehnten Jahrhunderts. Leipzig 1882; Killy 9 (1991), S. 249 f.; DBI.

\section{Reinbeck, Johann Gustav}

25. Januar 1683 (Celle) - 21. August 1742 (Schönwalde bei Berlin)

Beruf, Tätigkeit: Theologe, Propst, Konsistorialrat

Biographie: Sohn des nachmaligen Propstes und Superintendenten von Lüchow im Fürstentum Lüneburg Andreas Reinbeck (1641-1705) und der Sophie (Sophia), geb. Hen(c)ke (1641-1728). Häuslicher Unterricht durch Privatlehrer und durch den Vater.

\footnotetext{
${ }^{5}$ Im Traubuch der Oberkirche St. Nikolai zu Cottbus wird Pyras Vater mit dem Vornamen Immanuel geführt. Im Taufregister werden sowohl Vater als auch Sohn Pyra mit dem Vornamen Emanuel geführt. Pyras zweiter Vorname wird dort Jacob geschrieben.

${ }^{6}$ Traubuch der Oberkirche St. Nikolai: „amtger. Advocat"
} 
1701 Studium der Theologie und Philosophie in Halle, 1709 Predigtadjunkt an der Friedrichswerderischen und Dorotheenstädtischen Kirche in Berlin, 1713 Zweiter, 1714 Erster ordentlicher Prediger, 1716 Ernennung zum Propst an der Peterskirche in Cölln an der Spree, 1717 Amtsantritt, 1728 Konsistorialrat, 1736 Doktor der Theologie in Königsberg (in absentia).

Mitgliedschaften: Mitglied der Gesellschaft der Alethophilen (Societas alethophilorum) in Berlin

Ehe, Kinder: 1710 Ehe mit Nympha Margaretha Scott (1683-1762), 4 Töchter: Johanna Sophia Rosina (*1711), Wilhelmina Eleonora (*1718), Eleonora Sophia $\left({ }^{*} 1724\right)$, Gertrud Helene (* 1725), 7 Söhne: Andreas Robert (*1713), Alexander Carl (* 1714), Johann Gustav (1716-1782), Joachim Christian (* 1720), George Friedrich (* 1722), Otto Sieg(is)mund (1727-1805), Friedrich Ludwig (*1728)

Korrespondenz: 2 Briefe von Gottsched aus den Jahren 1737 und 1741, 2 Briefe an Gottsched aus den Jahren 1737 und 1738

Literatur: Acta historico-ecclesiastica 6/31 (1744), S. 85-133; Anton Friedrich Büsching: Beÿträge zu der Lebensgeschichte denkwürdiger Personen, insonderheit gelehrter Männer. Erster Theil. Halle: Johann Jacob Curts Witwe, 1783, S. 139-236; Georg von Reinbeck: Leben und Wirken des Dr. Th. Johann Gustav Reinbeck ... Nach Urkunden und Familien=Nachrichten hundert Jahre nach seinem Tode mitgetheilt. Ein Beitrag zur Lebens= und Charakter=Geschichte der Könige Friedrich Wilhelm I und Friedrich II. von Preußen. Stuttgart 1842, S. 65, 73, 104 f.; Johannes Geffcken: Die Berufung Johann Gustav Reinbeck's nach Hamburg im Jahre 1735. In: Zeitschrift des Vereines für hamburgische Geschichte 2 (1847), S. 518-532; Otto Fischer (Bearb.): Evangelisches Pfarrerbuch für die Mark Brandenburg seit der Reformation. Zweiter Teil. Berlin 1941, S. 680; Halle Matrikel 1, S. 351; DBI.

\section{Richey, Michael}

1. Oktober 1678 (Hamburg) - 10. Mai 1761 (Hamburg)

Beruf, Tätigkeit: Gymnasialprofessor, Historiker, Dichter

Biographie: Sohn des Kaufmanns Johann Richey und der Esther, geb. Engels. Häuslicher Unterricht durch Melchior Heinrich Francke, 1690 Johanneum, 1696 Studium am Akademischen Gymnasium, 1699 Studium der Theologie, Naturlehre, Geschichte und schönen Wissenschaften in Wittenberg, Magister, 1701 Rückkehr nach Hamburg, 1704 Rektor am Gymnasium in Stade, 1712 Flucht vor den dänischen Truppen nach Hamburg, 1713 Niederlegung des Rektorats, 1717 Professor für Geschichte und griechische Sprache am Akademischen Gymnasium.

Mitgliedschaften: 1715 Mitglied der Teutsch-übenden Gesellschaft in Hamburg, 1724 Mitglied der Patriotischen Gesellschaft in Hamburg

Ehe, Kinder: 1704 Ehe mit Anna Catharina Schulte ( $† 1712), 3$ Töchter: Esther Elisabeth (1708-1743), Catharina Maria (1711-1757), Hanna Elisabeth (1712-1719), 2 Söhne: Johann (1706-1738), Michael (†1712)

Korrespondenz: 6 Briefe an Gottsched aus den Jahren 1735 bis 1754

Literatur: Perels/Rathje/Stenzel, S. 143-157; Killy 9 (1991), S. 428-430; DBI. 


\section{Rohr, Julius Bernhard von}

28. März st. v. 1688 (Elsterwerda bei Dresden) - 18. April 1742 (Leipzig)

Beruf, Tätigkeit: Jurist, Verwaltungsbeamter, Kameralist

Biographie: Sohn des Kammerherrn, Hofrates und Prinzenerziehers Julius Albrecht von Rohr (1647-1712) und der Christina Elisabeth, geb. von Rohr (1662-1738). Oktober 1688 Expektant des Merseburger Domstifts, 1705 Studium der Rechte in Leipzig, 1711 kursächsischer Kammerjunker, 1712 Magisterexamen in Leipzig, Studium der Mathematik bei Christian Wolff (Korrespondent) in Halle, 1713 Reise nach Holland, 1714 Beisitzer der Merseburgischen Stifts- und Landesregierung, ${ }^{7} 1726$ Regierungsrat in der Niederlausitz, Oktober 1727 Domherr in Merseburg, 1731 sächsisch-merseburgischer Landkammerrat, ${ }^{8} 1741$ Ältester (aedilis) des Merseburger Domkapitels.

Ehe, Kinder: 1724 schloß Rohr die Ehe mit einer Frau (†1737), deren Identität nicht ermittelt werden konnte. ${ }^{9} 1739$ Ehe mit Anna Rebecka Köhler, 1 Sohn: Julius Philipp Benjamin (um 1735-1811).10

Korrespondenz: 1 Brief an Gottsched aus dem Jahr 1738

Literatur: Merseburg, Domstiftsbibliothek, Cod. I, 161, Bl. 177r, 218r; Cod. I, 161 (Series episcoporum, praelatorum et canonicorum ecclesiae cathedralis Merseburgensis; Ludovici, Wolff 3, S. 211-224;11 Zedler 32 (1742), Sp. 560-569; Gustav Heyse: Streifzüge durch die Literatur des Harzes. In: Heyse: Beiträge zur Kenntniss des Harzes, seiner Geschichte und Literatur. Aschersleben 1857, S. 1-48, 16; Gerhard Schulz: Neue Forschungen zu den märkischen v. Rohr. I. Stamm Schrepkow ab 1500. In: Genealogie, Jg. 24 (1975), Band 12, Heft 3 (März); S. 449-571, 570 f.; Killy 9 (1991), S. 506 f.; Leipzig Matrikel 2, S. 364; DBI.

\section{Rolief(f), auch Roliff, Johann Wilhelm}

um 1680 (vermutlich in Halberstadt) - nach 1756 (vermutlich in Halberstadt)

Beruf, Tätigkeit: Lehrer an der Martinischule in Halberstadt

Biographie: Unbekannt. In der Leipziger Matrikel werden unter den Namen Roliff bzw. Rohliff zwei Studierende aufgelistet: Tobias (aus Halberstadt, immatrikuliert 1638) und

7 Killy, S. 506: 1713.

8 Killy, S. 506: 1732

9 „Er hat in gedoppelter ungleichen Ehe gelebt, davon die erste unglücklich gewesen. Aus der zweyten hat er einen Sohn hinterlassen." Genealogisch=Historische Nachrichten von den Allerneuesten Begebenheiten, welche sich an den Europäischen Höfen zutragen. Der XXXVII. Theil. Leipzig: Johann Samuel Heinsius, 1742, S. 517-519, 518. Rohrs erste Ehefrau soll an einer psychischen Erkrankung gelitten haben.

${ }^{10}$ Die Lebensdaten des Sohnes nach Schulz, der bezweifelt, daß Julius Benjamin Rohr ein Sohn aus der zweiten Ehe sei.

${ }^{11}$ Auf Ludovici basieren die abweichenden Daten in Killy (Monika Schlechte). 
Tobias (aus Wernigerode, immatrikuliert 1671). Es könnte sich um Roliefs Großvater und Vater handeln. 1736 Doktorexamen in Göttingen. ${ }^{12}$

Ehe, Kinder: Unbekannt

Korrespondenz: 2 Briefe an Gottsched aus den Jahren 1737 und 1738

Literatur: Adres-Calender, Der sämtlichen Königl. Preußis. Lande und Provintzien (Ausser den Residentzien Berlin) 1756, S. 181;13 Leipzig Matrikel 2, S. 365; DBI.

\section{Rosenberg, Johann Albrecht II. von}

\section{November 1675 (Danzig) - 7. Oktober 1749 (Danzig)}

Beruf, Tätigkeit: Syndikus, Ratsherr, Richter, Sammler von Handschriften und Büchern zur Geschichte Danzigs und Königlich-Preußens.

Biographie: Sohn des Kaufmanns und Schöppen Georg von Rosenberg (1643-1684) und der Adelgunde, geb. Schumann (1646-1684). Besuch des städtischen Gymnasiums, 1693 Studium in Franeker, 1700 Stadtsekretär in Danzig, 1707 Subsyndikus, 1709 Syndikus, 1718 Ratsherr, 1721 Richter. Seine reiche Bibliothek gelangte über seinen Sohn in die Danziger Stadtbibliothek.

Ehe, Kinder: 1706 Ehe mit Baronesse Anna Brown (1686-1754), 2 Töchter: Anna Renate (1707-1757), Eleonore Elisabeth (* 1717), 4 Söhne: Carl Albrecht (* 1709), Georg Ernst (1710-1757), Heinrich Wilhelm (1711-1794), Reinhold Gottlieb (* 1719)

Korrespondenz: 3 Briefe an Gottsched aus den Jahren 1729 bis 1738

Literatur: [A. Bertling:] Katalog der die Stadt Danzig betreffenden Handschriften der Danziger Stadtbibliothek. Danzig 1892, S. 614 f.; Arthur Methner: Die Danziger Stadtschreiber. In: Danziger familiengeschichtliche Beiträge 2 (1934), S. 31-38, 35; Helmut Strehlau: Aus der Genealogie des Danziger Ratsgeschlechts Rosenberg. In: Ostdeutsche Familienkunde 10 (1962), S. 2-6; Weichbrodt 1, S. 397 (Stammtafel Rosenberg); Zdrenka, S. 267.

\section{Scharff, Gottfried Balthasar}

19. März 1676 (Liegnitz) - 9. August 1744 (Schweidnitz)

Beruf, Tätigkeit: Pfarrer, Dichter, Historiker

Biographie: Sohn des Anwalts und Beisitzers des Schöppenstuhls Johann Friedrich Scharff und der Anna Katharina, geb. Schultheiß. Besuch der Stadtschule Liegnitz und des Gymnasiums St. Elisabeth in Breslau, 1695 Studium der Theologie und Philosophie in Leipzig und Wittenberg, 1699 Magister, Hofmeister in Liegnitz im Haus des Super-

\footnotetext{
12 Johann Wilhelm Rolief: Fasciculus duarum dissertationum exegeticarum; vgl. unsere Ausgabe, Band 4, Nr. 181, Erl. 5. Die Arbeit ist Georg II. von England (1683-1760) gewidmet. Auf dem Titelblatt einer späteren Arbeit Juste praesumtum systema combinatum aus dem Jahr 1745 erscheint Rolief als Doktor („D.“) und Mitglied der Lateinischen Gesellschaft in Halle.

13 „Halberstadt ... Schul=Bediente ... Bey der Schule St. Martini ... Hr. Magister Joh. Wilhelm Roliff, Septimus Collega."
} 
intendenten David Schindler (1642-1711), 1700 Pastor in Gölschau, 1708 Diakon an der evangelischen Freiheitskirche in Schweidnitz, 1712 Archidiakon, 1714 Senior des geistlichen Ministeriums, 1717 Reise nach Dresden, Wittenberg, Leipzig und Halle, 1735 Herausgeber der Gelehrten Neuigkeiten Schlesiens, 1737 Nachfolger von Benjamin Schmolck als Pastor primarius, 1742 Kirchen- und Schulinspektor des Fürstentums Münsterberg, des Schweidnitzer Kreises sowie der Grafschaft Glatz.

Ehe, Kinder: 1706 Ehe mit Rahel Dorothea Herzog (†1741) aus Zittau, 1 Tochter: Rahel Eleonora, 2 Söhne, die vor den Eltern starben.

Korrespondenz: 13 Briefe an Gottsched aus den Jahren 1732 bis 1740

Literatur: Lebens=Lauff Des Wohlseeligen Herrn Inspectoris. In: Theodosius Gottfried Fuchs: Parentations-Rede: Als der Weyland Hoch=Ehrwürdige, Hochachtbare und Hochgelehrte HERR Gottfr. Balthasar Scharff ... Nach einer harten Niederlage Anno 1744. den 9. Augusti mit 68. Jahren, 5 Monat weniger 10. Tage, Seines rühmlich geführten Lebens, im HErrn JESU entschlaffen, Und den 12. Ejusd. ... zu Seiner Ruhe gebracht wurde. Schweidnitz: Johann Christian Müller, S. 35-40; Gottlob Kluge: Hymnopoeographia Silesiaca. Decas 1. Breslau: Johann Jacob Korn, 1751, S. 117-13414; Ehrhardt, Presbyterologie 4/2, S. 578-582; Theodor Wotschke: Scharffs Briefe an Cyprian. In: Correspondenzblatt des Vereins für Geschichte der evangelischen Kirche Schlesiens. Band 18 (1925), Heft 1, S. 1-72; Kirchner, Nr. 101; Krzysztof Migoń: Polonica in den „Gelehrten Neuigkeiten Schlesiens“ (1734-1741) und in der Büchersammlung G. B. Scharffs. In: Deutsche Polenliteratur. Breslau 1991. Acta Unversitatis Wratislaviensis Nr. 1297, Germanica Wratislaviensia XCII, S. 82-91; Sandra Kersten: Die Freundschaftsgedichte und Briefe Johann Christian Günthers. Berlin 2006, S. 27 f; DBI.

\section{Scheibe, Johann Adolph}

Taufe 5. Mai 1708 (Leipzig) - 22. April 1776 (Kopenhagen)

Beruf, Tätigkeit: Musikschriftsteller, Komponist, Kapellmeister

Biographie: Sohn des Orgelbauers Johann Scheibe (um 1680-1748) und der Anna Rosina, geb. Hesse. 1717 erster Klavier- und Orgelunterricht, 1719 Nikolaischule in Leipzig, 1725 Studium der Rechtswissenschaft in Leipzig, autodidaktische Intensivierung der musikalischen Ausbildung einschließlich Komposition und Musiktheorie, Abbruch des Studiums der Rechtswissenschaft aus finanziellen Gründen, 1730 Lehrer für Klavier und Komposition in Leipzig, 1735 vergebliche Bewerbungen als Kapellmeister in Prag und Gotha, 1736 in Sondershausen, Wolfenbüttel und Hamburg, 1737 Gründung der Wochenschrift Der Critische Musicus, 1739 Kapellmeister im Dienste des Markgrafen Friedrich Ernst von Brandenburg-Kulmbach-Bayreuth, 1740 königlich-dänischer Kapellmeister und Hofkomponist, 1748 Ablösung durch den italienischen Kapellmeister Scalabrini, 1749 Umsiedlung nach Sønderburg auf der Insel Alsen und Gründung einer

${ }^{14}$ Kluges Aufzeichnungen, die wiederum über weite Passagen wörtlich mit Fuchs' Parentation übereinstimmen, basieren auf einer handschriftlichen Autobiographie Scharffs. 
Musikschule, Auftragsarbeiten als Hofkomponist bis 1769, das genaue Datum der Rückkehr nach Kopenhagen ist unbekannt.

Mitgliedschaften: Mitglied der Freimaurerloge Zoroabel

Ehe, Kinder: 1741 Ehe mit Ilsabe Müller (* 1720)

Korrespondenz: 13 Briefe an Gottsched aus den Jahren 1739 bis 1745

Literatur: Hamburg, Staatsarchiv, Hochzeitenbuch der Hamburger Wedde, Bestand 332-1 I Wedde I Nr. 29, Bd. 13, S. 102; Leipzig Matrikel, S. 350; DBI.

\section{Schindel, Johann Christian}

5. November 1677 (Rauten) - 27. September 1750 (Brieg)

Beruf, Tätigkeit: Gymnasialprofessor, Prorektor, Kantor, Komponist

Biographie: Sohn des Kantors der Evangelischen Schule Christian Schindel († 1692) und der Martha Elisabeth, geb. Reichel aus Wohlau. Bis 1692 häuslicher Unterricht durch den Vater, weitere Erziehung durch den Rautener Rektor Christian Bleyel und den Senioratsadministrator Gottlieb Rosenberg (1665-1734), 1693 Gymnasium in Brieg, 1698 Studium der Theologie und Philosophie in Leipzig, 1701 Hauslehrer der Familien Lange und Klepperbein in Großglogau, 1702 Kantor in Crossen, 1703 Konrektor, 1704 Rektor in Fraustadt, 1708 Prorektor und Professor der schönen Wissenschaften, klassischen Sprachen, Philosophie, Theologie und Geschichte der Gelehrsamkeit am Gymnasium in Brieg.

Ehe, Kinder: 1711 Ehe mit Theodora Rosina Seidel, 3 Töchter, 2 Söhne: Christian Ernst, Johann Gottlieb (1718-1738); 1739 Ehe mit Johanna Theodora, verw. Krause, die Ehe blieb kinderlos.

Korrespondenz: 31 Briefe an Gottsched aus den Jahren 1732 bis 1742

Literatur: Leben und Tod Herrn Johann Christian Schindels, des Königlichen Gymnasii in Brieg gewesnen Prorectoris und Profeßoris. In: Der Schlesische Büchersaal, in welchem von allerhand Schlesischen Büchern und andern Gelehrten Sachen Nachricht ertheilt wird. Schweidnitz: Joseph Friedrich Overfeldt, 1751, S. 57-72; Nachricht von des seligen Herrn Prorector Schindels Schriften. In: Schlesischer Büchersaal, 1751, S. 161-173; DBI.

\section{Schmid(t) (Schmidius), Johann Christoph}

20. November 1704 (Langensalza) - 23. Mai 1781 (Eisleben)

Beruf, Tätigkeit: Kanzleidirektor, Verwaltungsbeamter

Biographie: Sohn des Ratskämmerers und Kaufmanns Johann Christoph Schmidt (1659-1756) und der Katharina Juliane, geb. Aurbach († 1729). 1726 Studium in Leipzig, 1728 Baccalaureat der Rechtswissenschaften, 1729 Doktor der Rechtswissenschaften, 1732 Fürstlich Mansfeldischer Hof- und Bergrat in Eisleben, Herr auf Tunzenhausen, Ludersborn, Schönfeld und Niederdolzig.

Ehe, Kinder: 1732 Ehe mit Christiana Friederika Meurer (1713-1774), 3 Töchter: Christiane Maria (* 1733), Charlotte Friederike (*1738), Elisabeth Friederike (1740-1812), 2 Söhne: Heinrich Wilhelm (1734-1813), Karl Gottlob Friedrich (* 1742)

Korrespondenz: 2 Briefe an Gottsched aus den Jahren 1739 und 1740 
Literatur: Johann Martin Lappenberg (Hrsg.): Briefe von und an Klopstock. Ein Beitrag zur Literaturgeschichte seiner Zeit. Braunschweig 1867, S. 435-448, 445; Franz Muncker: Friedrich Gottlieb Klopstock. Geschichte seines Lebens und seiner Schriften. Berlin 1893, S. 5; Deutsches Geschlechterbuch, Band 63 (1929), S. 287; Rainer Schmidt (Hrsg.): Friedrich Gottlieb Klopstock, Briefe 1751-1752 (Historisch-kritische Ausgabe, Abteilung Briefe: II). Berlin; New York 1985, S. 13, 265; Leipzig Matrikel, S. 359.

\section{Schneider, Johann Caspar}

Taufe 26. Januar 1712 (Kitzingen) - Oktober 1786 (Frankfurt am Main) ${ }^{15}$

Beruf, Tätigkeit: Kaufmann, Fürstlicher Reichsagent und Rat

Biographie: Sohn des Goldschmiedes Johann Heinrich Schneider und der Eva Barbara. 1733 Studium in Leipzig; 1737 und 1738 Aufenthalt in Kitzingen; Schneider bewohnte seit 1758 in Frankfurt am Main im Degenschen Haus am Rebstock Nr. 90 eine Wohnstube und eine Schlafkammer. Zur Legitimation legte er dort seine Patente als Agent des Kurfürsten von Bayern, des Fürsten von Sachsen-Hildburghausen, der Fürstbischöfe von Würzburg und anderer Reichsstände vor.

Ehe, Kinder: Unverheiratet

Korrespondenz: 3 Briefe an Gottsched aus den Jahren 1737 und 1738

Literatur: Kitzingen, Kirchenbücher 1712, S. 220; Johann Christoph Gottsched: Zeugnis für Johann Caspar Schneider aus Kitzingen in Franken vom 7. September 1733 (1 Seite fol. lateinisch), Leipzig, UB, Sign. Neubauer, L 235, Gottsched; Alexander Dietz: Der Goethesche Hausfreund Rat Schneider. In: Berichte des Freien Deutschen Hochstifts zu Frankfurt am Main 1890 (Heft 2), S. 314-317; Wolfgang Pfeiffer-Belli (Hrsg.): Johann Caspar Goethe, Cornelia Goethe, Catharina Elisabeth Goethe, Briefe aus dem Elternhaus. Erster Ergänzungsband der Goethe-Gedenkausgabe. Zürich; Stuttgart 1960, S. 36-38; Klaus-Detlef Müller (Hrsg.): Johann Wolfgang Goethe. Sämtliche Werke. Briefe, Tagebücher und Gespräche. I. Abteilung: Sämtliche Werke, Band 14. Aus meinem Leben. Dichtung und Wahrheit. Frankfurt am Main 1986, S. 80, 159, 230-236, 439, 858; Leipzig Matrikel, S. 366.

\section{Schwabe, Johann Joachim}

29. September 1714 (Magdeburg) - 12. April oder August 1784 (Leipzig)

Beruf, Tätigkeit: Universitätsprofessor, Publizist, Herausgeber, Übersetzer

Biographie: Sohn des Juristen Johann Schwabe. 1733 Studium der Theologie in Leipzig, 1736 Magister, Privatlehrer und Hofmeister, 1750 Kustos der Leipziger Universitätsbibliothek, 1765 außerordentlicher Professor der Philosophie in Leipzig.

Mitgliedschaften: 1727 Mitglied der Nachmittäglichen Rednergesellschaft in Leipzig, 1736 Mitglied der Deutschen Gesellschaft in Leipzig, Mitglied der Gesellschaft der freyen Künste in Leipzig, der Deutschen Gesellschaft in Königsberg, der Deutschen Gesellschaft in Greifswald, der Deutschen Gesellschaft in Göttingen

15 Schneider starb im Alter von 74 Jahren und 9 Monaten. 
Ehe, Kinder: Unverheiratet

Korrespondenz: 10 Briefe an Gottsched aus den Jahren 1734 bis 1749, 2 Briefe an Luise Adelgunde Victorie Gottsched aus dem Jahr 1738, 1 Brief (als Mitglied der Deutschen Gesellschaft in Leipzig gemeinsam mit May, Knöcher, Winkler, Steinwehr, Schellhaffer, Bärmann, Ludwig, Morgenbesser und Ziegler) an Gottsched aus dem Jahr 1738

Literatur: Gottsched, Verzeichnis; Kroker, Nr. 290; Otto Ladendorf: Ein verschollenes Pamphlet Johann Joachim Schwabes. In: Euphorion 10 (1903), S. 655-657; Franz Ulbrich: Die Belustigungen des Verstandes und Witzes. Ein Beitrag zur Journalistik des 18. Jahrhunderts. Leipzig 1911, S. 63-76; Suchier, Göttingen, S. 77, Nr. 163; Leipzig Matrikel, S. 382; DBI.

\section{Schwäneschuch (Schwenschuch, Schwemschuch), Christian Franz}

* um 1700 (Bartenstein), † nach 1772 (vermutlich Hamburg)

\section{Beruf, Tätigkeit: Gutsinspektor}

Biographie: 1714 Studium der Philosophie und Theologie in Königsberg, 1721 noch in Königsberg als Bewerber für ein Stipendium, 1727 Hofmeister im Hause des Landrates Hans Henrich von Ahlefeldt (1656-1720) auf Seestermühe bei Hamburg, 1739 Inhaber der Gerichtsbarkeit über die Marsch- und Freibauern im Raum Seestermühe, Domherr des Hamburger Domstiftes, Senior (Struktuar ${ }^{16}$, Scholaster, Salinator und Panista ${ }^{17}$ ). Ehe, Kinder: 1751 Ehe mit einer Frau von Beßler

Korrespondenz: 2 Briefe an Gottsched aus den Jahren 1727 und 1739

Literatur: Olsztyn, Archiv der Universität Königsberg, Albertus-Universität zu Königsberg Sign. 1646 (ehemals XXVIII/1) Nr. 1689, Stipendien 1700-1790: Alumnen Rechnung was Academischer Probst wegen Speisung königl. Alumnorum vom 27 Sept: Michäelis bis d 19. Dec: Luciae des 1716ten Jahres in allem zu fordern hat (Vom dritten Tisch. Schwemschuch Praec: Lithv. Eccl. Praen:; Nr. 1683 Stipendien 1700-1790, Bl. 150r/v); Johann Hinrich und Willhelm Heuß: Bei der Schwäneschuch= und von Beßlerischen gesegneten Eheverbindung bezeugten ihre Ergebenheit zwene verbundne Diener. Hamburg: Piscator, 1751; Des neuen Genealogischen Reichs $=$ und Staats $=$ Hand= Buchs Auf das Jahr MDCCLXXII. zweiter Theil; oder neues Addres=Hand=Buch der Staaten von Europa. Frankfurt am Main: Franz Varrentrapp, 1772, S. 225; Karl Koppmann: Das Kollegium des Klingelbeutels an der Domkirche und dessen Konvivium. In: Zeitschrift des Vereines für hamburgische Geschichte, Band 7 (1883), S. 327-344, 330; Hermann Hüllmann: Die Chronik von Seestermühe. Uetersen in Holstein 1934, S. 98; Franz Otto: Die rechtlichen Verhältnisse des Domstiftes zu Hamburg von 1719 bis 1802. Hamburg 1962, S. 75; zu einigen musikalischen Aufführungen auf dem „Hamburgischen Schauplatz" hat ein Verfasser namens Schwemschuch die Textbücher geliefert; vgl. Reinhart Meyer (Hrsg.): Bibliographia dramatica et dramaticorum. 2. Abteilung. Einzeltexte. Band 5 (1722-1725). In Zusammenarbeit mit Eva Sixt. Tübingen 1996, S. 328-332, 463-465; Königsberg Matrikel, S. 282, Nr. 8 (Schwenschuch).

\footnotetext{
16 Zur Funktion dieses Senioratsamts: Otto, S. 71.

17 Zur Funktion dieser Senioratsämter: Otto, S. 72 f.
} 


\title{
Schwar(t)z, Albrecht (Albert) Georg von
}

\author{
16. April 1687 (Gristow) - 10. Juni 1755 (Greifswald)
}

Beruf, Tätigkeit: Universitätsprofessor, Landeshistoriker

Biographie: Sohn des Pfarrers Albrecht Schwartz (1634-1705) und der Maria, geb. Zarnikow. Häuslicher Privatunterricht bei dem Großvater Georg Zarnikow (1634-1694, Pastor in Gristow), 1704 Gymnasium Stralsund, 1705 Studium der Philosophie und Theologie in Greifswald, 1708 in Wittenberg, 1709 Rückkehr nach Greifswald, 1710 Informator im Hause der Familie von Behr in Bandelin und Dargezin, 1711 Hauslehrer beim russischen Stadtkommandanten Generalmajor von Buck, 1716 bis 1717 Aufenthalt in Hamburg und Verbindung mit Johann Albert Fabricius (1668-1736), 1717 Magister, 1721 Adjunkt der Philosophischen Fakultät in Greifswald, 1732 ordentlicher Professor der Eloquenz und Poetik, 1747 der Geschichte und Moral in Greifswald und Erhebung in den Reichsadelsstand.

Mitgliedschaften: Begründer der Societas Collectorum Historiae et Juris Patrii in Greifswald

Ehe, Kinder: 1722 Ehe mit Anna Elisabeth Behrends, 1 Tochter: Albertine Elisabeth, 3 Söhne: Albrecht (1735 in Greifswald immatrikuliert), Albrecht Georg (1740 in Greifswald immatrikuliert) und Johann Albrecht (1742 in Greifswald immatrikuliert)

Korrespondenz: 1 Brief an Gottsched aus dem Jahr 1739

Literatur: Zedler 35 (1743), Sp. 1912-1924; Johann Carl Dähnert: Gedächtniß=Rede auf Herrn Albert Georg von Schwarz Königl. Professor der Geschichte zu Greifswald. in der St. Nicolai Kirche den 16. Jun. 1755 gehalten. In: Pommersche Bibliothek 4/6 (Juni 1755), S. 195-205 (mit „Verzeichniß sämmtlicher gedruckten Schriften des Hrn. Professors A. G. von Schwarz."); Hermann Müller (Hrsg.): Albrecht Georg v. Schwartz's Autobiographie. Nach der Handschrift der königlichen Universitäts-Bibliothek zu Greifswald [Mss. Pomer. Folio 235]. In: Zeitschrift für Preußische Geschichte und Landeskunde 11 (1874), S. 90-112 (mit ausführlichem Schriftenverzeichnis); Hellmuth Heyden (Bearb.): Die Evangelischen Geistlichen des ehemaligen Regierungsbezirkes Stralsund. Band 2: Kirchenkreise Barth, Franzburg und Grimmen. Greifswald 1959, S. 255, 261; Dirk Alvermann, Birgit Dahlenburg: Greifswalder Köpfe. Gelehrtenporträts und Lebensbilder des 16.-18. Jahrhunderts aus der pommerschen Landesuniversität. Rostock 2006, S. 182 f.; Greifswald Matrikel, S. 31, 169, 215, 221; Wittenberg Matrikel, S. 319; DBI.

\section{Schwarz, Johann Christoph}

23. Oktober 1709 (Redwitz in Oberfranken) - 25. Dezember $1783^{18}$ (Mannheim)

Beruf, Tätigkeit: Konsistorial- und Ehegerichtsrat, Dichter, Übersetzer Biographie: Sohn des Zeugmeisters und Marktrichters Johann Schwartz (1660-1737) und der Ursula Magdalena, geb. Löb (1681-1759). Schulbesuch in Regensburg, Stu-

18 Richter, Allgemeines biographisches Lexikon alter und neuer geistlicher Liederdichter. Leipzig 1804, S. 360: 1781 
dium in Altdorf, 1733 Studium in Leipzig, kurpfälzischer Wirklicher Konsistorial- und Ehegerichtsrat in Mannheim, Mitglied der lutherischen Oberkirchenbehörde.

Ehe, Kinder: Vermutlich unverheiratet ${ }^{19}$

Korrespondenz: 17 Briefe an Gottsched aus den Jahren 1738 bis 1756

Literatur: Zwei Gedichte von Joh. Christoph Schwarz anläßlich der Entbindung der Kurfürstin Elisabeth Augusta 1761. In: Mannheimer Geschichtsblätter 9 (1908), Nr. 8 und 9, Sp. 184-186; Franz Capeller: Geschlechterbuch von Marktredwitz. Band 3. München 1969, S. 377; Leipzig Matrikel, S. 383; DBI.

\section{Seelen, Johann Heinrich (Henrich, Hinrich) von}

8. August 1687 (Assel bei Stade) - 22. Oktober 1762 (Lübeck)

Beruf, Tätigkeit: Theologe, Polyhistor, Rektor

Biographie: Sohn des Pastors Erich Zacharias von Seelen (1637-1698) und der Margaretha Elisabeth, geb. Hoffmann $(\dagger 1713)$. Häuslicher Unterricht durch den Prediger und Diakon Tobias Schep(p)ler, Gymnasium in Stade, 1711 Studium der Philosophie, Theologie und der orientalischen Sprachen in Wittenberg, 1713 Konrektor am Gymnasium in Flensburg, 1715 Konrektor am Gymnasium in Stade (1716 Amtseinführung), 1717 Rektor am Lübecker Katharineum (1718 Amtseinführung), 1725 in Rostock Lizentiat der Theologie.

Ehe, Kinder: 1716 Ehe mit Ursula Koch $(\dagger 1742), 1$ Tochter: Sophia Margaretha (17301804/05), 5 Söhne: Erich Simon Henrich (1717-1755), Adolph Peter (1720-1723), Daniel Joachim (1723-1732), Johann Henrich (1725-1729), Nicolaus Ludewig (17271732); 1746 Ehe mit Margareta Dorothea zum Felde ( $\uparrow 1771)$, die Ehe blieb kinderlos. Korrespondenz: 4 Briefe an Gottsched aus den Jahren 1736 bis 1755

Literatur: Lübeck, Archiv der Hansestadt: Schnobel, Hs. 817-2; Hans-Bernd Spies: Seelen, Johann Henrich von. In: Biographisches Lexikon für Schleswig-Holstein und Lübeck. Band 6. Neumünster 1982, S. 269-271; Ders.: Seelen, Johann Henrich von. In: Alken Bruns (Hrsg.): Lübecker Lebensläufe aus neun Jahrhunderten. Neumünster 1993, S. 366-368; DBI.

\section{Siemsen, Joachim Heinrich}

$(\dagger$ nach 1739)

Die Identität des Korrespondenten konnte nicht ermittelt werden. Recherchen im Kirchenbuchamt des Kirchenkreises Hamburg-Ost (Schiffbeck) verliefen ergebnislos. $\mathrm{Da}$ es sich um den späteren Lehrer an der Paßmannschen Schule, Joachim Hinrich

${ }_{19}$ Die Einsicht in die lutherischen Kirchenbücher von Mannheim ergab keine Verifizierung eines Eheeintrages in den Jahrgängen 1725 bis 1769. Ebenso schweigen die Taufeinträge der Jahrgänge 1735 bis 1760 . Entsprechende Recherchen im Stadtarchiv Mannheim verliefen ebenfalls ergebnislos. 
Simon $^{20}$ (1727-1781), handelt, ist eher unwahrscheinlich, wenngleich nicht auszuschließen.

Korrespondenz: 1 Brief an Gottsched aus dem Jahr 1739

Literatur: C. H. Wilhelm Sillem: Die Matrikel des Akademischen Gymnasiums in Hamburg 1613-1883. Hamburg 1891, S. 119, Nr. 2525; Adolph Hofmeister (Hrsg.), Ernst Schäfer (Bearb.): Die Matrikel der Universität Rostock. Band 4. Rostock 1904 (Nachdruck Nendeln 1976), S. 244b. ${ }^{21}$

\section{Stein, Johann Friedrich}

17. Juni 1705 (Tegernau bei Sausenberg) - 22. September 1770 (Karlsruhe)

Beruf, Tätigkeit: Pfarrer, Hofprediger, Superintendent

Biographie: Sohn des Tegernauer Pfarrers Johann Friedrich Stein (1680-1717) und der Maria, geb. Ziegler (1681-1747). Gymnasium in Karlsruhe, 1724 Studium in Jena, 1728 Informator im Hause des Pfarrers Burkhard Jacob Deimling (1676-1743) in Köndringen, 1730 Hauslehrer in Mühlburg, Stadtvikar in Karlsruhe, 1731 Hof- und Stadtdiakon, 1734 Pfarrer in Eichstetten, 1738 Hofprediger und Kirchenrat, Stadt- und Militärpfarrer in Karlsruhe, 1744 Doktor h. c. der Theologie, 1745 Wirklicher Kirchenrat in Karlsruhe, 1748 Fürstlicher Beichtvater, 1751 Oberhofprediger, 1760 Professor der Theologie am Gymnasium in Karlsruhe und Spezialsuperintendent der Diözesen Karlsruhe und Durlach.

Ehe, Kinder: 1732 Ehe mit Susanna Maria Elisabetha Deimling (1708-1771), 2 Töchter: Friederica Ernestina Dorothea (29. Januar - 5. Mai 1733), Louysa Sophia Wilhelmina (7. - 15. Januar 1745), 3 Söhne: N. N. (*† 2. September 1734), N. N. $*^{* \dagger} 22$. Juli 1735), Friedrich Christian (1743-1751)

Korrespondenz: 1 Brief an Gottsched aus dem Jahr 1738

Literatur: Genealogische Daten nach freundlicher Auskunft von Herrn Armin Meyer (Karlsruhe); Carl Joseph Bouginé: Handbuch der allgemeinen Litterargeschichte nach Heumanns Grundriß. Band 4. Zürich: Orell, Geßner, Füßli und Comp., 1791, S. 745; Karl Friedrich Vierordt: Geschichte der im Jahr 1586 zu Durlach eröffneten und 1724 nach Karlsruhe verpflanzten Mittelschule. Karlsruhe 1859, S. 136; Karl-Gustav Fecht: Geschichte der Haupt- und Residenzstadt Karlsruhe. Karlsruhe 1887, S. 102 f.; Jörg Schneider: Die evangelischen Pfarrer der Markgrafschaft Baden-Durlach in der zweiten Hälfte des achtzehnten Jahrhunderts. Lahr 1936, S. 80-86 und Register; Heinrich Neu: Pfarrerbuch der evangelischen Kirche Badens von der Reformation bis zur Gegenwart. Teil 2: Das alphabetische Verzeichnis der Geistlichen mit biographischen Angaben. Lahr 1939, S. 589; Ortsfamilienbuch Eichstetten (Deutsche Ortssippenbücher, Band 309, Reihe A, Band 98 der Badischen Ortssippenbücher). Eichstetten 2002, S. 639.

${ }^{20} 1747$ Akademisches Gymnasium in Hamburg, 1748 Immatrikulation in Rostock.

${ }^{21}$ Die Rostocker Matrikel weist 12 unterschiedliche Varianten des Familiennamens Siemsen auf: Siemes, Siemonis, Siem(s)sen, Simen, Simens(s), Simon, Symon, Simonides, Symonides, Simonius, Symonius. 


\section{Steinauer, Johann Wilhelm}

1. Juli 1715 (Naumburg) - 1786

Beruf, Tätigkeit: Schriftsteller, Soldat

Biographie: Sohn des Juweliers, Kaufmanns und Kommissionsrats Johann Christian Steinauer $(† 1748)$ und der Dorothea Margareta, geb. Warlitz (1692-1780). 1734 Studium in Leipzig, 1737 Magister, 1738 Aufenthalt in Straßburg, 1739 Hofmeister in Schweighausen im Hause des Friedrich Ludwig Freiherr Waldner von Freundstein (* 1708) und der Maria Cordula, geb. Rothschütz auf Altenhof (* 1707), 1743 Hauptmann in französischen Diensten im zweiten Bataillon des Schweizerregiments von Vigier. Mitgliedschaften: 1727 Mitglied der Nachmittäglichen Rednergesellschaft in Leipzig, Mitglied der Vormittäglichen Rednergesellschaft in Leipzig, Mitglied der Gesellschaft der freyen Künste in Leipzig

Ehe, Kinder: Vermutlich unverheiratet

Korrespondenz: 12 Briefe an Gottsched aus den Jahren 1738 bis 1744

Literatur: Naumburg, St. Wenzel, Trauregister, Taufregister, Sterberegister; Johann Christoph Löschenkohl (Hrsg.): Sammlung einiger Uebungsreden, welche unter der Aufsicht Sr. Hochedelgeb. des Herrn Profess. Gottscheds, in der vormittägigen Rednergesellschaft sind gehalten worden. Leipzig: Bernhard Christoph Breitkopf, 1743, S. **3; Schwabe, Proben, Nr. 53; Erich Michael: Zu Erich Schmidts, Charakteristik der Bremer beiträger im Jüngling'. In: Zeitschrift für deutsche Philologie 48 (1920), S. 115-125, 118; Werner Lauterbach: Bergrat Christlieb Ehregott Gellert. Leipzig; Stuttgart 1994. S. $111 \mathrm{f}$; Bernd Zeitzschel (Bearb.): Gold- und Silberschmiede in Naumburg (Museumsverein Naumburg e. V., Internetquelle: www.museumnaumburg.de/GSS/GS/ 1706_Steinauer.html); Leipzig Matrikel, S. 403.

\section{Stoppe, Daniel}

\section{November 1697 (Hirschberg) - 12. Juli 1747 (Hirschberg)}

Beruf, Tätigkeit: Spezereiwarenhändler, Konrektor, Dichter

Biographie: Sohn des Schleierwebers Tobias Stoppe. 1712 Evangelisches Gymnasium in Hirschberg, 1719 Studium der Philosophie und Theologie in Leipzig, 1722 oder 1723 Rückkehr nach Hirschberg, Spezereiwarenhändler und Hauslehrer, 1742 Konrektor am dortigen Gymnasium.

Mitgliedschaften: 1728 Mitglied der Deutschen Gesellschaft in Leipzig

Ehe, Kinder: 1726 Ehe mit Anna Rosina Hübner, Stiefsöhne 22

22 Am 29. Juli 1742 wurde einer von Stoppes Stiefsöhnen in Connewitz bei Leipzig tödlich verwundet: „Der Gestochene ist Herr Stoppens des berühmten Poetens aus Hirschberg in Schlesien Stiefsohn, welcher über die unvermuthete Post sehr betrübt sein wird." Vgl. Auszüge aus Johann Salomon Riemers Leipzigischem Jahrbuche. 1714-1771. In: Gustav Wustmann (Hrsg.): Quellen zur Geschichte Leipzigs. Veröffentlichungen aus dem Archiv und der Bibliothek der Stadt Leipzig. Band 1. Leipzig 1889 , S. $300 \mathrm{f}$. 
Korrespondenz: 18 Briefe an Gottsched aus den Jahren 1728 bis 1743, 1 Brief von Gottsched aus dem Jahr 1742

Literatur: Daniel Stoppe: Auf den vergnügt erlebten Namenstag Frauen Annen Rosinen Stoppin geb. Hübnerin. In: Daniel Stoppe: Der Parnaß im Sättler, Oder Scherz= und Ernsthafte Gedichte. Frankfurt; Leipzig: Gottlieb Siegert, 1735, S. 427-430; Ehrhardt, Presbyterologie 3/2, S. 208 f.; August Heinrich Hoffmann von Fallersleben: Spenden zur deutschen Litteraturgeschichte. Band 2. Leipzig 1844, S. 179-192; Johann Jakob Baebler: Daniel Stoppe. In: Archiv für Litteraturgeschichte 9 (1880), S. 297-324; Kroker, Nr. 230; Hildegard Just: Der Hirschberger Dichterkreis. Ein Beitrag zur schlesischen Literaturgeschichte in der ersten Hälfte des 18. Jahrhunderts. Breslau 1934, S. 40-90; Daniel Stoppe: Der Parnaß im Sättler. Derbdreiste Lieder und Episteln. Ausgewählt und herausgegeben von Eberhard Haufe. Weimar 1977, S. 139-151; Leipzig Matrikel, S. 409; DBI.

\section{Strimesius, Johann Samuel}

26. Juli 1684 (Frankfurt an der Oder) - 27. Dezember 1744 (Frankfurt an der Oder)

Beruf, Tätigkeit: Universitätsprofessor, Publizist

Biographie: Sohn des Pastors und späteren Professors der Theologie Samuel Strimesius (1648-1730). ${ }^{23} 1699$ Studium in Frankfurt an der Oder, 1709 Magisterexamen in Frankfurt an der Oder, 1710 Professor der Beredsamkeit und Geschichte in Königsberg, 1722 erster reformierter Rektor der Universität Königsberg, 1734 Zwangsbeurlaubung wegen Alkoholmißbrauchs und Majestätsbeleidigung, 1735 Mitarbeiter der Zeitschrift Nützliche Sammlung zum nähern Verstande des Neuen in der Politischen und Gelehrten Welt, 1736 Aufenthalt in Danzig, 1737 in Potsdam, 1738 Übersiedelung nach Frankfurt an der Oder, erneute Lehrtätigkeit an der dortigen Universität.

Ehe, Kinder: Unbekannt, vermutlich unverheiratet

Korrespondenz: 4 Briefe an Gottsched aus den Jahren 1739 und 1742

Literatur: Daniel Heinrich Arnoldt: Zusätze zu seiner Historie der Königsbergischen Universität, nebst einigen Verbesserungen derselben, auch zweyhundert und funfzig Lebensbeschreibungen Preußischer Gelehrten. Königsberg: Johann Heinrich Hartungs Witwe, 1756 (Nachdruck Aalen 1994), S. 72; Georg Christoph Pisanski: Entwurf einer preußischen Literärgeschichte in vier Büchern. Hrsg. von Rudolph Philippi. Königsberg 1886 (Nachdruck Hamburg 1994), S. 634, 667; Botho Rehberg: Geschichte der Königsberger Zeitungen und Zeitschriften. I. Persönlichkeiten und Entwicklungsstufen von der Herzogszeit bis zum Ausgang der Epoche Kant-Hamann. Königsberg 1942, Register; Quassowski Se-Sz, S. 988; Bernhart Jähnig: Königsberger Universitätsprofessoren für Geschichte im Jahrhundert der Aufklärung. In: Hanspeter Marti, Manfred Komorowski (Hrsgg.): Die Universität Königsberg in der Frühen Neuzeit. Köln u. a. 2008, S. 319-344, 326-332; Gottsched, Briefwechsel, Band 5, Nr. 191; Ernst Friedländer

23 Johann Samuel Strimesius' Mutter war eine geborene von bzw. von der Lith, vermutlich eine Verwandte des Universitätsprofessors und Bürgermeisters von Frankfurt an der Oder Tido Henrich von der Lith; vgl. Zedler 17 (1738), Sp. $1663 f$ 
(Hrsg.): Ältere Universitäts-Matrikeln. Band 2: 1649-1811, Leipzig 1888 (Nachdruck Leipzig 1965), S. 247; Königsberg Matrikel, S. 265; DBI.

\section{Suke (Suck, Sucke), Christoph Gerhard}

um 1700 (Ratzeburg) - 13. September 1782 (Wien)

Beruf, Tätigkeit: Pfarrer, Legationsprediger

Biographie: Akademisches Gymnasium in Hamburg; ${ }^{24} 1734$ Studium in Leipzig, 1737 Legationsprediger in Wien als Nachfolger von Christoph Friedrich Tresenreuter (17091746), 1742 Bewerbung um die Predigerstelle an der deutschen Dreifaltigkeitskirche in London.

Mitgliedschaften: Mitglied der Nachmittäglichen Rednergesellschaft und der Gesellschaft der freyen Künste in Leipzig

Ehe, Kinder: Unbekannt; Suke hatte mehrere Kinder. ${ }^{25}$

Korrespondenz: 6 Briefe an Gottsched aus den Jahren 1738 bis 1753

Literatur: Johann Christian Müller: Als seine Hochwohlehrwürden, Herr Christoph Gerhard Suke, im Christmonate 1737 von Leipzig nach Wien abgieng, um daselbst das Amt eines Königl. Schwedisch. Gesandtschafts=Predigers anzutreten, stattete die Gesellschaft guter Freunde ... ihre Ergebenheit ab. Leipzig: Bernhard Christoph Breitkopf; Lorenz Henning Suke: Fratri Optimo Ac Suavissimo Christophoro Gerardo Sukio S. D. P. Frater ... In: Lorenz Henning Suke: De Cautione In Administratione Iuris Circa Sacra Adhibenda Disserit Et Fratri Suo Optimo Ac Dilectissimo Christophoro Gerardo Sukio Munus Pastorale A Potentissimo Svionum Rege Clementissime Ipsi Callatum Ad Ex Animo Gratulator Frater Germanus ... Hamburg: König, 1738, S. A2-A3v; Schwabe, Proben, Nr. 42; Heinrich Sander: Beschreibung seiner Reisen durch Frankreich, die Niederlande, Holland, Deutschland und Italien. Zweiter Theil. Leipzig: Friedrich Gotthold Jacobäer und Sohn, 1784, S. 484-487; Heinrich Blume: Die schwedische Gesandtschaftskapelle in Wien im Jahre 1782. In: Jahrbuch der Gesellschaft für die Geschichte des Protestantismus in Österreich 51 (1930), S. 142 f.; Wilhelm Kühnert: Das Taufbuch der schwedischen Gesandtschaftskapelle in Wien 1733-1786. In: Jahrbuch der Gesellschaft für die Geschichte des Pietismus in Österreich 68/69 (1953), S. 99-111, 100; Günter Schulz (Hrsg.): Briefe Lessings aus Wolfenbüttel. Bremen, Wolfenbüttel 1975, S. 41-46, 45; Dieter Knall: Aus der Heimat gedrängt. Letzte Zwangsumsiedlungen steirischer Protestanten nach Siebenbürgen unter Maria Theresia. Graz 2002, S. 139; C. H. Wilhelm Sillem: Die Matrikel des Akademischen Gymnasiums in Hamburg 1613-1883. Hamburg 1891, S. 104, Nr. 2275; Leipzig Matrikel, S. 413 .

${ }^{24}$ Sander, S. 487: „Er ist aus dem Mecklenburgischen und noch ein Schüler vom grossen Wolf und Fabrizius in Hamburg."

25 Sander, S. 487 (21. April 1782): „Er sprach von seinen im Haag, Friedberg und Hamburg zerstreuten Kindern. Die älteste und die jüngste Tochter sind diesem alten Vater allein noch übrig geblieben." 


\section{Suke (Suck, Sucke), Lorenz Henning}

1715 (Ratzeburg) - 1785 (Klein Wölkau bei Delitzsch)

Beruf, Tätigkeit: Kammerkommissionsrat, Amtmann, Legationssekretär

Biographie: 1734 Studium in Leipzig, Informator im Hause des kurfürstlich-sächsischen Kammerherrn, Geheimen Rats, Hauptmanns des Leipziger Kreises und späteren Gesandten am Wiener Hof Heinrich von Bünau (1697-1745), sächsischer Legationssekretär in Dresden.

Mitgliedschaften: Mitglied der Nachmittäglichen Rednergesellschaft, Mitglied der Gesellschaft der freyen Künste in Leipzig

Ehe, Kinder: Ermittelt wurde eine Tochter: Susanne Christiane Caroline, nachmalige Freifrau von Gutschmid ( $†$ nach 1786).

Korrespondenz: 15 Briefe an Gottsched aus den Jahren 1738 bis 1746

Literatur: Schwabe, Proben, Nr. 40; Theophilus (Hrsg.): Gründliche Anweisung zum Briefschreiben ... Nebst Deutlichem Unterrichte zur deutschen Orthographie, und einem Neuen Titularbuche ... Leipzig: Johann Gottfried Müller, 1770, S. 406; ${ }^{26}$ Churfürstlicher Sächsischer Hof= und Staats=Calender auf das Jahr 1777. Leipzig: Weidmanns Erben und Reich, S. 130; Leipzig Matrikel, S. 413.

\section{Thamm, Christian Bernhard}

* um 1710 (Königsberg) - † nach 1738 (vermutlich Königsberg)

Beruf, Tätigkeit: Jurist

Biographie: Sohn des kurfürstlichen Kommissionssekretars, ordentlichen Hofhalsgerichtsassessors und späteren Zweiten Bürgermeisters Johann Thamm (1663-1727) und der Katharina, geb. Pauli, verw. Hölzner. 1711 Immatrikulation in Königsberg (Phil. et U.J. stud. 1727).

Ehe, Kinder: Vermutlich unverheiratet

Korrespondenz: 2 Briefe an Gottsched aus den Jahren 1736 und 1738

Literatur: Kessler, Altpreußische Briefe, S. 16; Gallandi, S. 110 f.; Quassowski T, S. 61 f.; Königsberg Matrikel, S. 270.

\section{Venzky, Georg}

18. Dezember 1704 (Gommern) - Juli 1757 (Prenzlau)

Beruf, Tätigkeit: Theologe, Schriftsteller, Übersetzer, Rektor

Biographie: Sohn des Superintendenten und Oberpredigers Daniel Venzky (1662-1705) und der Anna Elisabeth, geb. Weller († 1743). Schulbesuch in Möckern, häusliche Unterweisung durch den Stiefvater Gottfried Christian Grube († 1741), 1716 Schulbesuch

26 „An den Cammer=Commiss. Rath und Amtmann (Lorenz Henning) Sucke. A Monsieur Monsieur Sucke, Seigneur de Welckau, Conseiller des Commissions de Chambre des finances et baillif du baillage de Delitzsch de S. A. El. de Saxe." 
in Burg, 1718 Übersiedlung nach Barby, Unterricht im Hause seines Vetters, der in Barby Rektor war, 1720 Schulbesuch in Halle, 1722 Studium der Theologie in Halle, Informator an der dortigen Waisenhaus-Schule, 1724 Aufenthalt in Leipzig, 1725 Informator in Friesack (Brandenburg), 1726 Informator in Havelberg, 1728 Bibliotheksgehilfe und Informator, später Konventual und Rektor der Schule Kloster Berge bei Magdeburg, 1731 Subkonrektor der Domschule in Halberstadt, 1738 Konrektor, 1740 Dombibliothekar, 1742 Konrektor und adjungierter Rektor in Prenzlau, 1749 Doktor der Theologie an der Theologischen Fakultät Kopenhagen.

Mitgliedschaften: 1733 Mitglied der Deutschen Gesellschaft in Leipzig, 1739 Mitglied der Prüfenden Gesellschaft in Halle, 1740 Mitglied der Lateinischen Gesellschaft in Halle, 1741 Mitglied der Philologischen Gesellschaft in Schulpforta, 1743 Mitglied der Sozietät der musikalischen Wissenschaften in Leipzig, 1745 Mitglied der Literarischen (Gelehrten) Gesellschaft in Halberstadt, 1751 Mitglied der Königlich Deutschen Gesellschaft in Greifswald sowie Ehrenmitglied der Deutschen Gesellschaft in Königsberg Ehe, Kinder: 1731 Ehe mit Ilsabe Dorothea von Bülau, 1 Tochter, 3 Söhne; sowohl die Kinder als auch die Ehefrau starben vor Venzky.

Korrespondenz: 16 Briefe an Gottsched aus den Jahren 1732 bis 1739

Literatur: Schultz, Greifswald, S. 123; Paul Ferdinand Portmann: Die deutschen Übersetzungen von Shaftesburys ,Soliloquy'. Studien zur Wechselbeziehung zwischen der Stil-, Begriffs- und Geistesgeschichte im 18. Jahrhundert. Willisau 1942, S. 76-82; Margot Faak: Die Verbreitung der Handschriften des Buches „De Imposturis Religionum“ im 18. Jahrhundert unter Beteiligung von G. W. Leibniz. In: Deutsche Zeitschrift für Philosophie Jg. 18 (1970), Heft 2, S. 212-228; Karl Ventzke: Dr. Georg Ventzky (17041757), 10. Mitglied der Mizlerschen „Societät der musikalischen Wissenschaften“. In: Die Musikforschung, Jg. 1923 (1970), Heft 3, S. 321-324 (mit zeitgenössischem Kupferstich); Reinhard Breymayer, Friedrich Häußermann (Hrsgg.): Friedrich Christoph Oetinger, Die Lehrtafel der Prinzessin Antonia. Teil 2. Berlin; New York 1977, S. 168-175; Rebekka Horlacher: Bildungstheorie vor der Bildungstheorie. Die Shaftesbury-Rezeption in Deutschland und der Schweiz im 18. Jahrhundert. Würzburg 2004, S. 46-51; MarkGeorg Dehrmann: Das „Orakel der Deisten“. Shaftesbury und die deutsche Aufklärung. Göttingen 2008, S. 193-209; Jennifer Willenberg: Distribution und Übersetzung englischen Schrifttums im Deutschland des 18. Jahrhunderts. München 2008, S. 259-265; Halle Matrikel 1, S. 475; DBI (Hauptquelle, auf Venzkys eigenen Angaben beruhend und mit vollständigem Schriftenverzeichnis: Neubauer, Theologen, S. 944-989).

\section{Volkelt (Volckelt), Johann Gottfried}

um 1710 (Lauban) - $1738^{27}$

Beruf, Tätigkeit: Prediger

Biographie: Sohn des Michael Volkelt. 1732 Studium in Leipzig, Informator im Hause des Christian Gottlieb von Holtzendorff (Korrespondent).

27 Schwabe, Proben: „Joh. Gottfried Volkelt, aus Lauben in der Lausitz, ward Prediger im Gebirge und starb." 
Mitgliedschaften: Mitglied der Nachmittäglichen Rednergesellschaft in Leipzig

Ehe, Kinder: Unverheiratet

Korrespondenz: 3 Briefe an Gottsched aus dem Jahr 1738

Literatur: Schwabe, Proben, Nr. 44; Leipzig Matrikel, S. 437.

\section{Weichmann, Christian Friedrich}

24. August 1698 (Harburg) - 4. August 1770 (Wolfenbüttel)

Beruf, Tätigkeit: Jurist, Verwaltungsbeamter, Journalist, Dichter

Biographie: Sohn des Rektors Friedrich Weichmann (Korrespondent), 1716 Studium der Philologie und der Rechtswissenschaften in Halle, 1720 Hofmeister bei Herzog Philipp Ernst von Schleswig-Holstein-Glücksburg (1673-1729), 1722 Redakteur des Hamburgischen Correspondenten, Koordinator und Redakteur des Hamburgischen Patrioten, 1728 Reise nach England, Baccalaureus der Rechtswissenschaften in Oxford, Anstellung in Blankenburg bei Herzog Ludwig Rudolph von Braunschweig-Wolfenbüttel (1671-1735), 1729 Rat in der Justizkanzlei, 1731 Geheimsekretär in der fürstlichen Geheimratstube Wolfenbüttel, vermutlich 1734 Hofrat, 1737 Konsistorialrat, 1765 Entbindung von den Aufgaben im Konsistorium, Geheimer Justizrat.

Mitgliedschaften: Mitglied der Teutsch-übenden Gesellschaft in Hamburg, 1724 Mitglied der Patriotischen Gesellschaft in Hamburg, 1754 Ehrenmitglied der Deutschen Gesellschaft in Göttingen, Mitglied der Englischen Sozietät der Wissenschaften Ehe, Kinder: Unbekannt

Korrespondenz: 4 Briefe an Gottsched aus den Jahren 1738 bis 1750

Literatur: Elger Blühm: Christian Friedrich Weichmann. Redakteur des Schiffbecker „Correspondenten“. In: Zeitschrift des Vereins für Hamburgische Geschichte 53 (1967), S. 69-78; Perels/Rathje/Stenzel, S. 173-185; Killy 12 (1992), S. 185 f.; DBI.

\section{Weichmann, Friedrich}

15. Januar 1667 (Adelebsen) - Januar oder Februar 174428 (Braunschweig)

Beruf, Tätigkeit: Rektor

Biographie: 1694 Konrektor in Harburg, 1696 Rektor in Harburg, 1701 Rektor in Wolfenbüttel, 1710 Rektor der Martinsschule in Braunschweig, 1733 Ruhestand.

Ehe, Kinder: Der Name von Weichmanns Ehefrau $(\dagger 1721)^{29}$ sowie das Jahr der Eheschließung konnten nicht ermittelt werden; 4 Töchter: Anna Maria Dorothea (1701-1753), Clara Elisabeth (* 1703), Hedwig Eleonora (* 1705), Dorothea Marga-

${ }^{28}$ Weichmann wurde am 2. Februar 1744 auf dem St. Martini-Kirchhof beigesetzt. Das die Beerdigungen nachweisende Kirchenbuch von St. Martini enthält kein Todesdatum.

29 Weichmanns Gemahlin wurde am 14. März 1721 auf dem St. Martini-Kirchhof beigesetzt. Das die Beerdigungen nachweisende Kirchenbuch von St. Martini enthält keine Informationen über das Lebensalter, das Todesdatum und den Vornamen. 
retha (* 1707), 4 Söhne: Christian Friedrich (Korrespondent), Justus Heinrich (* 1708), Johann Georg Diterich (* 1710), Johann Heinrich (* 1712).

Korrespondenz: 6 Briefe an Gottsched aus den Jahren 1738 und 1739

Literatur: Wolfenbüttel, Tauf-Kirchenbuch Hauptkirche Beatae Mariae Virginis, $1 \mathrm{~Kb}$ Nr. 1307 und 1308; Braunschweig, Kirchenbuch St. Martini, 7 Kb 202, S. 590 und S. 909; Zedler 54 (1747), Sp. 203; Acta Scholastica, Band 6 (1745), 2. Stück, S. 167; Richard Elster (Hrsg.): Gymnasium Martino-Katharineum Braunschweig. Festschrift zur 500-Jahr-Feier am 17. und 18. März 1926. Braunschweig, S. VII; DBI.

\section{Zedtwitz, Christian Ferdinand von}

1717 (Gut Bonau bei Weißenfels) - 1803 (Gut Bonau bei Weißenfels)

Beruf, Tätigkeit: Polnischer und kursächsischer sowie kurfürstlich-kölnischer Kammerherr, Oberaufseher über verschiedene Ämter des weißenfelsischen Gebietes

Biographie: Sohn des herzoglich-sachsen-weißenfels-querfurtischen Oberjäger- und Oberforstmeisters Anton Ferdinand von Zedtwitz (um 1690-1742) und der Christiane Charlotte, geb. von Könitz († 1742). 1733 Studium in Leipzig, 1736 Aufenthalt in WeiBenfels, 1738 in Brüssel.

Ehe, Kinder: Ehe mit Friederike Sophie Louise, geb. von Jungk († 1769), ermittelt wurden 3 Söhne: Friedrich Christian, ${ }^{30}$ Heinrich Ferdinand, ${ }^{31}$ und Ludwig Friedrich Ferdinand. ${ }^{32}$

Korrespondenz: 3 Briefe an Gottsched aus den Jahren 1738 bis 1746

Literatur: Testimonium triennii academici (1736) für Christian Ferdinand von Zedtwitz, Leipzig Universitätsarchiv, Signatur: UAL, GA XIV, Nr. 17 (Titelblatt und 14 Blätter r/v Text); Zedler 61 (1749), Sp. 1839; John F. Reynolds (Hrsg.): C. F. Gellerts Briefwechsel. Band 1 (1740-1755). Berlin; New York 1983, S. 388 f.; Leipzig Matrikel, S. 470 .

\footnotetext{
301762 Immatrikulation in Leipzig

311762 Immatrikulation in Leipzig

321769 Immatrikulation in Leipzig
} 